\title{
BRYCE HENDEN
}

\section{[Api]tecture:}

An ecomimetic design in Wellington City 


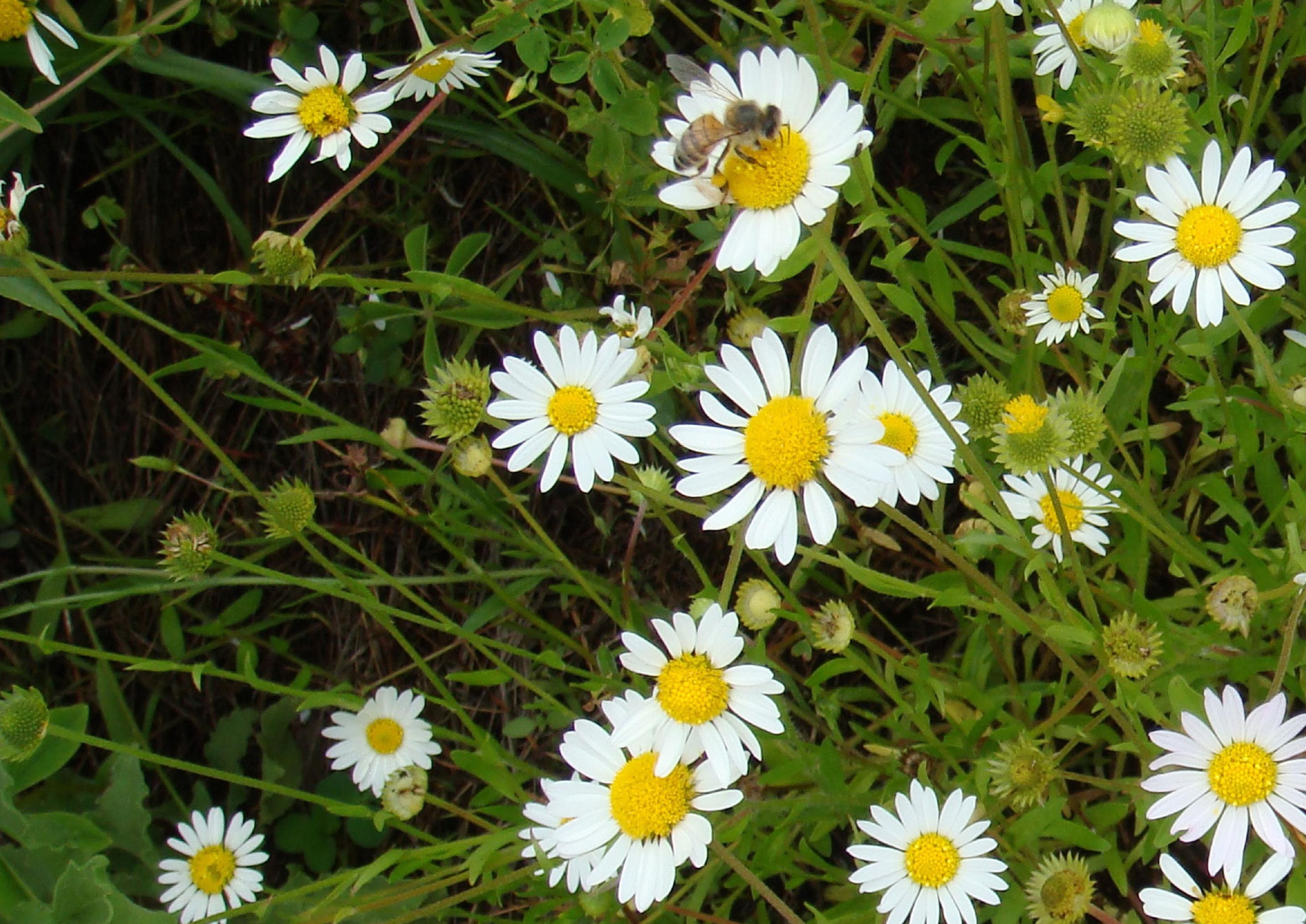




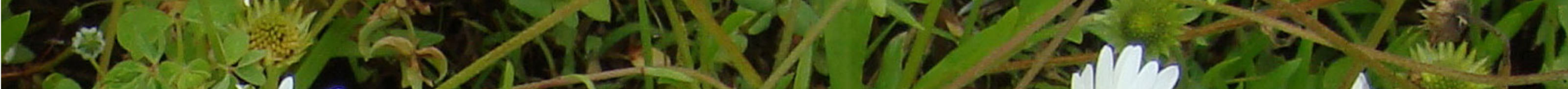
(s) 20 y $2 \sin 5$

ond in 



\section{ABSTRACT}

$\mathrm{B}_{\mathrm{y}}$

y engaging with ecomimicry concepts, it is hypothesized that an architecture of mutual inhabitation, of bees and humans, can provide a model for a sustainable city. The research reviews current architectural literature within the field of ecomimicry and adapts key theories to inform an urban bee/human building in Wellington City. These theories inform seven design characteristics that the building preforms as a 'living structure' to accommodate bees, at the same time accommodating humans.

The research follows these seven design characteristics throughout the design process and applies them to an existing earthquake building within central Wellington City. The outcome of this research is a scenario where the relationship between humans and bees is synergistic and provides a model for an ecomimetic, sustainable architecture. The findings from this research suggest bees can co-inhabit with humans in an architecture that extracts aesthetic and sustainable principles that, in turn, can enrich the city. 


\section{ACKNOWLEDGEMENTS}

I would firstly like to thank my supervisors Peter Parkes and Simon Twose. Without their support and advice, this thesis would not have been possible. I would also like to thank my close friends and family who have been there for me throughout this process. I would like to thank the graduating class of 2012 from Victoria School of Architecture. Your constant support and friendship has been greatly appreciated not only over the past 12 months, but from the beginning of our architectural studies. And finally, I would like to thank those who understand the role in which bees play in our everyday lives. The simple act of pollination often goes unseen and unappreciated. 
INTRODUCTION

Aim

Research approach

CHAPTER ONE - Literature Review

CHAPTER TWO - Case Studies

Introduction 2.1 The Virgin Comb in Architecture 2.2 The Traditional Beehive in Architecture

2.3 The Lloyd Crossing Project - a new approach

\section{CONTENTS}

Conclusion

CHAPTER THREE - Urban Ecology

Introduction

3.1 Why is greening a city important?

3.2 Where can greening be done?

3.3 How can pollination within a city be done?

3.4 What kind of bee would do best in a Wellington

context?

3.5 Site: Selection

3.6 Site analysis

Site: Orientation

Built and unbuilt space

3.7 Site: Transport analysis

3.8 Site: Building analysis

Conclusion

CHAPTER FOUR - Design Research

Introduction

4.1 Brief and Programme

4.2 The design requirements of the bee

4.3 The Skin

4.4 A 'living' building

4.5 Respiration

Skin Details

The components of the skin

4.5.2 Heating and Cooling

4.6 Movement and Senses

4.7 Growth

4.8 Plans

Building Details

4.9 Reproduction

4.10 Nutrition + Excretion

Design Reflection

CHAPTER FIVE - Conclusion

Conclusion

5.1 The Design

Limitations

BIBLIOGRAPHY

LIST OF FIGURES

APPENDIX 


\section{INTRODUCTION}

In response to worldwide climate and ecological crises, the emphasis on planting more vegetation in urban environments is gaining considerable momentum. However, consideration for how this new vegetation is pollinated and the role bees play in our everyday life is regularly unseen. People depend on insect pollination for survival as some $70 \%$ of modern food crops require bee pollination. With threats facing the apian industry such as the Varroa mite and Colony Collapse Disorder, the impact bees have on the pollination of these crops and the role in which bees play in society is arguably more crucial now than ever before.

Ecomimicry provides an approach to sustainable design where features from ecosystems are mimicked with the aim of reducing human reliance on non-renewable resources. These mimicked features are used in a design to establish linkages to the specified ecosystem using sustainable methodologies. The research presented in this thesis looks at ecomimicry as a design paradigm. The apian ecosystem - extending from the beehive and the efficient systems used by the bee, through to the plants that the bee pollinates - is used to inform the design of a mutually beneficial bee facility in central wellington City.
This thesis explores apian ecosystems in order to create an architecture and habitat for humans, bees and plants in central Wellington City. The research looks at recent literature by experts within the growing field of ecomimicry to help inform this. In so doing, it will be shown that a building can be created which helps reduce reliance on local resources, creates a habitat for humans, bees and plants and provides a model for an ecomimetic, sustainable architecture, and, a sustainable city.

In Chapter One, background on ecomimicry is presented. The main authors the research looks at are; Datuk Ken Yeang, Maibritt Pedersen Zari, Michael Pawlyn, J Scott Turner and Rupert Soar. These authors were selected for their recent publications on the subject and scope of work that digresses outside the traditional area of biomimicry. Chapter Two discusses works of architecture by many notable 20th century architects who were influenced by bees and the products of their produce. These architects include; Antoni Gaudi, Frank Lloyd Wright, Hans Söder and Mies van der Rohe. Many of the findings from this chapter will inform design decisions made in later chapters.
Aim

\section{Research Approach}


Chapter Three discusses four things and focuses on the planting of vegetation around Wellington City. The questions this chapter answers include:

- Why is greening a city important?

- Where can greening be done?

- How can pollination within a city be done?

- What kind of bee would do best in a Wellington context?

A site selection is made at this point based upon the information gained from this Chapter. This work is then brought together in Chapter Four where a building design concept is presented proposing a mutual habitation bee facility for humans and bees. Finally a conclusion is given which summarises the research and suggests areas where the design could develop further, limitations encountered and the fruitfulness this research has on sustainable design. 
Chapter One

Literature Review

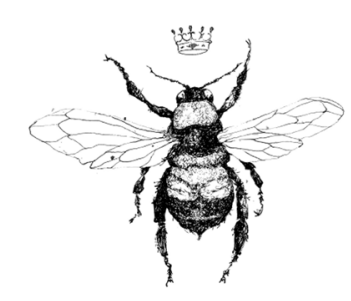


It is well established within literature that the notion of biomimicry has been around for hundreds of years. Traditionally, 'biomimicry' encompasses design metholodogies in which designers from many different fields have looked at nature's way of solving design problems and how these techniques can be adapted for human use. Within the field of biomimicry there is a relativity new concept surfacing which offers regenerative potential for buildings to perform as 'living structures' by imitating nature and providing linkages to entire ecosystems. This has been coined 'ecomimicry' by architect Datuk Ken Yeang, a leading pioneer within the field of sustainable design. Throughout this Chapter, significant experts from various fields within biomimicry will provide some insight into the different benefits various forms of mimicry offer. It is hypothesized that by looking into ecomimicry for a Wellington-based design, an architecture of mutual inhabitation, of bees and humans, can provide a model for a sustainable city. The following literature review attempts to support this hypothesis.

Maibritt Pedersen Zari, a leading expert in the field of biomimicry form Victoria University of Wellington, states that "examples of successful biomimicry that have progressed past the concept and development stage are typically of products or material, rather than of buildings or building systems and tend to mimic an aspect of a single organism" (Zari, 2007, p. 1). These examples typically mimic form or aesthetic gesture and do not necessarily mean the resulting products will be more sustainable than the traditional equivalent. In response to this, Pedersen Zari offers two ways of viewing biomimicry as a tool to "increase regenerative capacity of the built environment" (Zari, 2007, p. 3). She categorises these two approaches as: design looking to biology and biology influencing design.

'Design looking to biology' is useful when initial design parameters are set up by the designers and solutions from the natural world are used in order to solve specific design problems. An example of this could be using the shape of a bird's wing by applying its form to a new passenger jet in the aim of reducing air resistance. This method allows designers to address specific design problems without needing an in-depth understanding of how the life-form or organism fits into its immediate context. The main disadvantage with such an approach that Pedersen Zari asserts to is that this "translation of such biological knowledge to a human design setting has the potential to 
remain at a shallow level" (Zari, 2007, p. 3).

The second approach that Pedersen Zari discusses is 'biology influencing design'. With this approach the designer is influenced by his or her knowledge of an area of ecological research; "identifying a particular characteristic, behaviour or function in an organism or ecosystem and translating that into human designs" (Zari, 2007, p. 3). The benefit being that previously unthought-of design solutions have the potential to influence humans outside the design parameters. In addition to this, an "approach to architectural design that incorporates an understanding of ecosystems could become a vehicle for creating a built environment that goes beyond simply sustaining current conditions to a restorative practice where the built environment becomes a vital component in the integration with and regeneration of natural ecosystems" (Zari, 2007, p. 1).

When categorising the kind of biomimicry, each approach (i.e. design looking to biology or biology influencing design) can be further classified into three levels, namely: mimicry of a specific organism (organism level); mimicry of how an organism behaves or relates to its broader context (behaviour level); and mimicry of an ecosystem (ecosystem level). In terms of the regenerative potential, mimicry at an ecosystem level has the greatest potential to positively transform the environmental performance of the built environment (Zari, 2007). Throughout her paper, Pedersen Zari expands upon the different kinds of mimicry and the regenerative possibilities for each. This is echoed in the second text by Michael Pawlyn, who shares a similar view on the subject. He suggests in his book, Biomimicry in Architecture, that many current approaches to environmentally sustainable architecture are based primarily on mitigation. For many of the current examples of sustainably designed architecture, there is a potential to go further than mere mitigation and for buildings and cities to become regenerative (Pawlyn, 2011).

Throughout his book, Pawlyn covers examples of biomimicry at both the organism and behavioural levels. However, no architectural examples of ecosystem-based biomimicry are mentioned. The example that Pedersen Zari refers to in her paper 'Biomimetic Approaches to Architectural Design for Increased Sustainability' is the Lloyd Crossing Project that has been proposed for Portland, Oregon. This design integrates multiple sustainable strategies for energy, water and habitat. As this project is not yet complete, it is not feasible to comment on how successful such a project would be. However, the forecasted savings 
of non-renewable resources calculated over a 40-year timeline are expected be vast. These savings are; $60 \%$ water conservation, a three-fold increase in solar energy usage and the creation of an abundance of natural habitat on the 35-block site (Mithun, 2004).

In order to understand the relevance of a biomimetic approach to an architectural design, we must first understand why biomimicry is used in the first place. Nature has solved many of the design challenges that architects and designers are faced with. "Biological organisms can be seen as embodying technologies that are equivalent to those invented by humans, and in many cases they have solved the same problems with a far greater economy of means" (Pawlyn, 2011, p. 1). These technologies have naturally evolved over time and therefore make extremely economical use of material and form. When applying these natural systems and methodologies to a design-based discipline, they are generally used in the realm of sustainability in order to create more resourceful efficient designs. Ecosystem-based design (so called ecomimicry) however, is a relatively new concept within the field of biomimicry. One of the prevailing experts in the field of ecomimicry is ecologist, writer and architect Datuk Ken Yeang. Yeang also invented the principles behind ecomimicry, which he describes as "imitating the eco-system and maintaining linkages and connectivity between the human-built environment and the surrounding's eco-system" (Koh, 2010).

Yeang shares a similar view to Pedersen Zari that buildings which look at eco-systems or draw inspiration from the natural world can become regenerative. One of the main ways he describes this happening is by designing buildings to perform as passive low-energy structures. "In nature, the only source of energy is from the sun. Photosynthesis. So if you can design with renewable sources of energy, then we are imitating nature" (Koh, 2010). As a relativity new concept, ecomimicry has been primarily used in architectural design to reduce carbon emissions and the reliance on non-renewable energy sources. Through his design approach, Yeang brings together many interconnected systems, which provide life support, to create buildings that are 'living structures'.

The idea that a building could be considered a 'living structure' is reaffirmed in the text by J Scott Turner and Rupert Soar of Loughborough University. Turner and Soar argue that biomimetic buildings can go "beyond biomimicry - from 
buildings that merely imitate life to buildings that are in a sense, alive" (Soar, J Scott Turner and Rupert C, 2008, p. 1). They postulate that an object (e.g. a building) can potentially exhibit the seven characteristics of life - movement, reproduction, senses, growth, respiration, excretion and nutrition. When an object embodies these seven characteristics, it becomes in a sense, a living organism and moves beyond mimicry at purely the organism or behaviour level.

The example Turner and Soar refer to in their paper is Zimbabwe's Eastgate Centre. The building is based upon the termite mound, and in particular the ventilation techniques a colony of termites use in order to maintain nest temperature. These techniques have been used to control the building's temperature, but as Turner and Soar suggest, these techniques have been misinterpreted to how a termite colony actually controls its temperature. The exterior of a termite mound is porous, not solid as previously thought. As wind passes over termite mound's surface, it creates positive and negative pressures over the surfaces - sucking cool air through the tiny holes and removing warm stale air out the others. The method used in the Eastgate Centre is, in fact, reliant on the so-called 'Stack Effect'. This method requires a constant flow of air. The benefit of the porous surface of the termite mound is that this creates a dampening effect against sudden gusts of wind. Although Zimbabwe's Eastgate Centre has been celebrated as a successful model of a biomimetic building, Turner and Soar argue that with an in-depth understanding of how the naturally occurring systems work, this level of mimicry can be pushed further. Buildings could start to harness technologies and design interventions that mimic life - towards buildings that are extended organisms, where function and structure meld, and are controlled by the overriding demands of homeostasis (Soar, J Scott Turner and Rupert C, 2008, p. 15).

Another example of an insect that has been used as a source of design inspiration is the bee. In particular, the lives and structures of bees have been a source of inspiration to many notable twentieth century architects. Historically the form of the hive and the metaphor of social organisations gained from bees are foregrounded rather than the wider ecological significance. Juan Antonio Ramirez, a professor of art history at the University of Madrid, traces the genesis of Modern architecture in the 19th and 20th centuries using the metaphor of the bee. In his book The Beehive Metaphor, Ramirez suggests that many of the 
founders of the Modern movement were inspired by both social and technological aspects of bees and their structures. Antoni Gaudi, Hans Söder, Frank Lloyd Wright, Mies van der Rohe and Paul Gösch are a few architects that Ramirez refers to in his book. He argues that a colony of bees could be viewed as a perfect society and that, with the invention of the observation beehive and removable frame beehive, beehive functions were able to be studied in-depth. The significance of this lead to vast improvements in building technology informed by various functions and aesthetics of a beehive.

Although many of the aforementioned architects are not necessarily using biomimicry to solve design problems, at the least they are using mimicry of the beehive as a design generator. Ramirez asks the question "Why should we be surprised that the complex world of the beehive should have had such an 'encouraging' influence on the shape and organization of human architecture?" (Ramirez, 2000, p. 16). The following chapter addresses this, in particular exploring case study examples where aspects of the beehive have been mimicked. 
Chapter Two

Case Studies

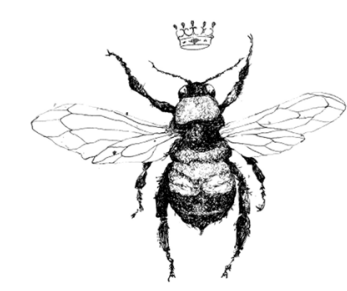




\section{INTRODUCTION}

The beehive metaphor has been used as an architectural design generator by many architects. From historic to modern interpretations, many share similarities when it comes to how the ideas of a beehive have been incorporated into an architectural design. Juan Antonio Ramirez states in his book, The Beehive Metaphor, "the organization and virtues of these insects and the properties of their produce have captivated us just as much as the shape of their architecture" (Ramirez, 2000, p. 35). The formal and ideological connections between apiculture and architecture have been expressed many different ways in the built environment. This chapter explores some examples where the beehive metaphor has been used strongly and where biological influence has informed design outcomes.

\subsection{The Virgin Comb in Architecture}

The discussion that follows outlines how different beehives work and to what extent humans have mimicked them. Little research is available on the constructional behaviours of bees and, in particular, how they form their natural beehives. As far as it is known, in order for bees to create a natural comb or 'virgin comb' a number of individuals form a chain by attaching themselves to the feet of another. When hung from a surface, the chain forms an arc which becomes the initial shape for the beehive. It is from here the combs are then created within this plane defined by the arc. This process is repeated until the flat layers of comb three-dimensionalise and a beehive is created. This hanging structure is pure wax. Bees fill the hexagonal cells with honey and use them to raise their young. Throughout history, many architects have been inspired by this primitive form of a beehive and the geometries it possesses.

Antoni Gaudi is arguably the most famous example of an architect who has been inspired by this form. Growing up, he had a close connection with his natural surroundings (Ramirez, 2000). Together with his keen powers of observation, Ramirez argues that this "must have encouraged his unique manner of confronting nature without any cultural references" (Ramirez, 2000, p.36). In many of his works, Gaudi uses his most famous architectural invention, the catenary curve, which has a very similar geometry to that of a parabolic arc. "Nothing seemed so imperfect to him than the lack of continuity between the arc and column that he perceived in traditional architecture" (Ramirez, 200, p. 38). The shape of the chain of bees and the shape of the resultant 
virgin comb have been mimicked in his buildings, but have been flipped upright. Though there does not appear to be any explicit evidence that Gaudi based his catenary curve on the hanging chain of bees or the shape of virgin comb, Ramirez suggests that it can be inferred that Gaudi must have been influenced by apiculture (Ramirez, 2000, p.46.). The representation of this naturally occurring form and the way in which it has been used in Gaudi's work, is perhaps the strongest case of an architect mimicking the virgin comb creation process and form, for human use. The benefit of such a structure is significant because this curve eliminates the need for flying buttresses or lateral supports.

Used in a wide range of applications, Gaudi applied his curve to a vast number of designs. It is believed the first application of his curve was in the Cooperativa Obrera Mataronese, a small warehouse in Spain. From here he used it in many of his designs, ranging from the shape of doorways to the vaulted form of large cathedrals and temples. Often designed by hanging chains as a guide with weights attached, Gaudi worked on the principal that "all the opposing elements of the temple are based in the shapes they produce" (Ramirez, 2000, p. 38). This is significant because the curve allowed Gaudi to create these large works of architecture with a function that creates the form.

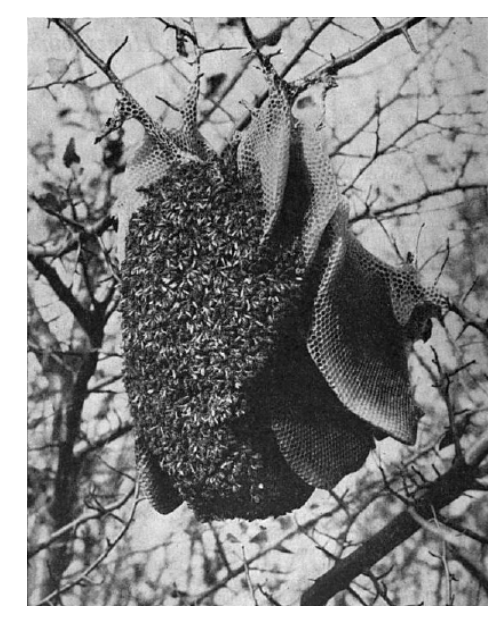

FIGURE 1: A completed virgin comb. Photographed by Alvard Bishop, 1946

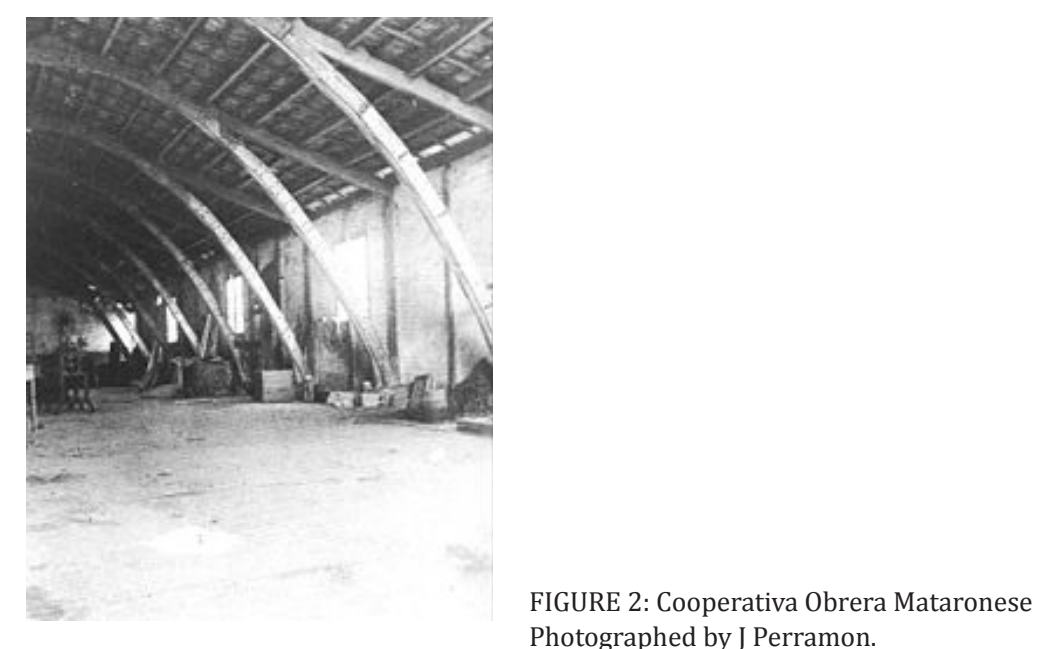


FIGURE 3: The construction process of a virgin comb. Image by author, 2011.

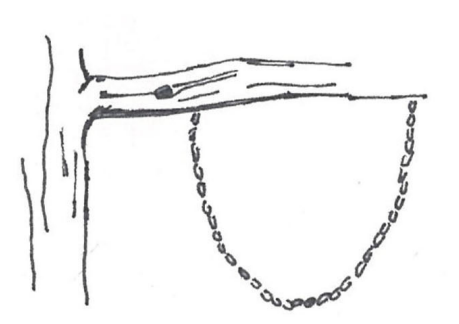

chain of hanging bees

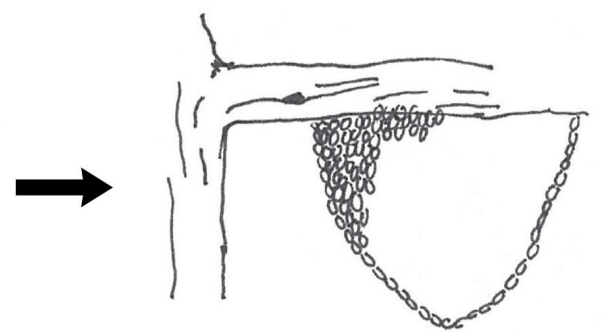

swarming

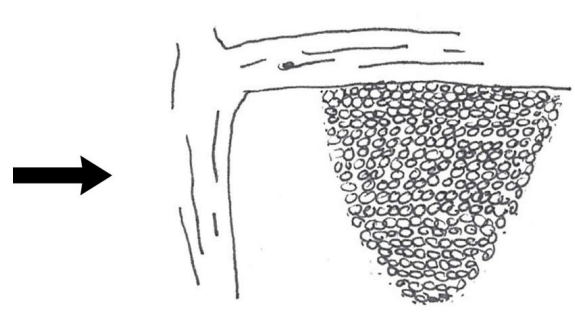

virgin comb

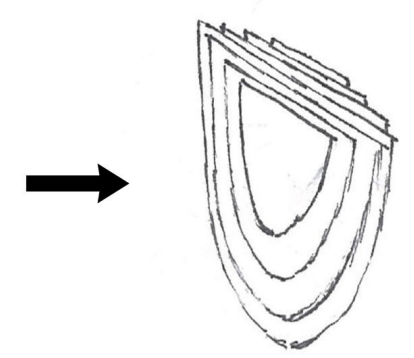

completed beehive 


\subsection{The Traditional Beehive in Architecture}

Changing little over the past two hundred years, the domestic beehive has become the most popular. Consisting of a wooden box with several honeycomb frames inside, the modern artificial beehive has changed the way beekeepers (or 'apiarists') tend to bees. Like the virgin comb, the beehive makes use of wax hexagonal cells, which are used by bees to raise their young and store honey. The main reason for the domestic beehive's success is the ease of extracting honey from the honeycomb without harming bees or destroying the beehive in the process.

The hexagonal cells that make up a beehive have been the inspiration to many biologicallyinfluenced buildings throughout history. Although diverse in their application, many of these buildings share the fundamental hexagonal shape for ordering space and aesthetic beautification. The first example is a design by architect Hans Söder who used the hexagonal shape in plan for his 1921 competition entry for a high-rise office block to be built in the centre of Berlin. "The ground plan showed a central hexagonal vestibule with six polygonal structures radiating from it: another three smaller towers, also of hexagonal cross-section, are situated in the vertices of the triangle" (Mertens, Spring 1922, p. 205). As a collective entity, the virtues and behaviour of bees were a rich source of inspiration to Söder. Although not the winning entry, Söder's design used the ideas of community and modularity found within a beehive and translated these into a human context. The result was a triangular tower complex (in plan) that made use of the pattern created from the hexagon.

Mies van der Rohe also entered a bee inspired building into the same competition. Although he did not use the hexagonal form, Mies's entry was titled 'Honeycomb' for other reasons. By using glass over the entire facade, Mies achieved a structure that reflected observation beehives popular among many households around the turn of the 20th century. These beehives consisted of honeycomb frames perpendicular to the glass. It is believed that Mies was inspired by these beehives to replace the solid construction of the external walls, which early high-rise buildings utilized, with modern lightweight glass.

The hexagonal form has been used symbolically in places of worship. Another example of a building where the hexagon can be found is Paul Gösch's Pilgrimage Chapel. In the ground plan, "the symbolic triangle of the Trinity radiates from 


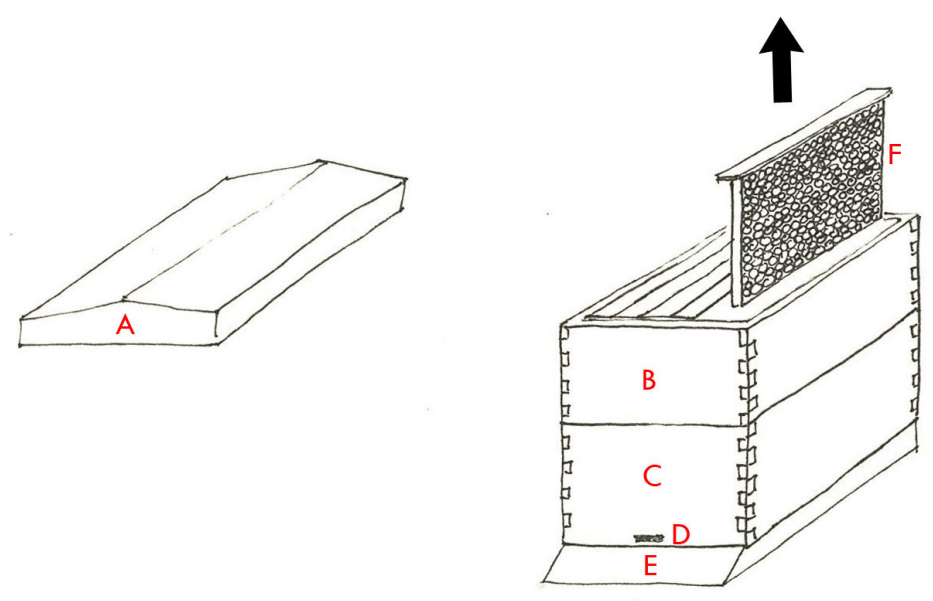

A. Hive cover

B. Comb honey super

C. Hive body

D. Hive exit/entrance

E. Alighting board

F. Honeycomb panel

FIGURE 4: A domestic beehive. Image by author, 2011. 
the central hexagon" (Ramirez, 2000, p. 100). Designed in 1920, Gösch used a central hexagon as a symbol to represent the idea of a collective communion. Although very loose, the aim of this reference is to mimic the utopian vision of a beehive and the 'perfect society' it symbolises.

Frank Lloyd Wright also used the hexagon to inform the design for a place of worship. Although never built, the Steel Cathedral consisted of nine large cathedrals and several smaller chapels all forming an enormous pyramid with a central hexagonal base. The hexagon was used here for similar reasons to those of Paul Gösch's Pilgrimage Chapel. The social and symbolic connotations associated with the beehive share parallel ideas to the fundamental principles behind religion. However, this is not the only building in which bees, and in particular their structures, have been the inspiration to the design of Wright's architecture. In 1937, Wright designed the Hanna House, also known as the Honeycomb House. This project is regarded as a piece of work that leaves little doubt that Wright was influenced by bees and their produce. Again the hexagonal shape is used but in a different way to his Steel Cathedral. The hexagon is used in plan following a modular pattern forming an L-shape. "The honeycomb is so obvious that it served as a model

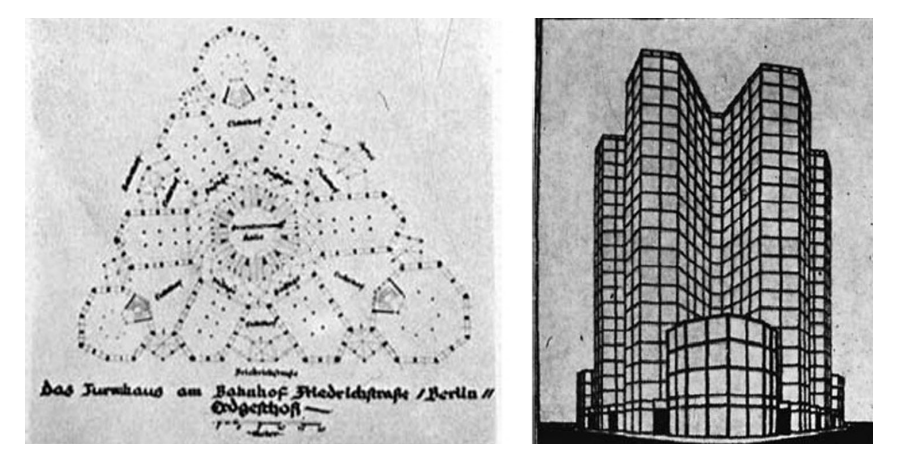

FIGURE 5: Hans Söder; Ground plan and elevation of the skyscraper project, Berlin. 1921.

Drawings by Hans Söder. 1921.
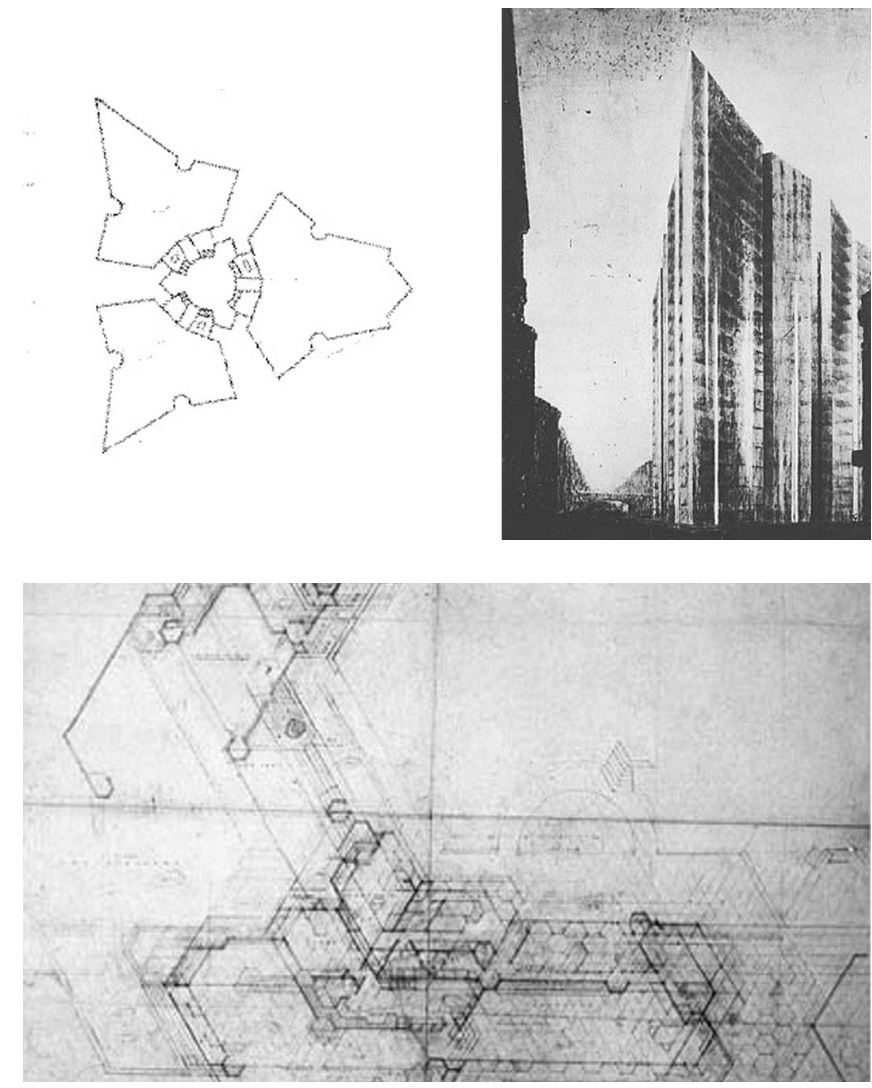

FIGURE 6: Mies van der Rohe; Ground plan and elevation of the glass skyscraper project, Berlin. 1921. Dwawings by Mies van der Rohe. 1921.
FIGURE 7: Frank Lloyd Wright; Ground floor plan of the Hanna House using the hexagon to arrange space. Dwaring by Frank Lloyd Wright. 1937. 

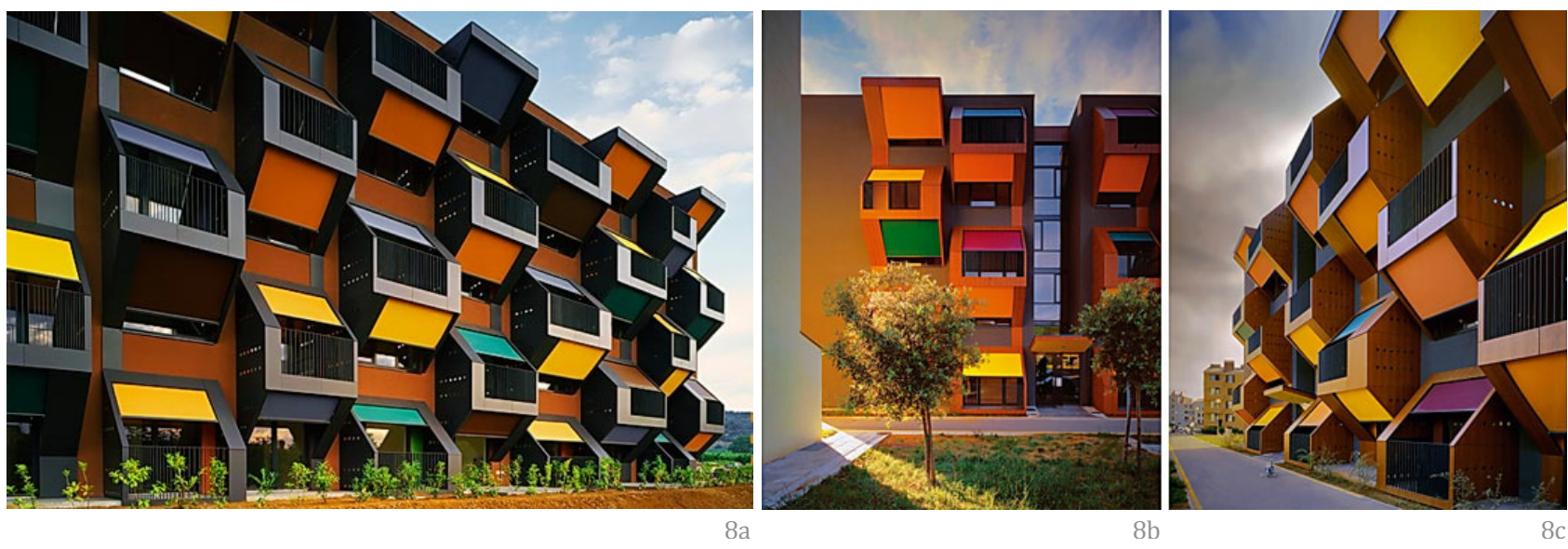

FIGURES 8a,8b,8c: Slovenia’s Honeycomb Housing Complex Photographed by M Chino, (2011) for the whole house" (Paul R and Jean S. Hannah, 1981). The rooms were then created by forming different sized hexagons intersecting the next. Furthermore the interior fit out was "based on the hexagonal screen of the honeycomb" (Ramirez, 2000, p. 113) and can be found in the design of furniture, ornamentation and the fireplace.

It is well established within literature that many architects have used beehive forms throughout history. Although these buildings are examples of architects using the beehive to influence their work, they are not necessarily mimicry of anything more than the hexagonal shape. These buildings offer a look into how some of history's more wellknown architects were influenced by bees and their structures. By its very nature, biomimicry offers design solutions to problems in order to become more resource efficient. The following examples of beehive-inspired architecture aim to achieve this and claim to use the hexagon for this reason.

The first example is Slovenia's Honeycomb Housing Complex. Located in an industrial district on the Slovenian coast, this modern building aims to push the idea of the stock-standard housing complex and orthodox facade. Designed in transverse section, the architecture mimics the hexagonal form of the honeycomb in the vertical plane. As a result, the building is split up into a hexagonal arrangement with each housing unit acquiring a balcony that makes use of the remaining space created by the angled walls of the hexagonal cells.

When analysing the building in plan, the idea of community comes through. This is read in the plan of the Slovenia's Honeycomb Housing Complex by creating multiple units stepped up over varying floor heights. The building uses the three-dimensional facade for temperature control and privacy. The use of angled walls allows privacy by blocking out unwanted views and temperature control within the units by regulating sunlight exposure. 
The number of un-built projects that use the 'beehive metaphor' as a conceptual basis continues to grow. Similar ideas to those of Slovenia's Honeycomb Housing Complex have been used in London's un-built Beehive Tower. The building is proposed to bring awareness to the reliance humans have on bees and to act as a central icon for London city. Designed using the hexagonal form as a modular structure, this vertical form makes use of as much open space as possible for vegetation and socialising alike. The building's large lattice hexagonal form acts as the primary structure allowing as much light and air into the open levels as possible - creating an urban garden for humans and wildlife.

Another London-based design which caters for both humans and bees is Vertical Farm. The building utilizes the honeycomb grid as a modular building block and makes use of the repetitive hexagonal pattern. Vertical Farm was part of a larger design competition held in early 2011, with a brief that called for greenery and accommodation in a vertical form. Much like Beehive Tower, the building uses the hexagonal pattern for the strength properties a hexagonal grid possesses. These buildings use the basic honeycomb form from the beehive which has been translated into a larger scale appropriate for human occupants.

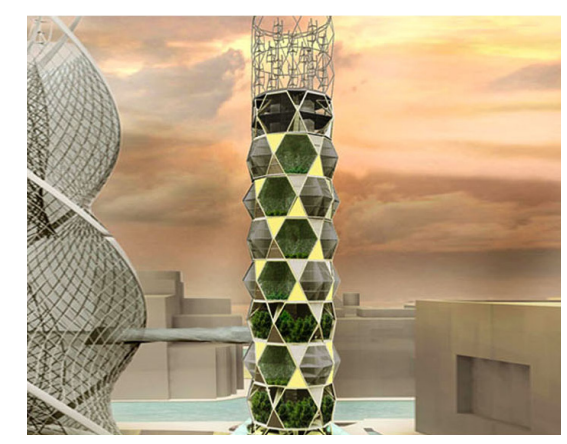

FIGURE 9: Beehive Tower Yoneda, Y. (2010).

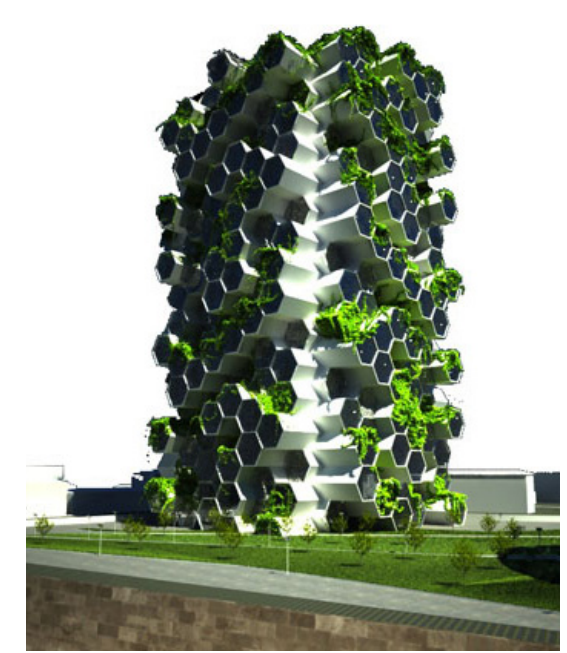

FIGURE 10: Vertical Farm Meinhold, B. (2011). 
Although this can be seen as mimicking the form of a beehive, other possibilities within the realm of biomimicry can also be explored. Pedersen Zari suggests in her paper, Biomimetic Approaches to Architectural Design for Increased Sustainability, that there is potential to employ a multiple sustainable strategies including water, energy and habitat. Such strategies could include food production and go beyond sustaining current conditions, that is to say be regenerative.

\subsection{The Lloyd Crossing Project - a new approach}

This section outlines the ways in which the Lloyd Crossing Project proposed for Portland, Oregon differs from previous examples of biomimicry, and why it offers a potential model to view sustainable design. Although still within the scope of biomimicry, this project aims to test the fruitfulness of the relatively new concept of ecomimicry. As previously discussed by Pedersen Zari, the Lloyd Crossing Project is a catalyst for community sustainability. The groups behind this project are Mithun Architects and GreenWorks Landscape Architecture Consultants. The vision for the project is to create a community that is financially and environmentally sustainable (Mithun, 2004, p. 6). There are several ways in which this is achieved. The following criteria are aspects of sustainable design that the project aims to employ over the 45 -year timeframe given to complete the entire project. These include: water management, energy management, habitat and Place-making. The idea behind the project is to live within the means of the immediate environment and to mimic aspects of it where appropriate in order to reduce the impact the built environment has.

In order to reduce energy consumption, buildings will be encouraged to incorporate solar, wind, biomass or other alternative energy technologies. Energy efficiency, including natural lighting and ventilation, low energy artificial lighting and appliances, and high performing insulation will be used in new buildings and major renovation projects (Mithun, 2004). This is predicted to "increase energy performance by a factor of three over the current energy code on all new buildings." (Mithun, 2004, p. 107). Energy upgrades on all existing buildings will also be carried out to achieve an energy savings goal of 23 percent.

To reduce water consumption within the Lloyd Crossing Project, rainwater and storm water will be collected, stored and used for irrigation of 


\section{CONCLUSION}

gardens and landscaping in place of city water. Aided by the use of highly efficient water fixtures, this will achieve a 60 percent conservation of water. Increased vegetation is also proposed for the 35-block site. This will provide a habitat for wildlife and help offset carbon emissions. This is done by planting a mixed-conifer forest into an urban streetscape, pedestrian streets and planting around open public spaces.

Finally, the use of open space, storm water and habitat recommendations for the Lloyd Crossing Project aim to provide a unique signature for the neighbourhood. This signature reinforces the idea that the community lives within the means of its immediate environment. In Pedersen Zari's discussion about the Lloyd Crossing Project, she states that, "the most important advantage of such an approach to biomimetic design may be the potential positive effects on overall environmental performance" (Pedersen Zari, M. 2007, p.7). By looking at a site-specific ecosystem and mimicking its functional aspects, the biology can start to influence the design at an ecosystem level and regenerative possibilities can positively transform both the natural environment and urban environment.
Although many of the ideas presented here are yet to be tested in built form, the new paradigm of ecomimicry offers the potential to create buildings that go beyond simply sustaining current building conditions to buildings which utilize interwoven systems and provide the inhabitants with energy efficient alternatives. This model of ecomimicry offers potential to regenerate the urban environment and restore the affect it has on the global environment in terms of waste, material and energy. Within the growing body of knowledge on ecomimicry, a gap has been established that will provide a vehicle to test the idea of an apian-based design in Wellington City. This design will be discussed over the following chapters. 

Chapter Three

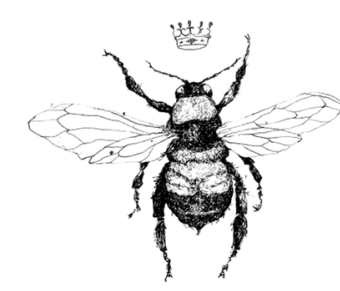




\section{INTRODUCTION}

It is well established within literature that an emerging urban trend is to increase the amount of green space within inner-city environments. This increase in green space includes the greening of parks and streets through the planting of vegetation. In turn, the greening of parks and streets helps promote the idea of an urban ecology in a society that is tending to focus more on sustainability. Despite many cities around the world already regarding green space as an essential part of any urban landscape, considerations as to first, the central role of pollination, and secondly, how the vegetation within the green space is pollinated are often ignored. This chapter will address the following questions:

- Why is greening a city important?

- Where can greening be done?

- How can pollination within a city be done?

- What kind of bee would do best in a Wellington context?

These questions will be discussed within the context of Wellington City, with reference to the proposed plans to increase the planting of vegetation in the Wellington City Council's 2040 Plan. From here a site with the potential to support this greening trend will be nominated for this project and analysed.
3.1 Why is greening a city important?

As a city expands, the need for its population to be more in touch with natural surroundings is an increasing effect. Wray Herbert from the University of Michigan believes this is primarily because "nature actually shifts our brains from one processing mode to another" (Herbert, 2011). In his book, On Second Thought, he discusses how humans are rooted in a natural surrounding from evolution and therefore it is embedded into our minds. Trees, smaller plants and animals have been proven both to stimulate and calm the psychological state of humans, which could possibly be through a subconscious reconnection to more primal human emotions. Seeking to achieve an environment that is in balance with nature by promoting planting within the city is one way in which this reconnection can be accomplished.

Wellington City (the capital of New Zealand) is getting behind this mode of thinking, as evidenced by how the idea is supported within the Wellington City Council's 2040 proposed plan (2040 Plan). Wellington City Council already has several redevelopment projects under consideration that utilise neglected public spaces by developing them into vibrant 'green'

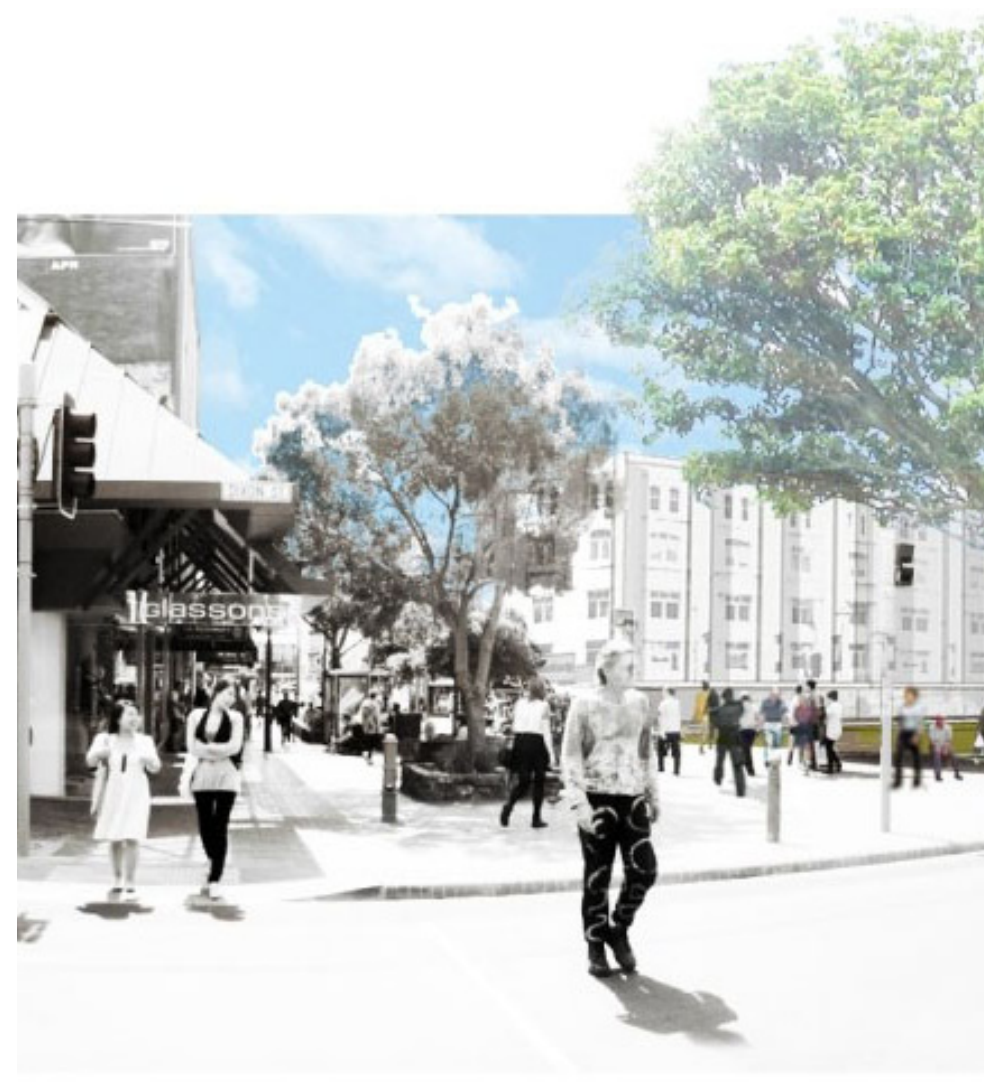




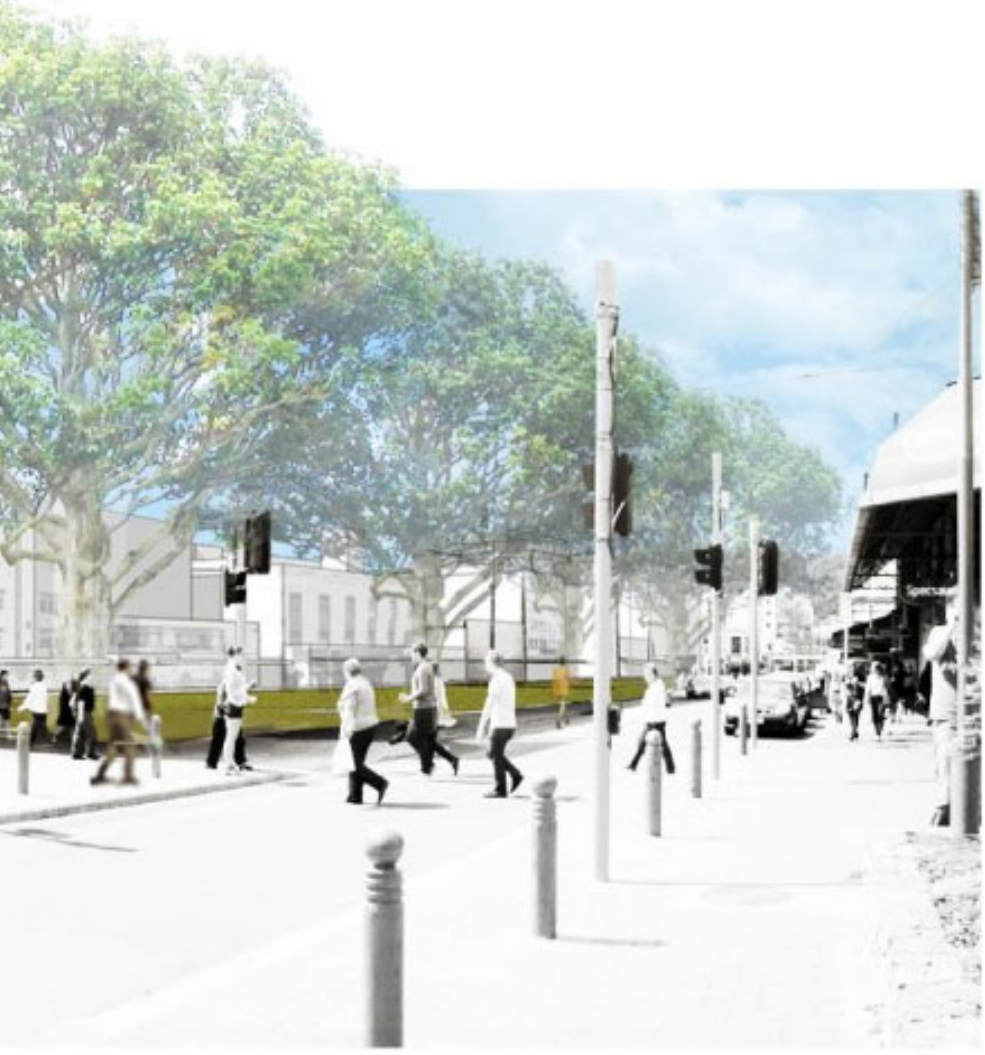

FIGURE 11: Te Aro Park redevelopment Source: Figure from Wellington City Council (2011) areas through the planting of many species of trees and flowering plants. Not only do trees and other plants provide the population with a closer connection to the natural environment (and the resultant benefits discussed in the preceding paragraph), but they also offset carbon emissions, act as sound buffers, provide sanctuary for wildlife and add to the overall atmosphere of the city. In this way a greening program in an innercity environment can be both environmentally and socially beneficial.

\subsection{Where can greening be done?}

The 2040 Plan urges redevelopment of many underused public areas and sets out a guide of how the city could take shape over the next 30 years. Neglected parks and popular roads with little vegetation are spaces that are targeted for redevelopment by the 2040 Plan. One site in particular is Te Aro Park through to Cuba Street via the existing Oaks Building. Here the proposed redevelopment is to demolish the Oaks Building and make a pedestrian connection from Cuba Mall through to a developed Te Aro Park. The new park will include many flowering plant species with open grass areas for the public to enjoy. It is hoped this will help activate the space and create a strong linkage to and from Courtenay Place.

Throughout the urban planning of Zurich and Dublin, green spaces within these large cities have been linked together in order to create effective green corridors. Vegetation in these green corridors provides a habitat for wildlife to live whilst supplying the city with much-needed greenery. If the green corridors are big enough, they can form a contrasting visual 'streak' through a city. Although Wellington is small by comparison to other major cities around the world, the connection from Cuba Mall through Te Aro Park and along Courtenay Place could potentially be the start of a green corridor that extends right through the greater Wellington region.

In addition to the number of green spaces already existing in Wellington City, the green areas proposed for the inner city in the 2040 Plan will increase this number noticeably. The 2040 Plan addresses the following areas which have the potential to be developed further over the coming 30 years. All areas focus on underused space and on ways in which greenery can be included to help activate and create better connections throughout Wellington. 


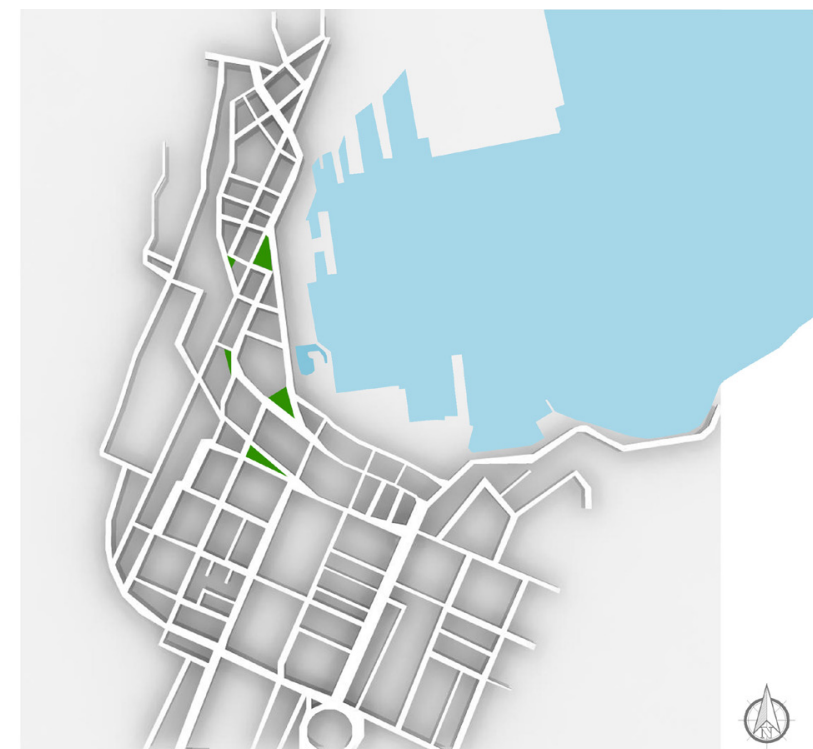

Triangular Spaces (FIGURE 12. Image by author, 2011.)

"Wellington's central city has an abundance of triangular spaces" (WCC, 2011). These spaces are significant to the history of the city and offer many design opportunities to enhance the walkability of the inner city. Many of the existing triangular spaces are underused and undervalued, for example Te Aro Park. With this site it is hoped to achieve: better integration from Courtenay Place to Cuba Mall, new walkways and more open areas and additional planting.

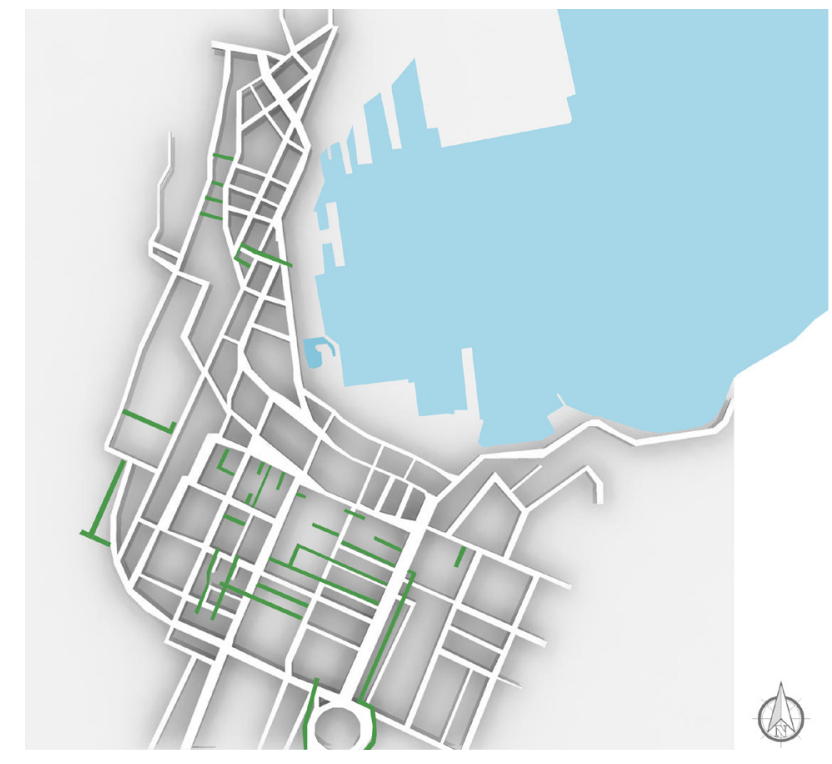

Laneways (FIGURE 13. Image by author, 2011.) The Council hopes to enrich many laneways throughout the inner city and enhance the pedestrian network over the next 30 years. These lanes offer opportunities for more activated retail frontage with integrated foliage. The Council hopes to work with the owners of adjacent buildings in order to achieve this. 


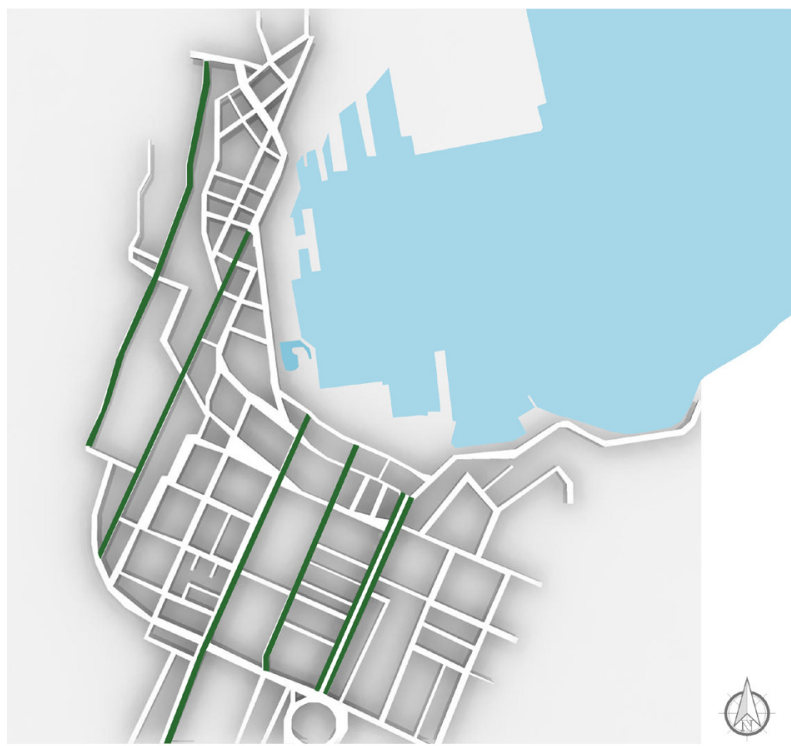

Boulevard Design (FIGURE 14. Image by author, 2011.) It is hoped that by making many of the northsouth streets running through the city desirable places for pedestrians to stop, it will enrich the experience of pedestrians and improve walkability of these streets. Making the streets desirable places to stop includes fixing problems such as unaligned footpaths, large street blocks and areas with little interest. These north-south streets are essential for vehicular as well as pedestrian access.

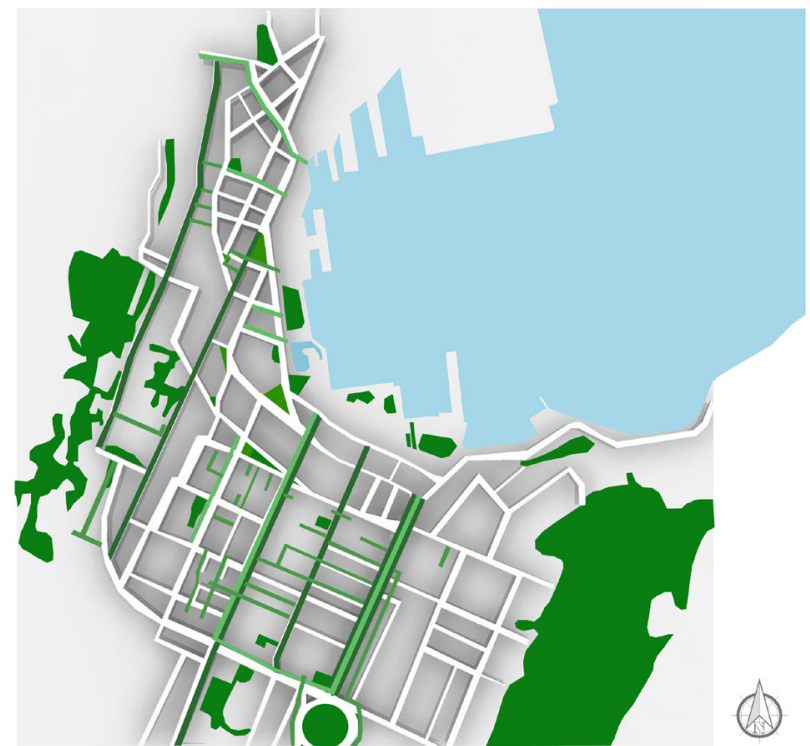

Green Infrastructure (FIGURE 15 Image by author, 2011.) Although the Triangular Spaces, Laneways and Boulevard Design areas address increased vegetation in the inner city, the 2040 Plan aims to increase vegetation throughout much more of the Wellington region. Additional planting of trees alongside major networks, and actively supporting eco-friendly buildings and green rooftops are additional strategies the Wellington City Council aims to adapt in the future. 
According to the Council, this is "in keeping with Wellington's aspiration to become an eco-city and will contribute to Wellington becoming a model for sustainable living" (WCC, 2011).

Despite this push for green infrastructure, one issue not addressed within the 2040 Plan is how the increased number of plants will be pollinated. A city can plant as much vegetation as it wishes, but with the lack of insects (in particular, bees) in the urban environment, these plants may possibly remain un-pollinated. Pollination is critical for plants to be able to realise their full potential in terms of the ecological benefit that they can potentially deliver. Therefore, when adopting greening programs by being present within an inner-city environment it is of utmost importance that pollination and how it will be implemented are also considered and planned for. This raises the question; can pollination be encouraged through an urban design solution?

\subsection{How can pollination within a city be done?}

As trees and plants are fixed into the ground, evolution has produced ways in which their pollen is spread. Insects, birds and wind distribution are all mechanisms of pollination. However, one of the most efficient mechanisms for pollination is the common bee. Colourful and sweet-smelling flowers attract bees with the prospect of nectar. As the bee harvests nectar, it also inadvertently accumulates pollen on its legs. Then, when the bee collects nectar from another flower, the pollen is dispersed and more pollen is accumulated. In this way, pollen is spread from the male parts of one flower to the female parts of another flower. Each side of this harmonious relationship has something to be gained. Bees turn the nectar into honey (their main food source) and vegetation flourishes to its full ecological potential. This pollination creates additional flowers, fruits, vegetables and forms the backbone of our food chain. Being such an efficient mechanism for pollination, it is an ideal candidate for an innercity solution.

Until recently in New York City, urban beekeeping was illegal. However, changes made to the city's bylaws have allowed beehives to be kept on rooftops throughout the city. With the push for rooftop gardens, bees from rooftop beehives now pollinate most of the trees and flowers throughout the city. The beehives also provide the people of New York with locally produced honey. Such rooftop gardens are popular among many cities where living in a localised environment is 
the only option. Beehives may offer some relief to enclosed urban living by creating a renewed connection to nature.

Similar ideas to those implemented in New York could be developed and used in Wellington City. A widespread urban beekeeping scheme could provide Wellington City with its pollination requirements for the future. Other environments that bees can be kept include greenhouses where the bees are kept to pollinate the crops within this environment. Eugenie L Birch, from the University of Pennsylvania suggests citizens ought to think about the benefits that natural services such as pollination can provide and how these services can be integrated into our cities. Often "those who advocate the greening of cities rarely focus on the economic services that natural services can provide" (Eugenie L Birch, 2008, p. 281). As he progresses his argument, he suggests that city planners could think of bees and beehives as an architectural generator - a way which includes them in the architectural makeup of the city.

Therefore, it is suggested that bringing beehives into Wellington City would help pollinate the increasing amounts of vegetation, which in turn would maximise the environmental and social benefit of inner-city green spaces. This suggests that an urban design that focuses on establishing beehives (bee habitation) and bee populations in Wellington City may help with inner-city pollination.

\subsection{What kind of bee would do best in a Wellington} context?

Many species of bee were introduced to New Zealand by early European settlers. Prior to this, many native species of flora were self-pollinating - a unique attribute to native plants. Although bees are not the only creature that can spread pollen (birds, bats and other flying insects can also undertake this task), it is something bees excel at. Now with more introduced plants, fruits and vegetables in New Zealand, the reliance humans have on bees to pollinate vegetation is much greater and indeed now essential for human food production (Aguirre, 2012).

There are many types of bee that undertake pollination throughout New Zealand. The most widespread however is the common honeybee (Apis mellifera). This bee lives in large colonies of up to 60,000 individuals. A hive of bees has the ability to last many years. Together with the fact 
they are easily domesticated makes the honeybee the most popular type of bee for farmers. With a diet consisting of nectar foraged from a vast array of different flowers, the honeybee would be one of the best candidates of bee to farm within Wellington City.

While some colonies live in traditional beehives provided by humans, others will choose wild sites such as a hollow in a Cabbage, Pine or Willow tree, on large rock faces or in small burrows in dry soil. Whatever the site, the beehive must maintain a relatively constant temperature and humidity. The temperature of the beehive is kept between $32^{\circ} \mathrm{C}$ and $36^{\circ} \mathrm{C}$ throughout the day regulating heat given off from the movements of individual bees within the hive. It is vital the beehive is kept at this temperature for the young larvae to develop properly.

The bumblebee (Bombus terrestris), is another popular bee found throughout the North Island of New Zealand. Like honeybees, bumblebees also live in colonies. However their beehives are made from irregular horizontal layers rather than the precise hexagonal combs like those of the honeybee. Colony sizes are also smaller - in the summer months, there are typically about 200 workers in a mature bumblebee hive. Although the number of individuals within a beehive is smaller, the bumblebee is the preferred bee for indoor pollination (greenhouse pollination) as they are not as susceptible to light confusion through glass. The crops they pollinate are typically tomatoes, capsicum and vine fruits such as passionfruit which are commonly grown within greenhouses.

Bees will only fly as far as necessary to collect nectar. According to the International Bee Research Association, "bee foragers commonly fly up to $6.5 \mathrm{~km}$ (4 miles) to collect nectar and pollen from flowers" (Carreck, 2010). Therefore, inner city vegetation would be solely reliant on the inner city bees from inner city beehives, however the inner city bees do not need to be solely reliant on the inner city vegetation. Thus, if a beehive was placed in central Wellington City, the potential pollination area covered by the bees could extend from Karori to Miramar. This suggests that either a honeybee or bumblebee may be a suitable candidate for inner-city bee keeping, and that neither would be restricted by the planting in inner-city green spaces. 


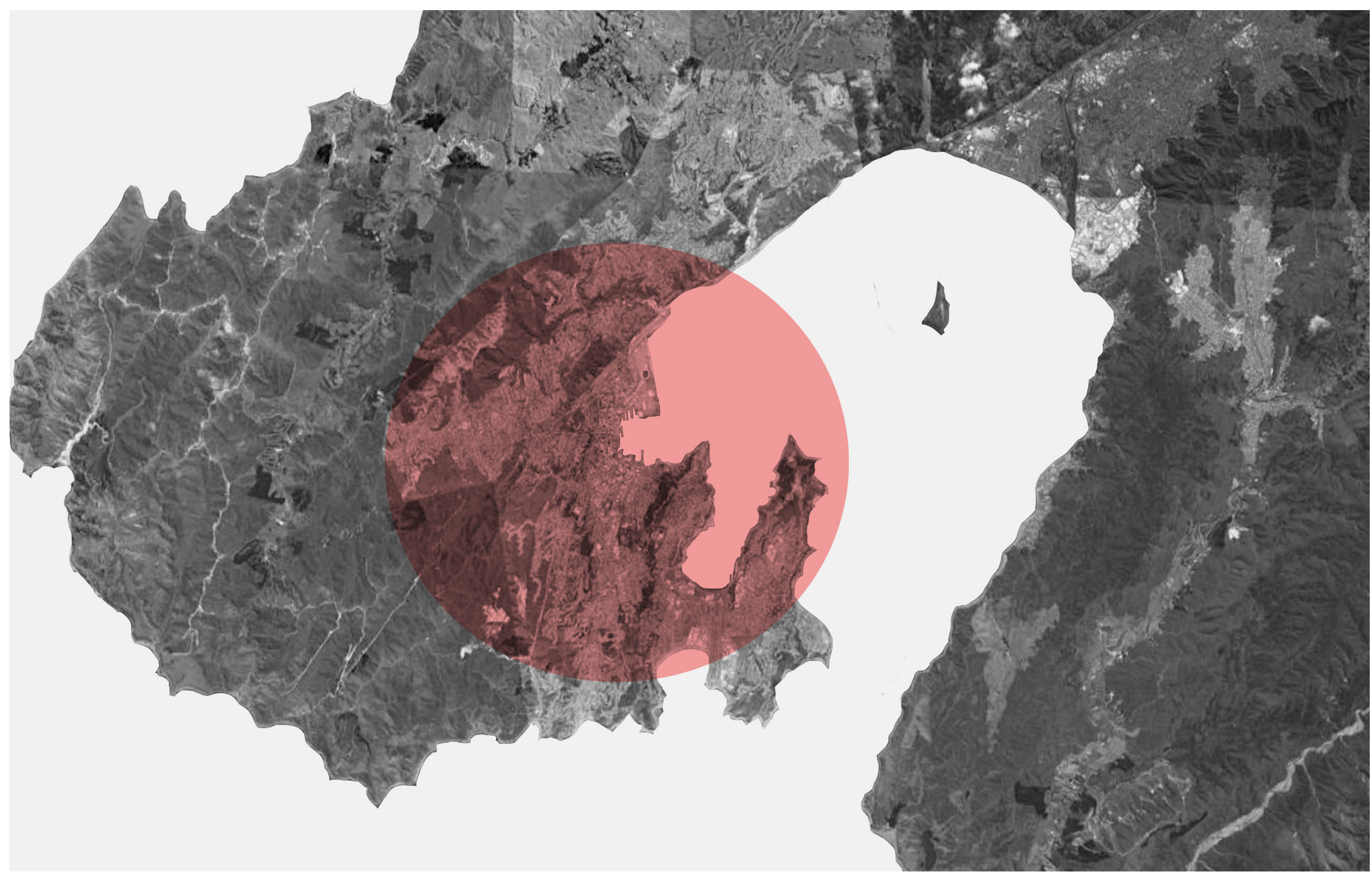

FIGURE 16: The area highlighted in red is the pollination radius bees will travel within Wellington City. This area would extend from Karori to Miramar. Image by author, 2011. 


\subsection{Site: Selection}

When finished, many of the redevelopment sites proposed for Wellington's inner city will offer additional vegetation. Te Aro Park when extended to Cuba Street (as discussed earlier in the chapter) would be an ideal location for an architectural intervention as the additional flowers, trees, bushes and shrubs would require insect pollination. This park is also located in an area of town surrounded by fairly low-rise buildings with wide streets. This leaves potential for rooftop gardens on neighbouring buildings in the future. Although an architectural intervention on the park would encroach into the proposed plans to plant vegetation, a building on a neighbouring site could offer design opportunities to test an architectural idea that of an ecological facility centred on bee habitation.

One site in particular is 131 Manners Street. Due to the historic nature of the existing Edward Building and the need for earthquake strengthening, this site is chosen to test this. The area highlighted in red on Figure 17 shows the position of the chosen site with respect to the park. With a proposed redevelopment of Te Aro Park under consideration, this site offers many opportunities in which an ecological facility could maximise the use of Te Aro Park for humans and bees alike. Figure 18 shows the extent of the Te Aro Park redevelopment, linking Courtenay Place with Cuba Street and suggests what the park could look like.

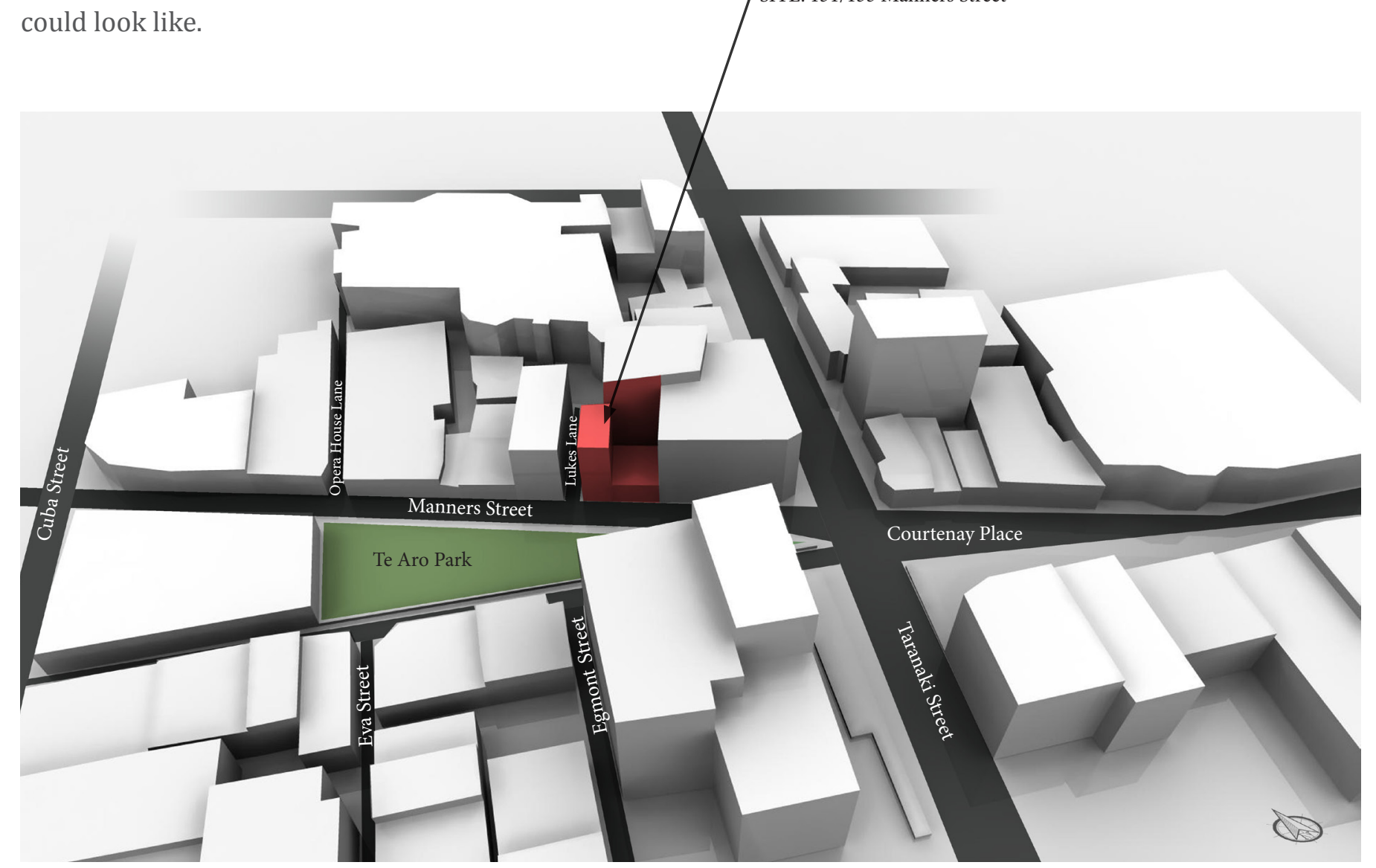

FIGURE 17: Te Aro Park and proposed site. Image by author, 2011. 


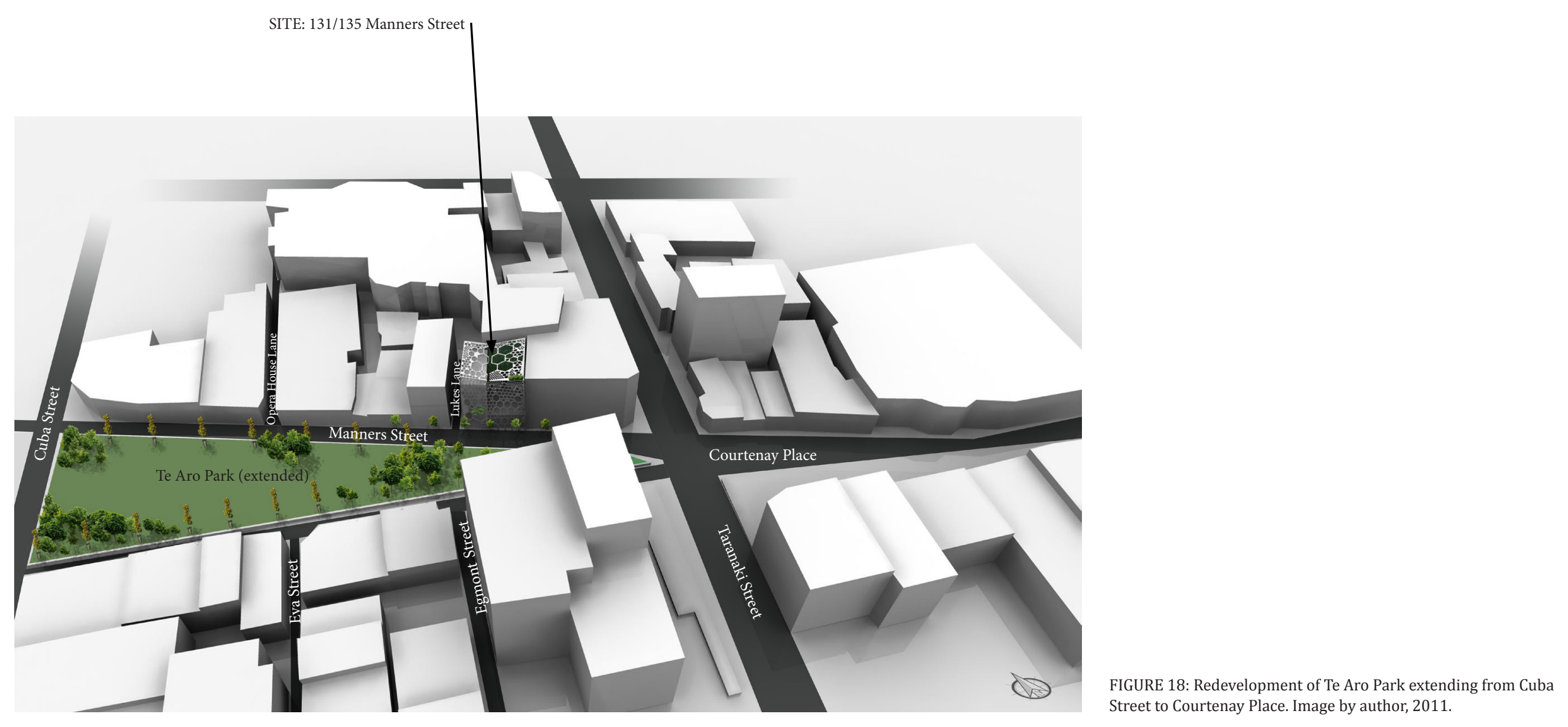




\subsection{Site analysis}

Designed in 1902, the Edward Building has potential in terms of strengthening, preserving and readapting a piece of Wellington's history. Adjacent to this is a small two storey building with a programme that includes a mixture of retail and residential space. As this small, rundown structure is surrounded on three neighbouring sides by large, solid walls, the potential to utilise this structure provides an opportunity to extend this space vertically and exploit any connections to the neighbouring Edward Building.

\section{Site: Orientation}

The site in its entirety faces South onto Te Aro Park. This means with larger buildings surrounding the site, direct sunlight from the North is limited, but not absent. The adjacent plansand sections (Fig 20a, 20b, 21a, 21b) illustrate the extent and direction of the shadows cast into the site, at midday, on the summer and winter solstice. The site gains large amounts of afternoon sun in both solstices. However, shadows cast on the site in winter are particularly dominant.

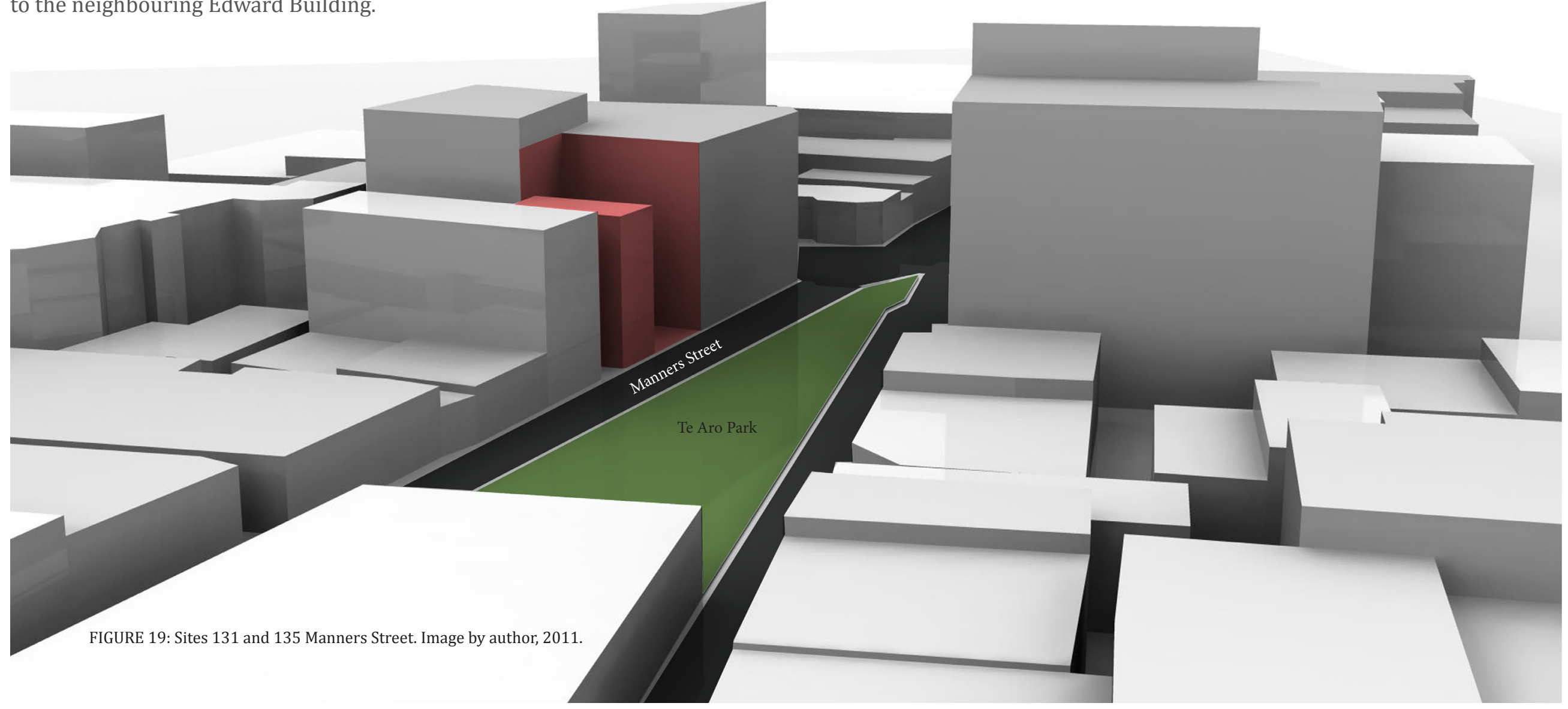




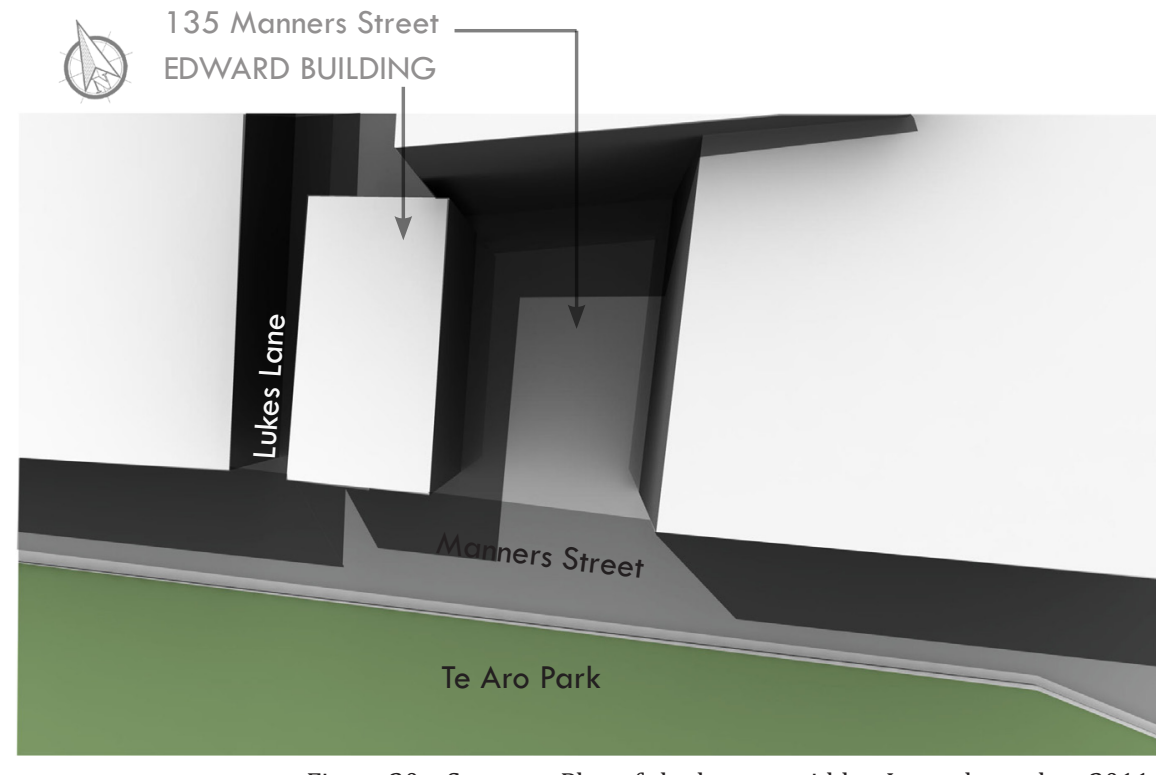

midday sun

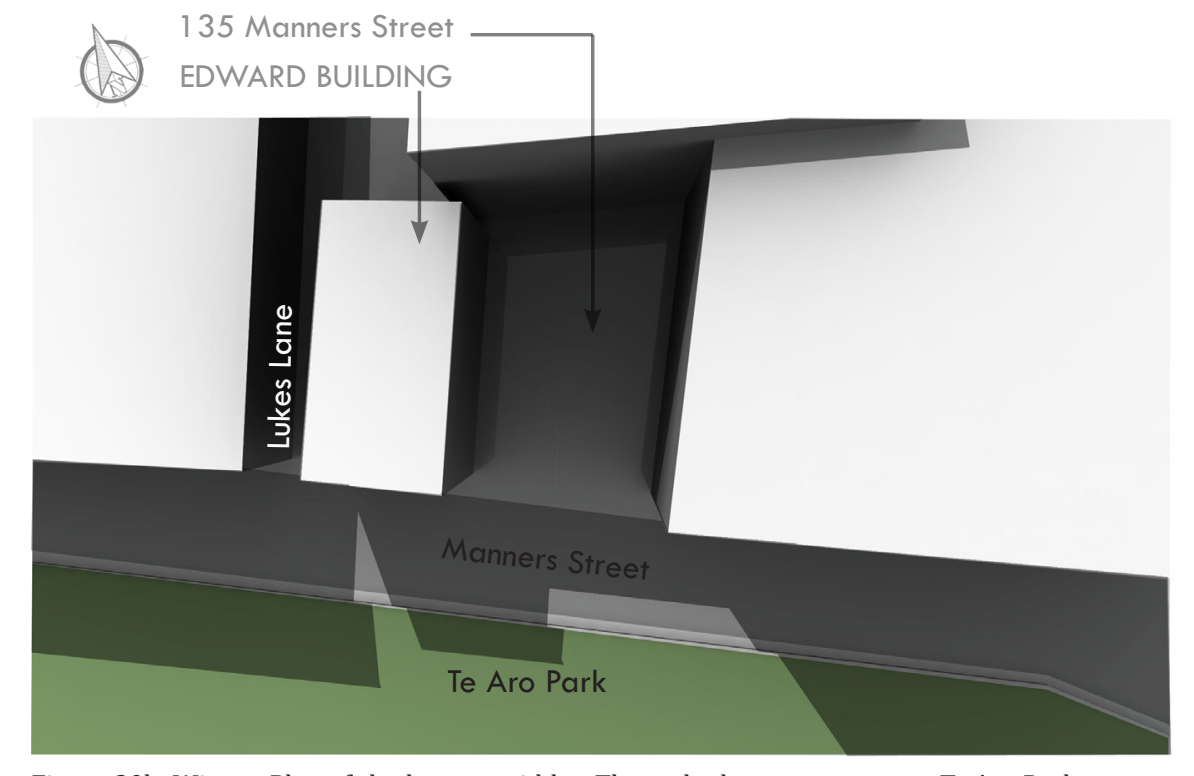

Figure 20b: Winter: Plan of shadows at midday. These shadows are cast onto Te Aro Park. Image by author, 2011 .
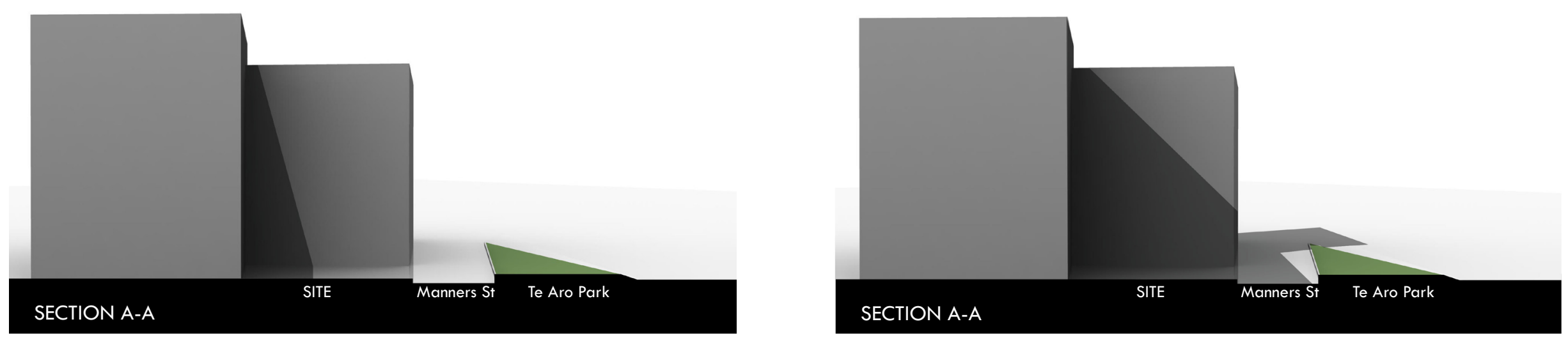

Figure 21a: Summer: Section of shadows at midday. Image by author, 2011. 


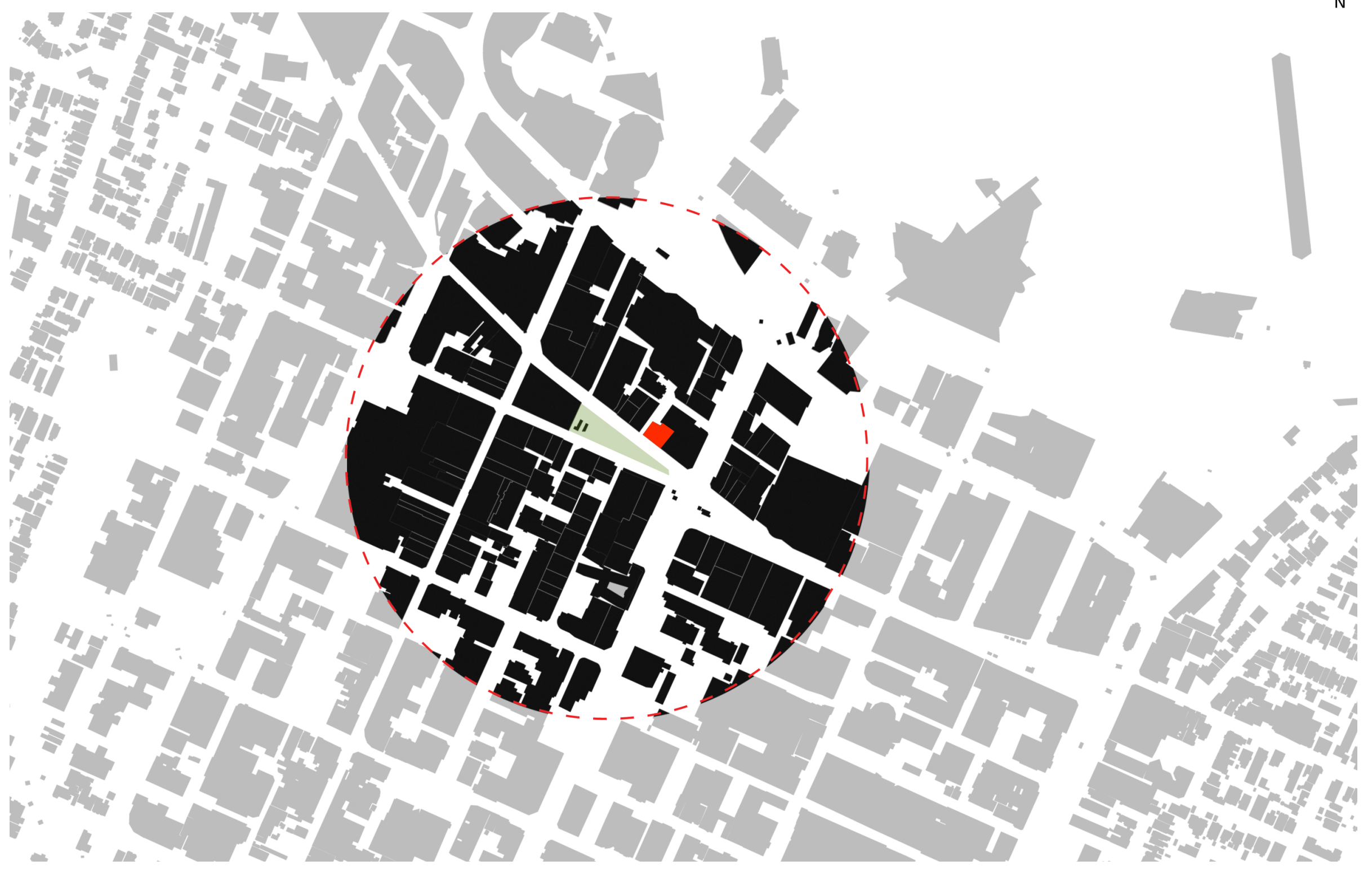

scale 1:5000

FIGURE 22: The above figure-ground diagram illustrates the position on the selected site within central Wellington and illustrates the relationship between built and unbuilt space. The area highlighted in red shows the position of the site within its surrounding context and the neighbouring buildings in which it sits. Image by author, 2011. 


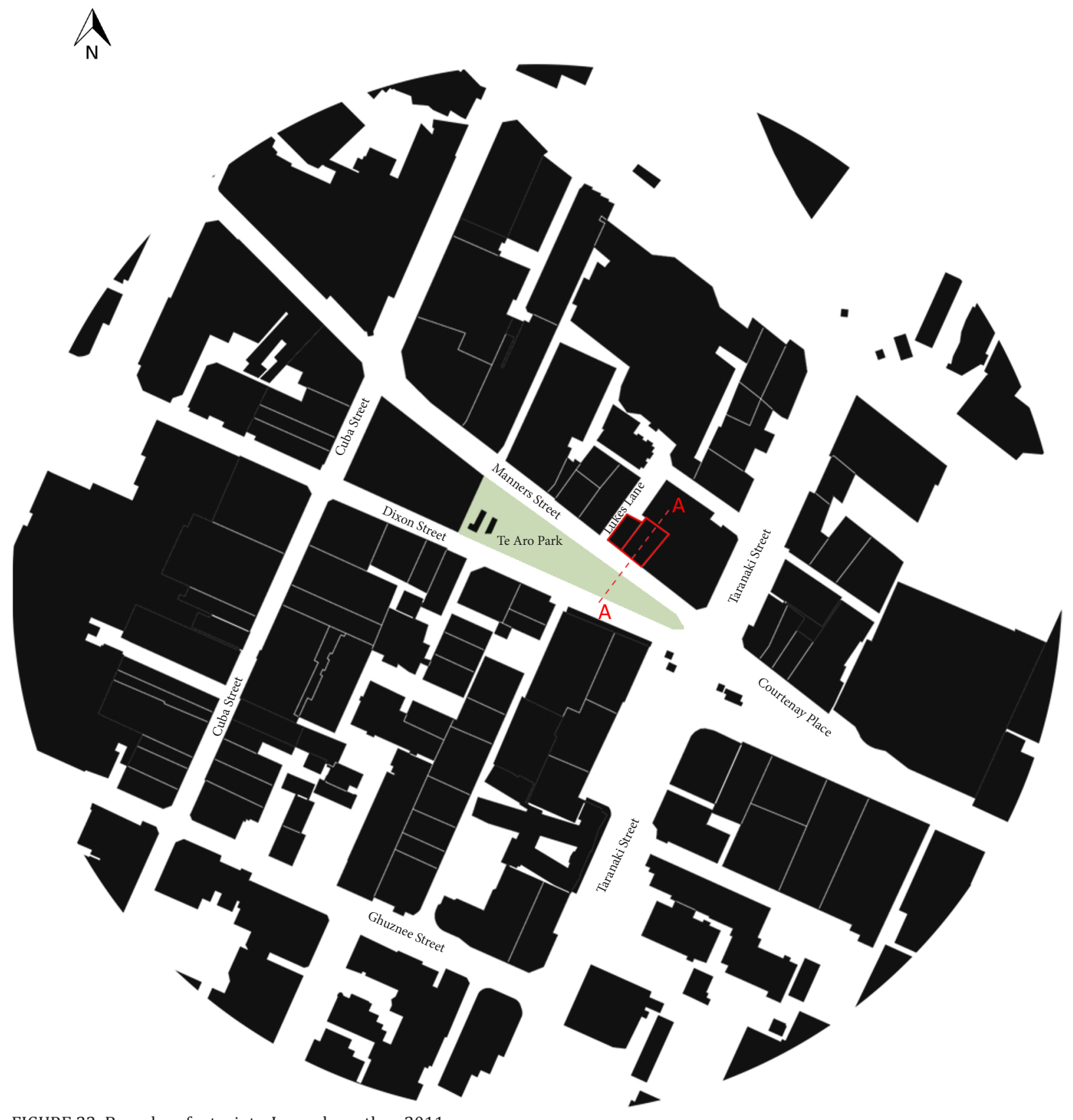

The adjacent figure-ground diagram illustrates the position of the selected site within central Wellington and illustrates the relationship between built and unbuilt space. The area highlighted in red shows the position of the site within its surrounding context and neighbouring buildings in which it sits.

Figure 23 illustrates the boundary footprints of the sites 131 and 135 Manners Street. A small service lane (Lukes Lane) runs along the Western façade of the Edward Building, which will be considered in the design phase of this thesis. Section line A-A indicates where the site is cut in order to show the extent of Summer and Winter shadows cast into the space by the sun.

FIGURE 23: Boundary footprints. Image by author, 2011 
The following images (Fig 24, 25 and 26) illustrate the immediate site and the context in which it sits. Figure 24 shows the different building heights around central Wellington City. Although the height of these buildings varies, the majority height of these buildings is between one and five storeys. This means the potential for rooftop gardens on many of these buildings could help with the Wellington City Council's vision to increase the amount of green infrastructure (namely vegetation), throughout much of Wellington City. Figure 25 shows a contour map and the nature of the land in which the site sits. Largely, the land throughout much of central Wellington City is flat. The dotted red lines on this map show the contours and are spaced at one metre intervals. The final image (Fig 26) illustrates the wind zones surrounding the site. The site is located within a 'high wind' zone (code three). This means buildings within this zone experience greater than normal winds, however,

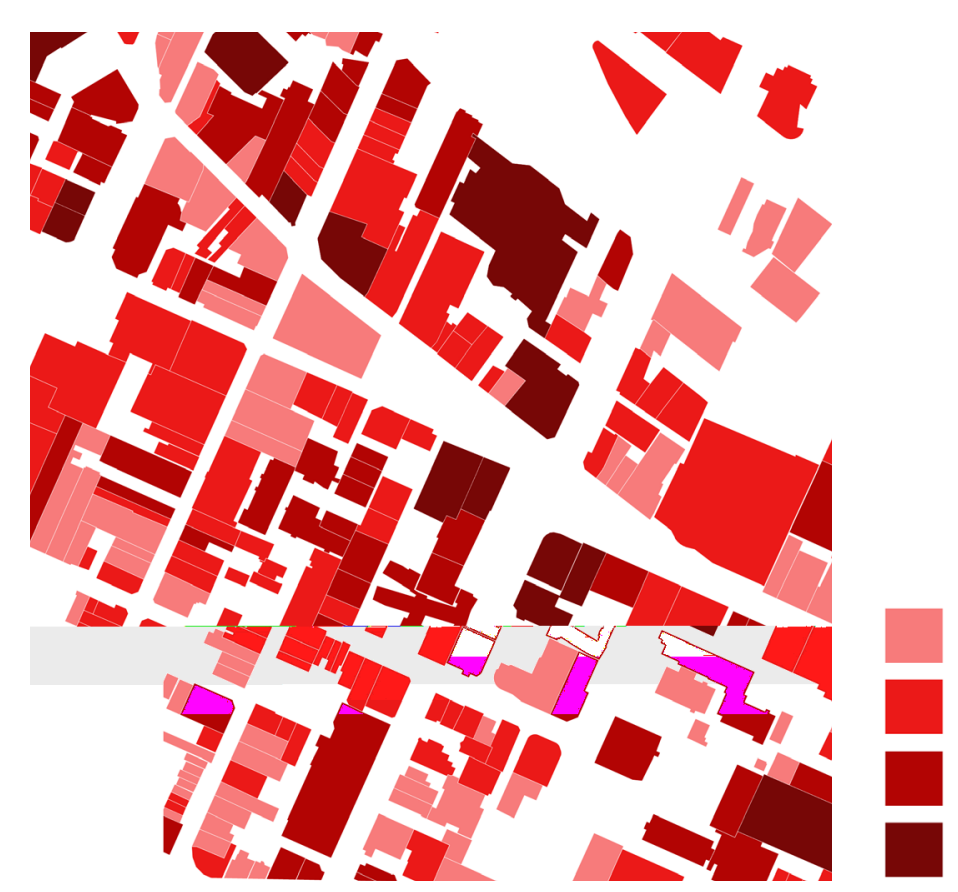

$0-2$ storeys 3-4 storeys 5-6 storeys $7+$ storeys

FIGURE 24: Building heights within central Wellington City. Image by author, 2011. 


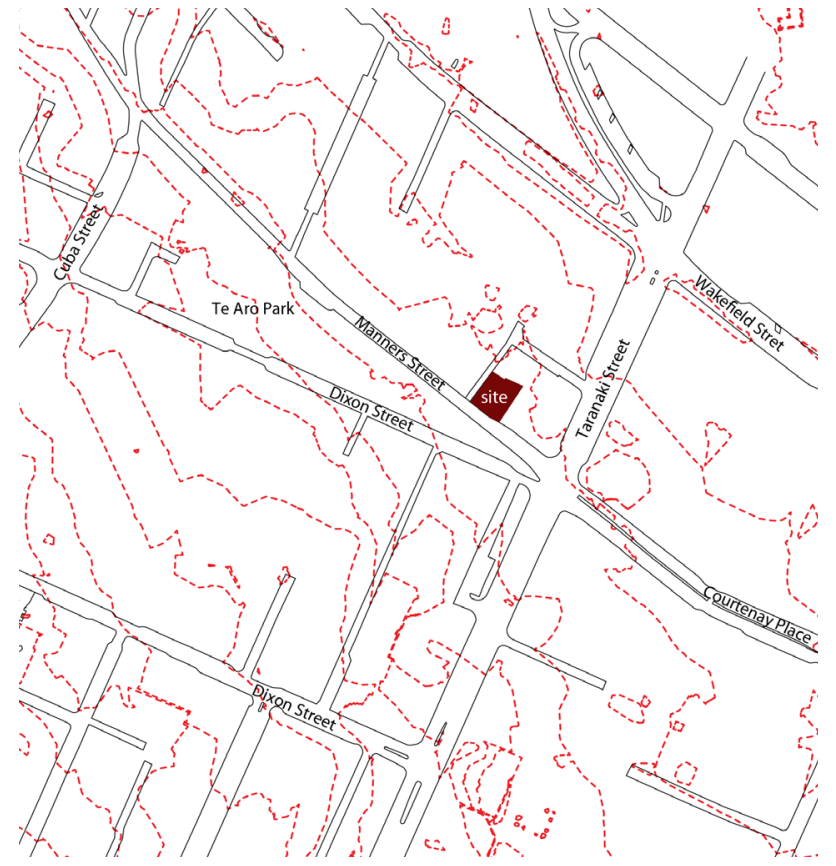

FIGURE 25: Contour map of central Wellington City. These contours are spaces at one metre intervals. Image by author, 2011.

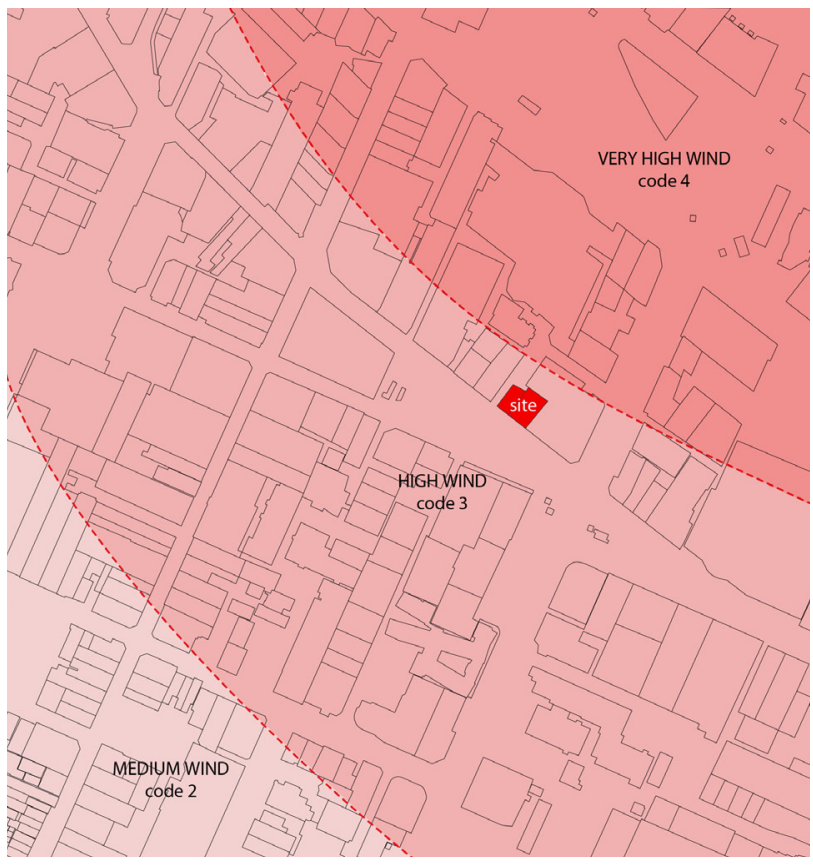

FIGURE 26: Wind zone. The site sits within a high wind zone (code three). Image by author, 2011. 


\subsection{Site: Transport analysis}

Manners Street is a significant transport corridor It links the Courtenay quarter with Cuba Mall and is used by many different modes of transportation. In 2004, Wellington City Council commissioned world renowned urban designer, Jan Gehl, of Gehl Architects, to undertake a study of how people use pedestrian and vehicular transportation routes around Wellington City. His findings show Manners Street as a secondary pedestrian and vehicular transportation route, with little or no activity down many of the surrounding laneways. The most popular pedestrian routes in this area were Cuba Street/Mall and Courtenay Place. This suggests many of the pedestrians walking between these two destinations will walk via Dixon Street or Manners Street. As the chosen site for this design project is located along the middle of Manners Street, retail frontage is something that ought to be considered in order to keep this street edge activated.

Figure 27 shows how the different pedestrian networks differ in terms of popularity. It is also hoped, a large majority of the foot traffic along these networks will help activate the redeveloped Te Aro Park. Figure 28 shows the popularity of vehicular transport along the streets in this survey area. Taranaki Street is the most popular in terms of vehicular transportation; this could be because it is one of Wellington's existing boulevards. All information for this survey area was conducted on behalf of Jan Gehl by recording transportation movements over the course of a typical summer's day. 
Main pedestrian routes

Secondary pedestrian routes

Alleyways and Laneways (least-used)

FIGURE 27: Pedestrian transportation Image by author, 2011.

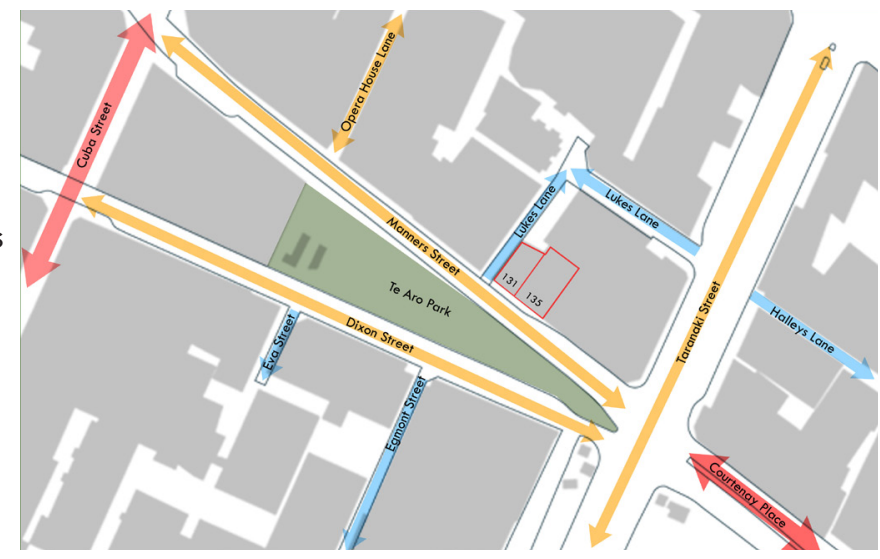

Vehicular transportation KEY

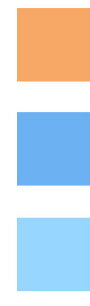

Main vehicular routes

Secondary vehicular routes

Alleyways and Laneways (least-used)

FIGURE 28: Vehicular transportation Image by author, 2011.

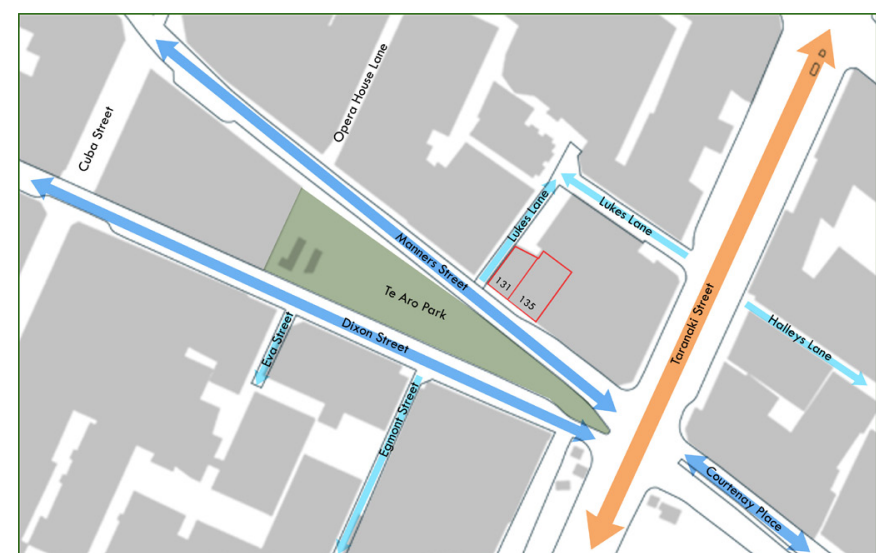




\subsection{Site: Building analysis}

The four storey Edward Building has had multiple uses over the years, but now accommodates a series of run-down flats. The building was originally designed as retail and factory space and now requires earthquake strengthening and additional repairs. Large masonry walls make up the majority of the structure with wooden floors spanning across the narrow space between the western and eastern walls. The adjacent image (Fig 30) is a plan of the building showing the major structural elements.

Although alterations have been made to the building over the course of its life, the original bones and internal walls of the structure have remained relatively untouched. In order to preserve as much of the existing building as possible, the new design will reuse and readapt large amounts of the existing structure. This includes reusing existing building components, materials, structural walls and ornamentation.

FIGURES 29a, 29b: Site photos Images authors own

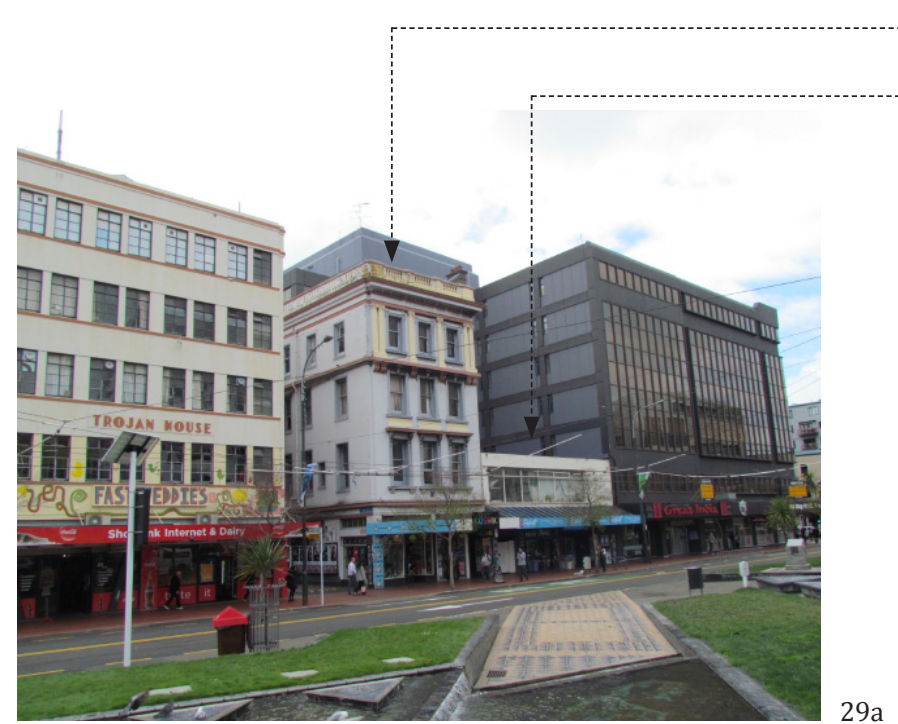

Edward Building

135 Manners Street

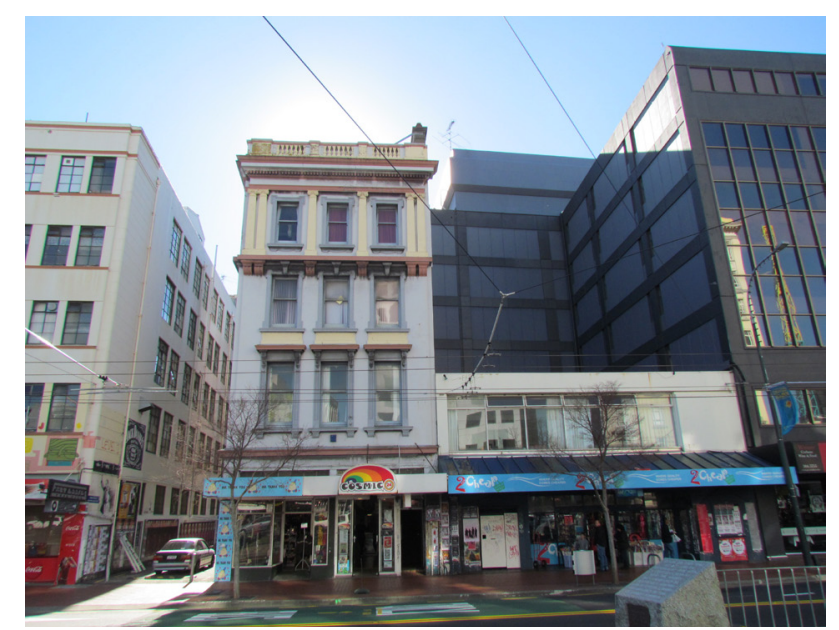




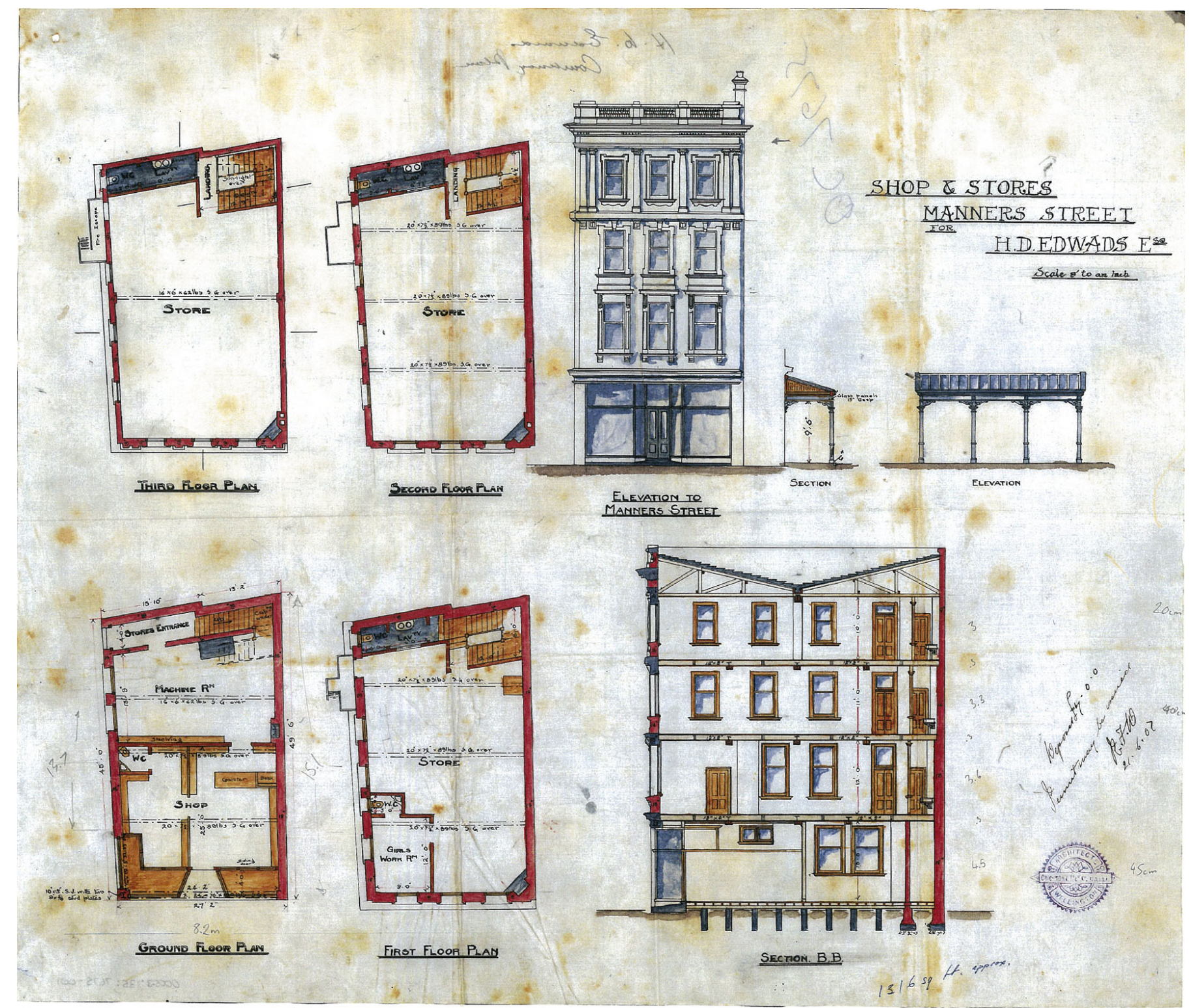

FIGURE 30: Original plans of the Edward Building

Source: Figure from the Wellington City Archives (1902) 
In order to maximise the enclosed vertical space of site135 Manners Street, the run-down building currently occupying the site must make way for future developments. However, parts of the existing structure can be reused in a new design. Figure 31 indicates what parts of the existing structure will be reused in a new architectural intervention on the site. The area on the plan highlighted in red indicates the location of the moment frames that will be reused. These moment frames offer a boundary in which new spaces can be formed.

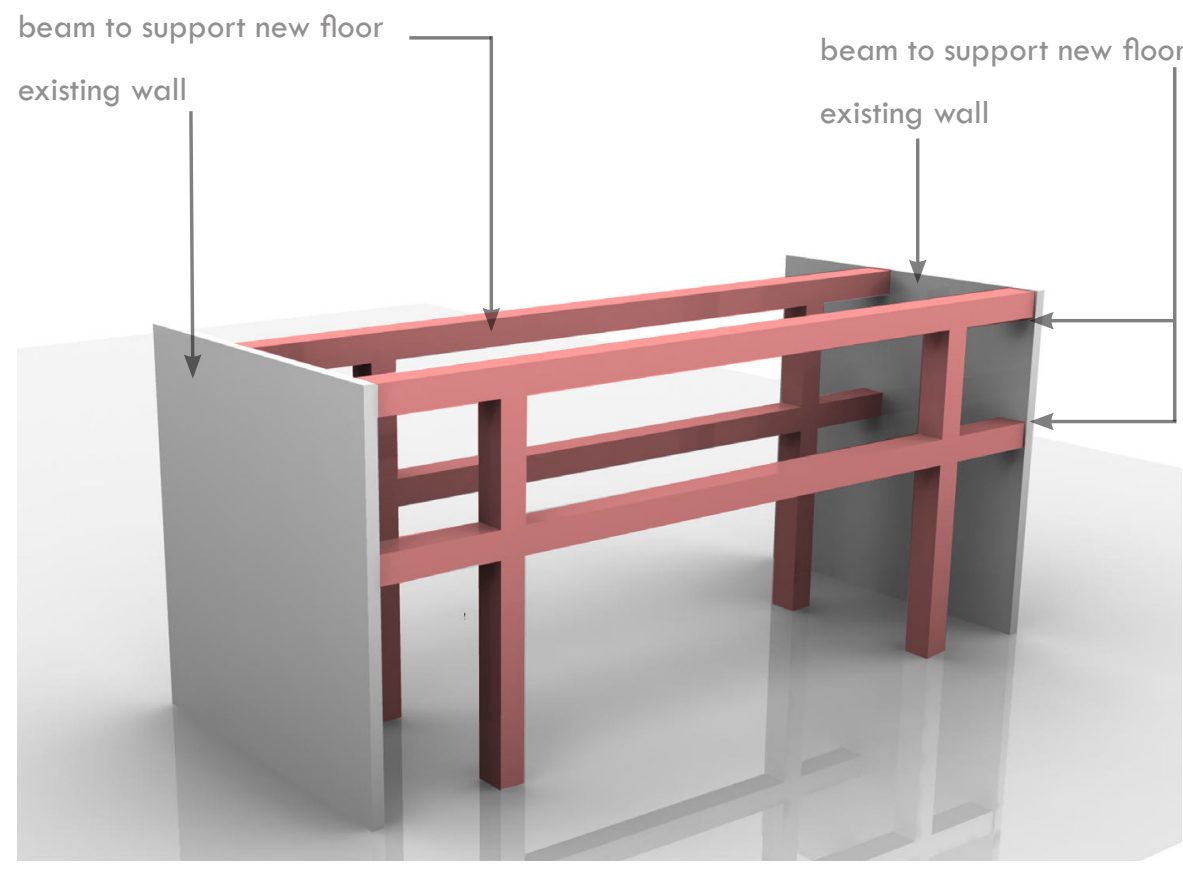

FIGURE 31: The structure highlighted in red illustrates the moment frames that will be reused. Image by author, 2011 . 


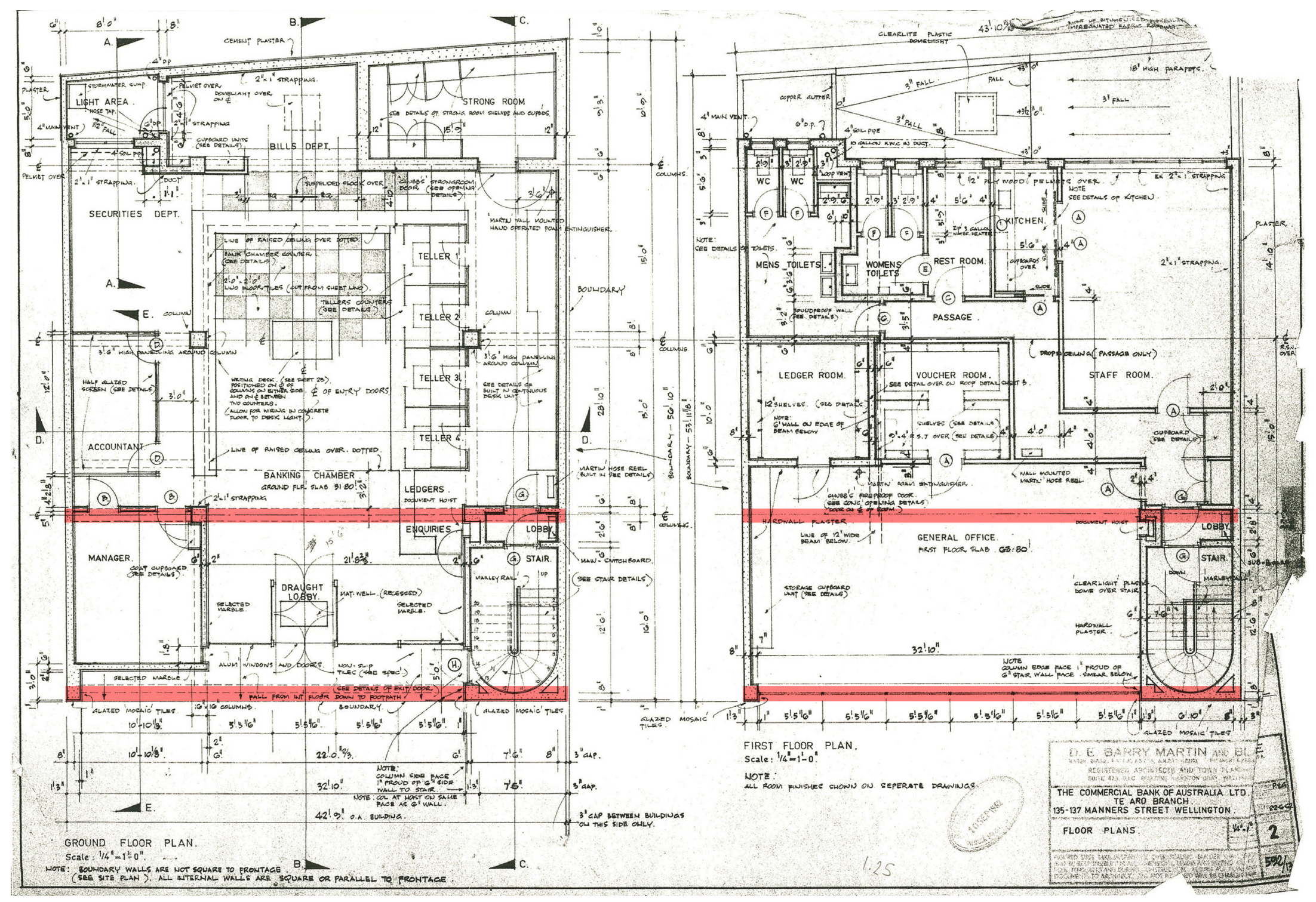

FIGURE 32: Ground Floor Plan of 135 Manners Street. The areas highlighted in red are the position of the moment frames that will be reused Source: Figure from the Wellington City Archives (1962) 


\section{CONCLUSION}

Many people consider vegetation something that largely takes care of itself. Although in some regards this may be true, the majority of vegetation requires pollination from some outside source. With the growing amount of vegetation in inner-city environment, bees can be considered a vital component not only to pollinate this vegetation, but also to provide humans with an essential connection back to a distant wilderness. Despite admirable attempts by the Wellington City Council to increase inner-city green spaces, there has been no discernible attempt to address inner-city pollination in their plans.

It is proposed to design a mutually-beneficial bee facility on 131 and 135 Manners Street. This facility will establish co-habitation inspired by beehive ecology. In particular, the design of the facility will focus on the interface between humans and bees. By providing a habitation space for bees (i.e. inner-city beehives and apiary), the facility will support inner-city bee populations, which will in turn be able to pollinate innercity vegetation. Thus, the facility will provide a solution to the problem of inner-city pollination. Further, these bees will in and of themselves, establish connections to nature. At the same, by providing a space for humans, it is hoped that the facility will promote awareness of bees and play a role in bee research. Thus, the facility will provide a solution to the broader challenges facing bees. The details of this design will be discussed in the following chapter and it will address how the ideas from Chapters One, Two and Three can be incorporated. 


\section{Chapter Four \\ Design Research}

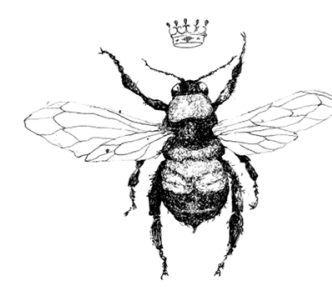




\section{INTRODUCTION}

This chapter explores some of the design and thus promote awareness of the importance of opportunities discussed in previous chapters. In bees;

particular, it will address how bees and the systems - A design with a consideration for the building as of a traditional beehive can be adapted into an a living object;

architectural concept based on ecomimicry of an - Help reduce the reliance on local resources;

apian ecosystem. Problems arising in areas such - Earthquake strengthening of the existing Edward as thermal comfort, geometric arrangements and Building;

structural configuration have been solved by bees in their structures. The design aims to imitate the systems developed or employed by the bee and also maintain linkages between humans and apian ecosystems.

\subsection{Brief and Programme}

The brief for the building has been informed by the findings from the previous chapters. This design will aim to achieve the following things:

- A building that draws inspiration from apian ecosystems (i.e. ecomimicry based on apian ecosystems);

- A mutually-beneficial co-habitation facility for bees and humans;

- Create a habitat for bees and plants, and thus promote bee populations and pollination in an inner-city environment;

- Create a space for humans to interface with bees,

The programme of the building is mixed use space. One half of the site's overall footprint area is set aside for bees, with the other half of the overall footprint area for humans. In so doing, both species are given equal significance.

Retail, education facilities, offices and a research lab are located within the existing Edward Building. It is hoped the building will be used by National Beekeepers' Association of New Zealand (or a similar association) to host meetings and to undertake research regarding threats facing the apian industry, including Colony Collapse Disorder and the Varroa mite. Retail space at street level will invite the public into the building with the prospect of viewing bees and the process of honey being made. From this retail space the public is welcomed into the upper floors of the building. The building will be used for class trips to educate children on the reliance humans have on bees and their fundamental importance. 
An apiary is a habitat in which bees live. The half of the site adjoining to the Edward Building will be a large apiary with beehives, plants and flowers. Many of the plants within this space will be flowering fruits and vegetables. In this apiary, bees are given their own environment with access to nectar and pollen. In addition, the bees are also encouraged to pollinate outside this dedicated space i.e. the greater Wellington region. In particular, the bees will be able to pollinate the existing and proposed inner-city green spaces, especially the neighbouring Te Aro park (before and after development). The types of spaces provided by the programme are designed to work together and promote the importance of bees within the environment.

In this chapter, the seven characteristics of life - respiration, movement, senses, growth, reproduction, nutrition and excretion - will be addressed. These will illustrate how each is realised in a design based upon an ecological relationship with bees. The use of these seven characteristics creates a living structure that mimics aspects of bee and beehives and establishes linkages that reference an apian ecosystem.

\subsection{The design requirements of the bee}

The design will provide habitat for two kinds of bee, namely the common honeybee (Apris mellifera) and the bumblebee (Bombus terrestris). Although each species of bee differ somewhat in terms of appearance, they share similarities in the types of vegetation and environmental conditions needed for survival. Each species of bee requires the interior hive temperature to be between $32^{\circ} \mathrm{C}$ to $36^{\circ} \mathrm{C}$. As bees are cold-blooded, this temperature is achieved through the act of heat given off from wing movements. The warmer the external environmental conditions means less energy is needed to heat a beehive. The design will ensure the temperature of the apiary is maintained by trapping heat given of from the sun. Conversely, if temperatures within the apiary get too warm this space is able to be cooled by removing excess hot air.

Bees must not be limited to the vegetation growing within the apiary. Hence numerous exit points should be made in the building in order for bees to collect nectar from the wider Wellington vegetation. The vegetation growing on and within the building should ensure a mix of different flowering plant and tree species. This will provide 
variety to the bee diet. Beehives will be included throughout the design. However, bees will not be limited to the confines of these hives. Bees will be free to construct their own hives within the apiary.

\subsection{The Skin}

The first feature of the beehive that this design uses is the skin. The importance of the skin on a traditional beehive and the function it performs is vital in maintaining beehive temperature and safety. A secondary skin wrapped around the Edward Building would perform a myriad of functions. A secondary skin has the potential to assist in: regulating interior temperatures; earthquake strengthening; privacy; ventilation; and being a host for planting. One opportunity that the case studies revealed was the potential to use the characteristic hexagonal grid of beehives for structural purposes in a building. The hexagonal structure, which is strong under lateral loads, has a resistance to external forces (Nihon Daigaku, 2009). For this reason, a secondary skin that uses a hexagonal grid could serve to strengthen the earthquake-prone Edward Building. The adjacent sequence illustrates the development of the secondary skin and how it wraps around the site. The purpose of the secondary skin is not to hide, but to protect. As an acknowledgement to the past, three existing windows from the Edward Building have been pulled forward through the secondary skin in order to reference and to reveal the building behind.

\subsection{A 'living' building}

As presented in Chapter One, three biomimicry experts (Datuk Ken Yeang, Scott Turner and Rupert Soar) all agree that a building can be considered as a 'living structure'. This concept of a 'living structure' supposes that a building could potentially exhibit the seven characteristics that are typical of life, namely - movement, reproduction, senses, growth, respiration, excretion and nutrition. When a building embodies these seven characteristics, it becomes - in a way - 'living' and the building moves beyond biomimicry at merely an organism or behavioural level. The following sections address each of these characteristics and how they have been applied to this design.

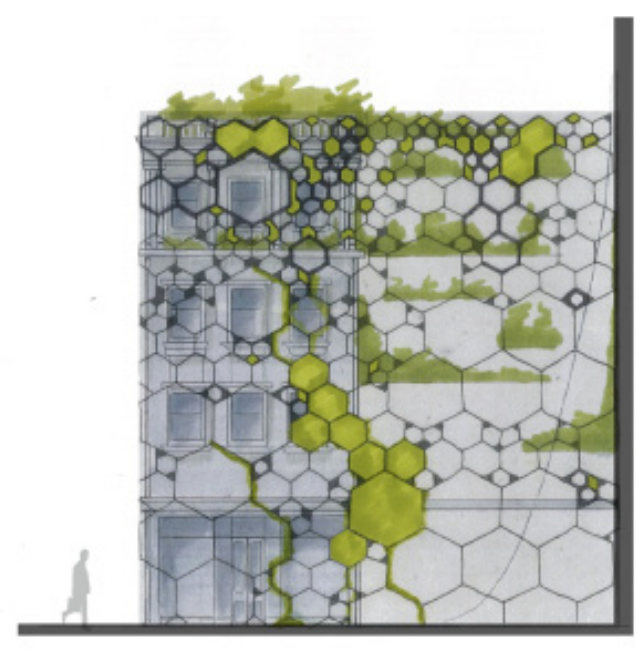

FIGURE 33: Early conceptual sketch using the hexagonal grid for structural and aesthetic purposes. Image by author, 2011. 

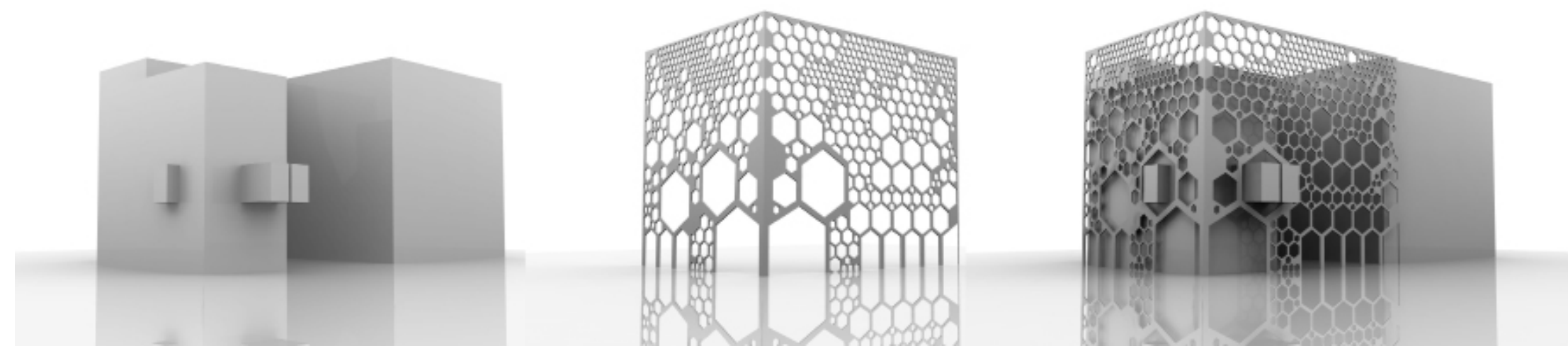

FIGURE 34: (early conceptual model)

Development of the skin showing how a secondary skin is applied to

the existing Edward Building. The three windows pushed through the existing Edward Building. The three windows pushed through
the hexagonal cut-outs in the skin reference the Edward Building behind. Image by author, 2011 . 
The first characteristic is respiration. The secondary skin must allow air to pass through freely in order for the internal spaces to breathe. This works by adopting similar technologies to those proposed by Turner and Soar in the Eastgate Centre. The secondary skin, constructed from steel and glass, is designed to act as a lowpass filter. The steel component is made from many fixed members joined together to create a hexagonal grid formation. Within each member are small cut-outs. These cut-outs regulate airflow by allowing the internal spaces to breathe. The benefit of this structure is that it results in a soft, constant airflow throughout the building, as opposed to a turbulent one.

Within this structural grid is glass infill. Glass is used because a large portion of the skin needs to be transparent so that sunlight can be captured by the pocket of air in the envelope formed between the building and secondary skin. Energy from sunlight that radiates this envelope is retained and adds to the thermal mass of the building. This, in turn, helps heat the interior spaces of the building.
An issue inherent in the site is the orientation of the building to the sun. This is most problematic for those parts of the building's skin that include plants. Since the site is south facing, direct sunlight onto the building's skin can be increased by angling the facets of the skin to gain more direct sunlight hours. This is particularly evident on the western façade where the afternoon sun is able to strike the angled skin earlier. In doing so, the angled portion of the skin is in direct sunlight for longer, which benefits the plants growing along the façade.

This hexagonal grid has been borrowed from the honeycomb of a beehive and used for respiration features of the building, as well as providing structural and thermal properties to the secondary skin. The adjacent image (Fig 35) illustrates how the building will appear from $\mathrm{Te}$ Aro Park. As this chapter progresses, more detail will cover other important features about the skin and how it operates. 


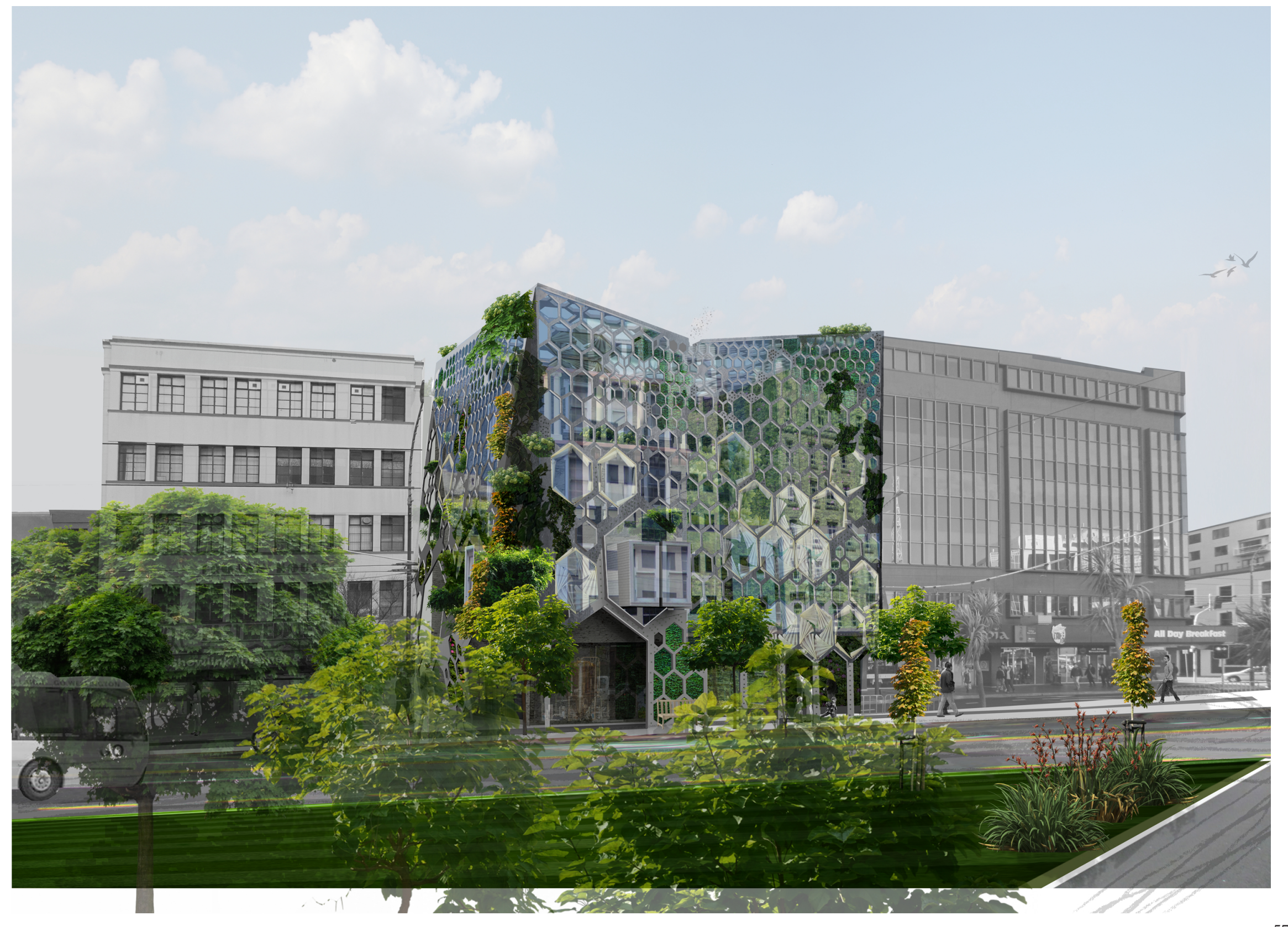

FIGURE 35: Street perspective of design the concept. This image shows the front elevation of the building from Dixon Street. Image by author, 2012 


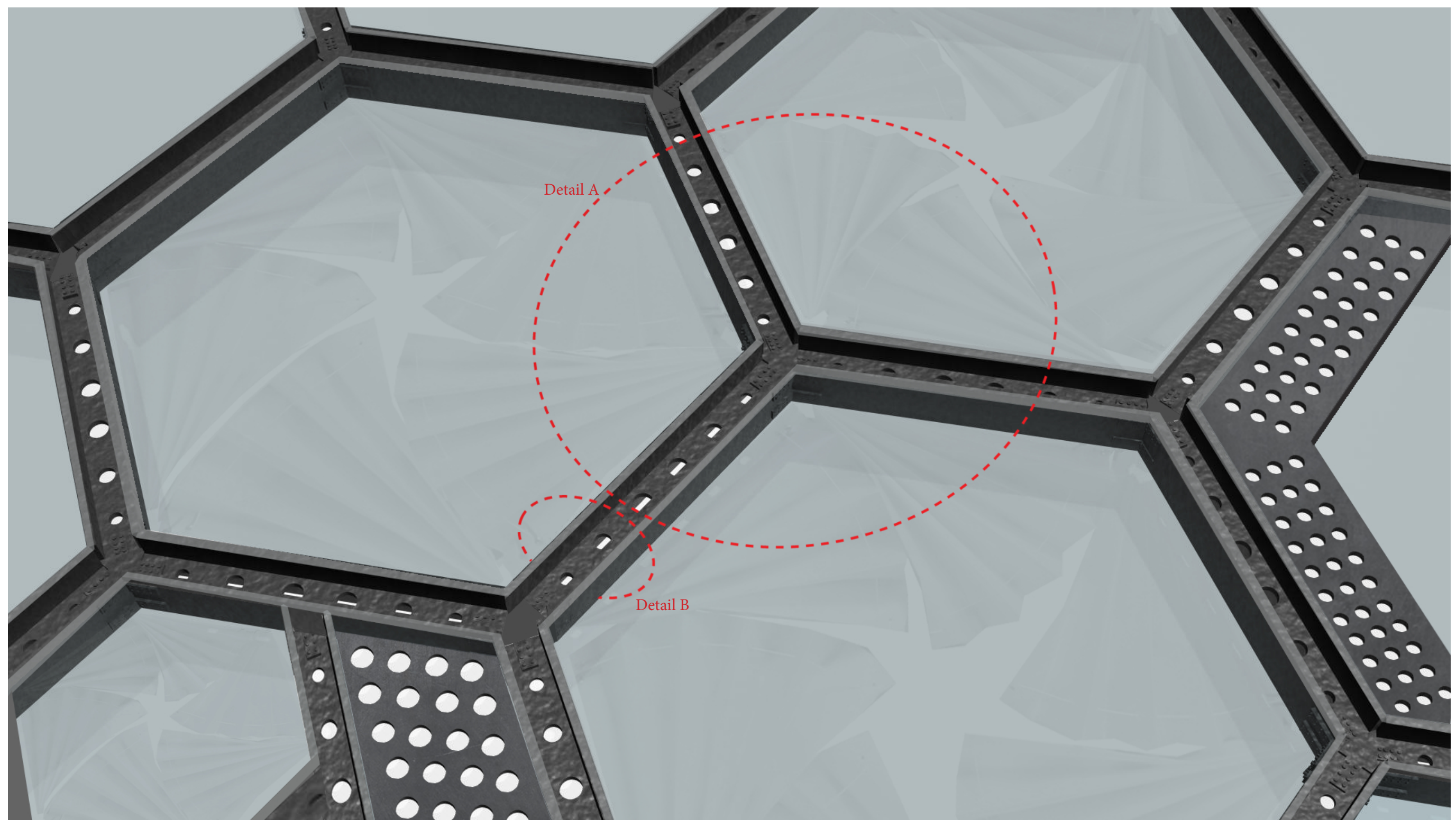

FIGURE 36:The above image illustrates the steel 'I-beams' that makeup the skin. By varying the size of these I-beams, a changing hexagonal pattern over the building was able to be created. As the size of these hexagons change, parts of the skin are created which do not conform to the hexagonal grid. These parts are flat sheets of steel and are used as exit and entry points for the bee with many small cut-outs. Between the steel members is glass. This glass acts as a thermal layer (as previously mentioned) trapping heat from the sun inside. 'Detail 1' and 'Detail 2' illustrate the how these I-beams are joined together. Image by author, 2012. 


\section{Skin Details}

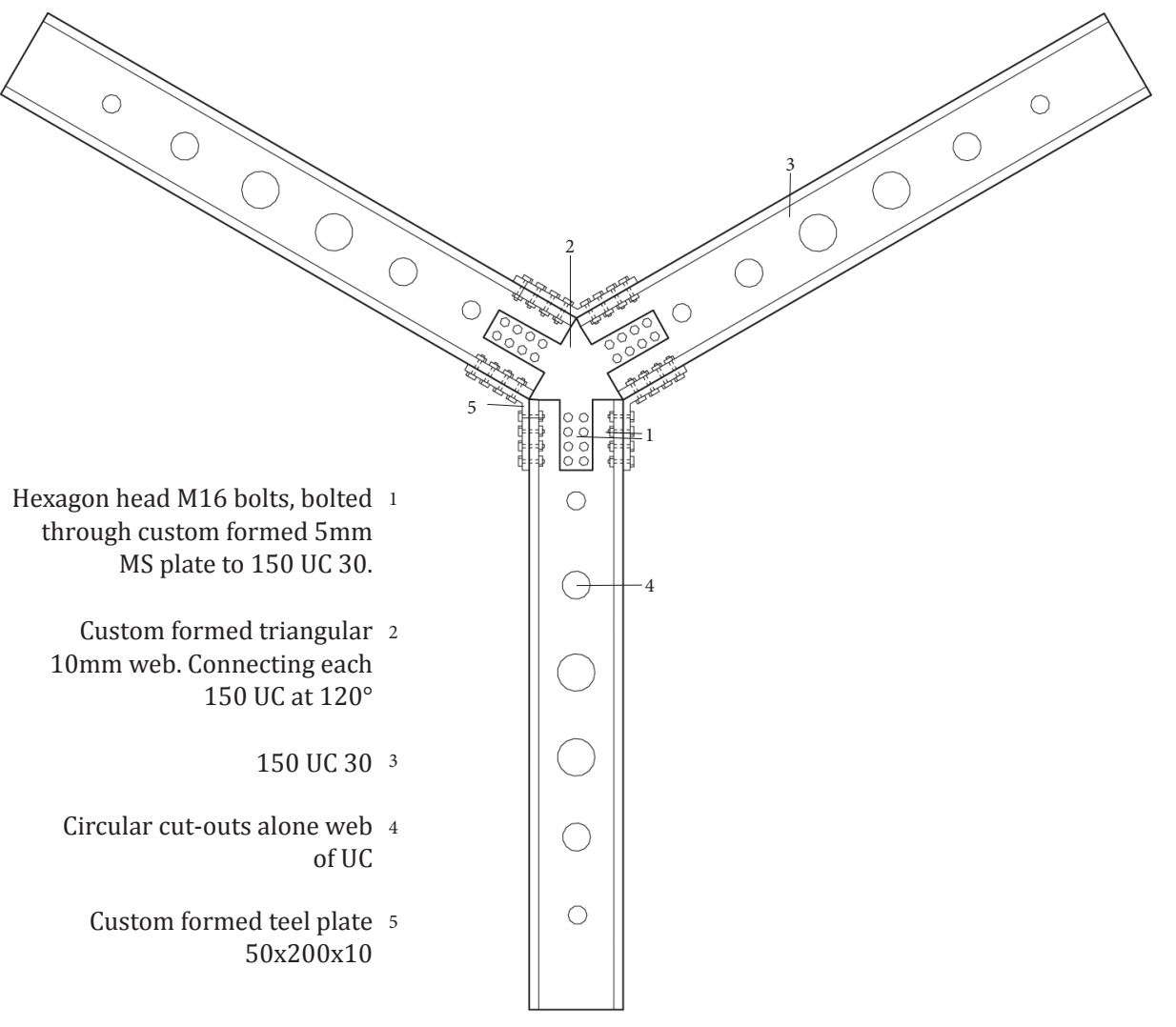

horizontal section through

I-beam, 150 UC 30
Detail A.

FIGURE 36.2: Structural makeup of the skin

Image by author, 2012 .
Detail A.2

FIGURE 36.3: Structural makeup of the skin - with windows and joinery Image by author, 2012.

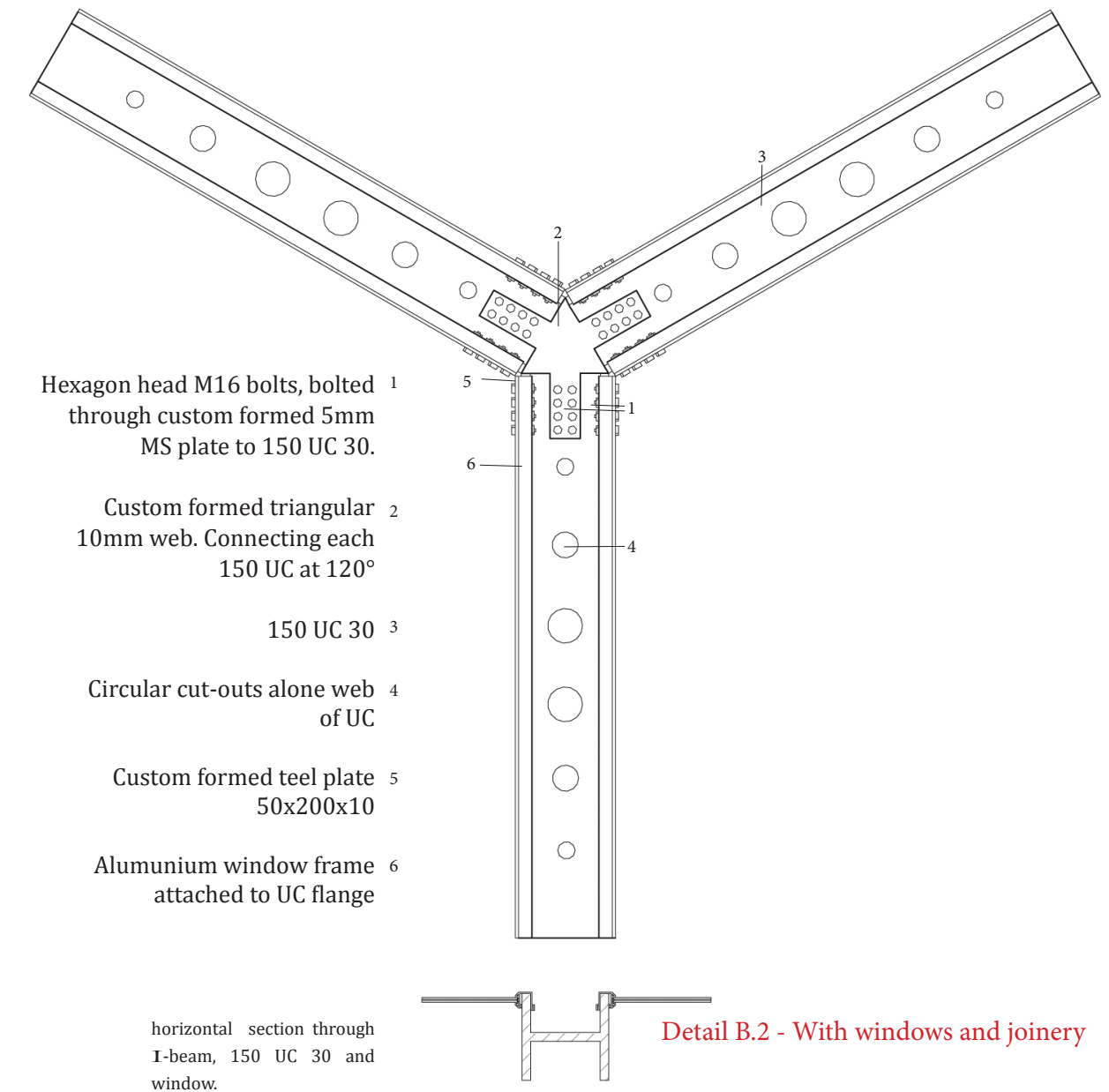

window.

Insulating glass $(6 \mathrm{~mm}$ float glass $+15 \mathrm{~mm}$ cavity $+6 \mathrm{~mm}$ toughened safety glass) i aluminium frame. 


\section{The components of the skin}

The discussion that follows outlines the main components of the skin and how these are joined together to create the hexagonal pattern. Figure 37 illustrates the components of the skin that can be mass produced. These components account for the majority of members that makeup the skin. As previously mentioned, there are parts of the skin that do not conform to the hexagonal pattern. These parts require specific shapes due to the changing sizes of hexagon and therefor, cannot be mass produced.

The I-beams come in three main sizes allowing a changing pattern over the skin. These I-beams are welded together along the ends of the flange to form a $120^{\circ}$ angle. To ensure no movement within these joints due to earthquake or wind forces, these I-beams are then joined together with a set of bolts attached to a steel strip over this weld. Three I-beams meet at a central point. This point is triangular, so a triangular steel plate connects the three webs of these I-beams together. The adjacent image (Fig 38) shows the member assembly of one hexagon being constructed.
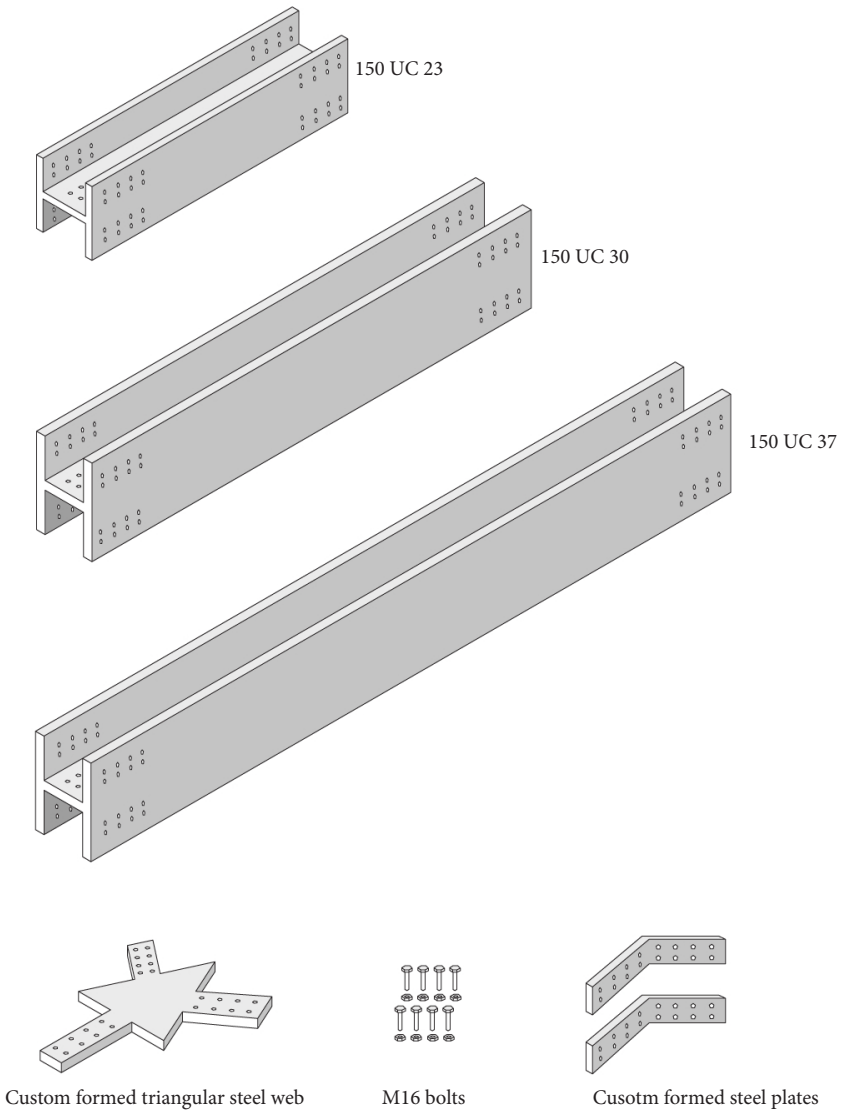

FIGURE 37: Construction members of the skin that can be easily mass produced. Image by author, 2012. 


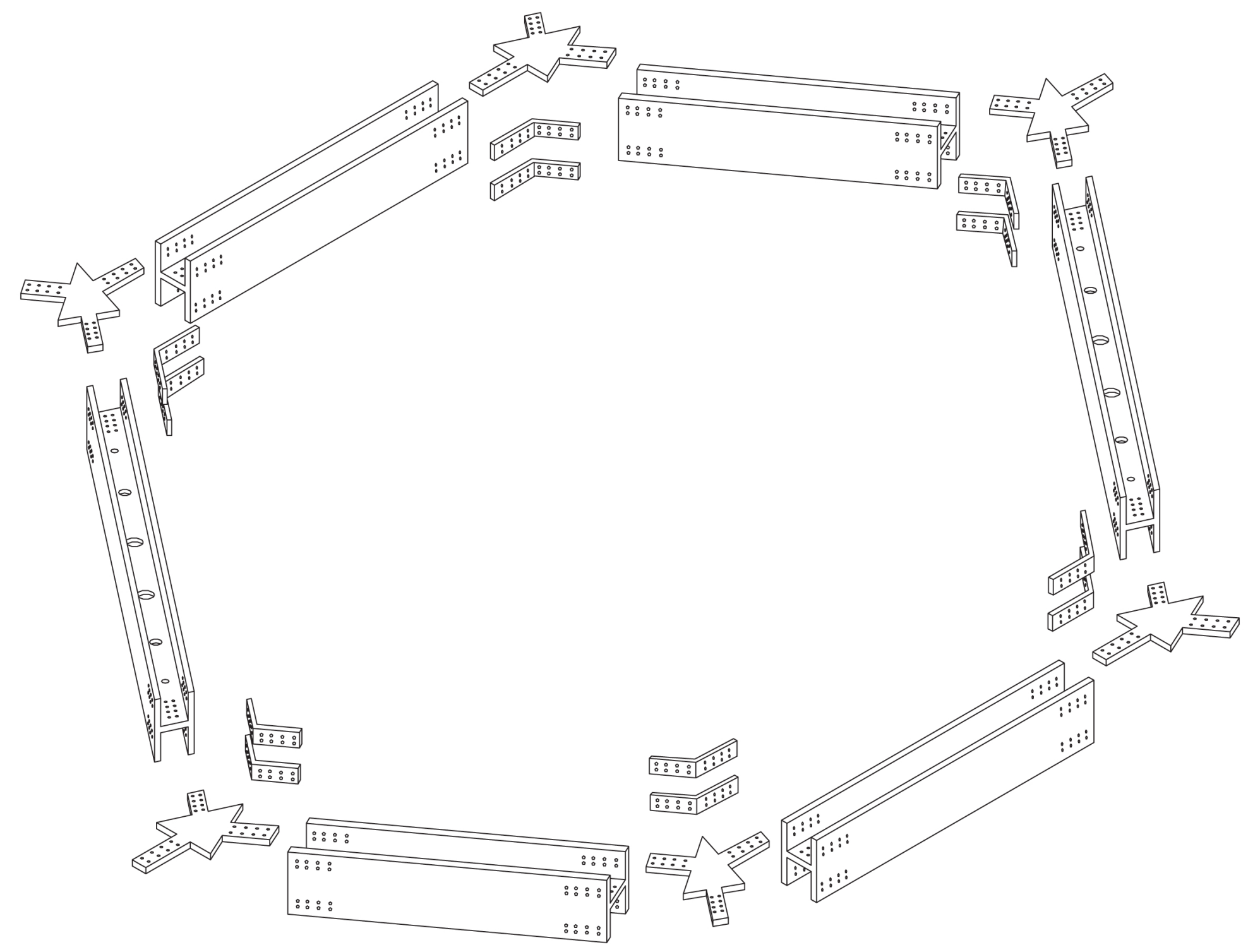

FIGURE 38: Member assembly. This image illustrates how the different pieces of structure fit together in order to for a hexagon. Image by author, 2012. 


\subsubsection{Heating and Cooling}

The heating and cooling systems used in this design operates in a similar way to the heating and cooling systems of a beehive. In a beehive, bees generate excess heat through their own movement which is then kept within the beehive by insulation. This stored heat can then be fanned to parts of the beehive when needed. Similarly, the heating method used in this design relies on catching heat from the sun and storing it in the apiary until it is needed. In much the same way that a greenhouse heats up, there would be a natural heat build-up in the apiary. From here it can be pumped throughout the Edward Building when needed. By relying on a natural source of energy, this heating method aims to reduce heating costs and maximise heating efficiency. In a beehive, cool air is fanned through a beehive by the movement of bee wings. The cooling system used in the design relies on a similar movement of air. To release excess heat from the apiary, the roof can be opened to create an upwards draft that removes the hot air, renewing the space inside the apiary with cooler air. By relying on a passive system, this cooling method aims to reduce cooling costs and maximise cooling efficiency.

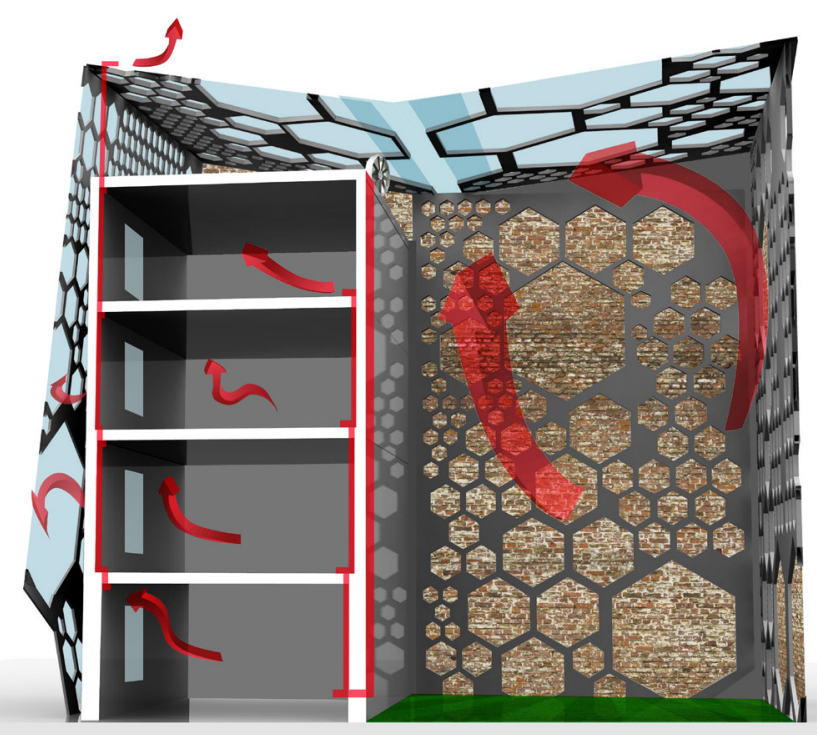

FIGURE 39: Heat from the sun is collected in the apiary. A fan then distributes this heat throughout the Edward Building when needed. This helps reduce reliance on electrical heating. Image by author, 2011. 


\subsection{Movement and Senses}

The characteristics of movement and senses are related to one another; how the building moves is related to how the building senses and adapts. A beehive will respond to different environmental conditions through the act of movement. As described above, in order to heat up or cool down, the act of movement sustains this. Thus it is proposed that the skin is able to change under different environmental conditions to help regulate the interior temperatures.

Shutters on the skin's windows open and close depending on the sun's position and strength. These operable attachments regulate interior temperature by controlling the amount of sunlight allowed into the inside space. The act of movement is evident in the opening and closing of the shutters. Each of the six sides of a hexagon has one folded blind attached to a pivot point. When the shutters are open, the hexagonal shape is maintained - when the shutters are closed, each shutter joins in the centre. The structure and movement of these shutters is suggestive of

FIGURE 40: The roof can be opened to let-out excess hot air. This creates an upwards draft removing unwanted warm air, a bee's wing and the act of flight. 
Sensors within the building control this movement. On a cool day, all the window shutters might be open to maximise the amount of sunlight entering the building. Conversely, on a warm summer's day, many of the shutters on the roof might be closed. This movement and sensory response is taken from a beehive and adapted to suit a design scenario intended for human occupants. Ultimately, these linkages to a beehive allow the design to minimise energy consumption and maintain steady interior temperatures.

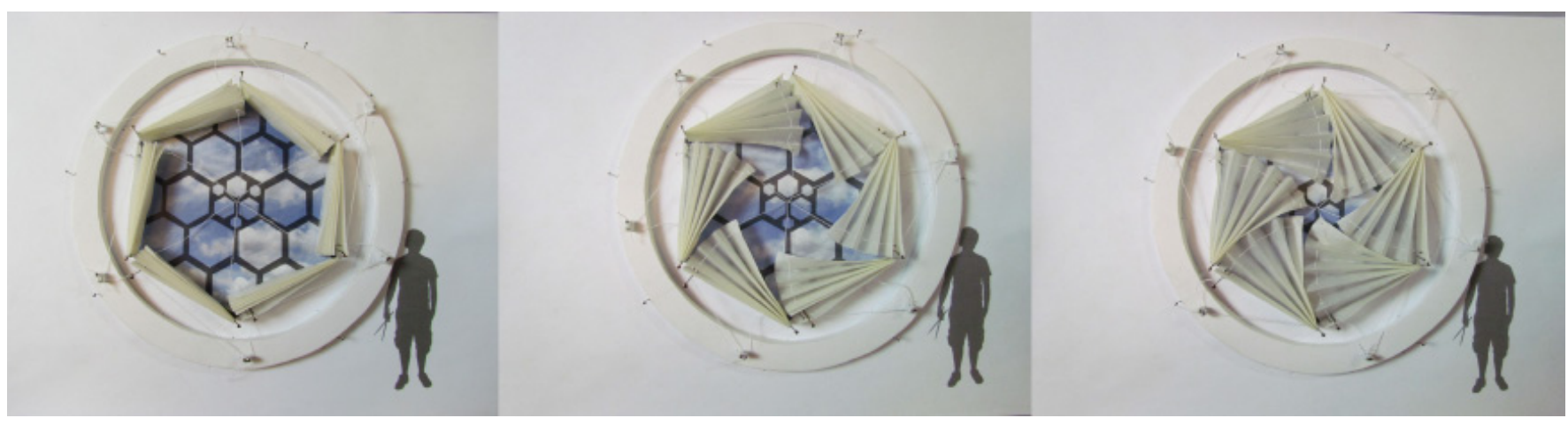

Figure 41: Working model of window shutter design Image by author, 2011. 

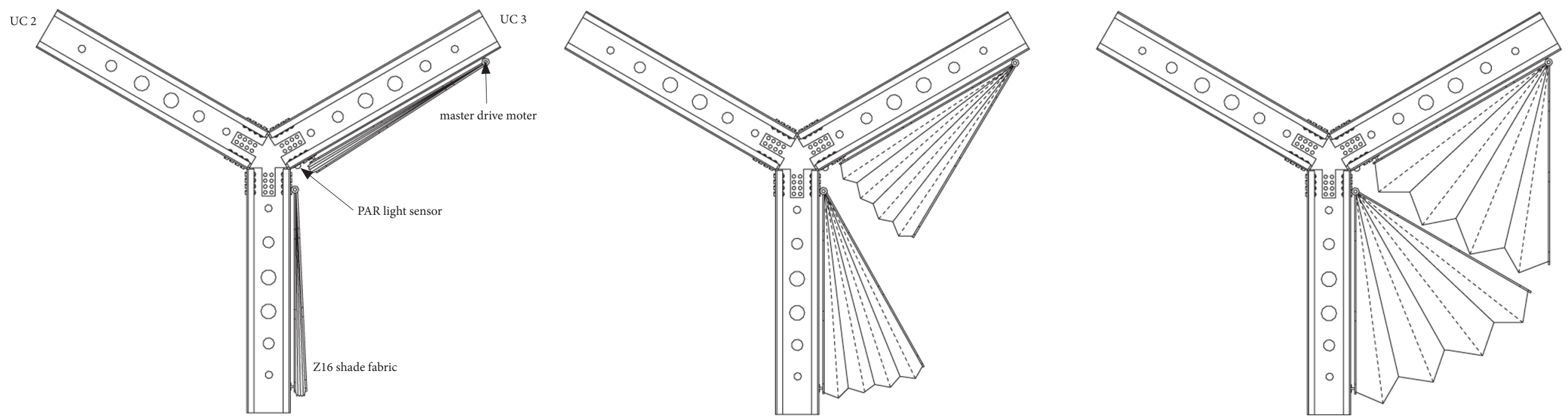

FIGURE 42: The above sequence shows the extent of the shutters in their open and closed position. These are controlled by light from the sun hitting the sensor. On a cool day, all the window shutters might be open to maximise the amount of sunlight entering the building. Conversely, on a warm summer's day, many of the shutters on the roof might be closed. The shutters are attached to the inside flanges of the I-beams via clips, and can be removed if necessary. Image by author, 2012. 


\subsection{Growth}

In many of his works, architect Frank Lloyd Wright implemented the theory that a building should be analogous to a biological organism (McGraw-Hill, 1973). That is, for a building to organise and serve a specific function and evolve as an organism evolves. This was evident in the design of his Hanna House as previously stated in the case study chapter. For the characteristic of growth, this design adopts a similar theory and looks at how a beehive develops and applies a similar method to the skin. The pattern and varying sizes of hexagons in the skin are based upon the importance each bee has within a beehive. As part of a greater collective, each bee is reliant on another for survival. This idea is used with each hexagon playing an important part in transferring loads vertically and horizontally, all the while working together to achieve stability.

The second aspect of growth comes from the plants and bees themselves. Plants and flowers grow within the apiary and promote the idea of an urban garden. Bees are encouraged to construct beehives within this space and to utilize the greenery that surrounds them. By creating these beehives, the development and construction process can be seen by the public. Bees however are not limited to the vegetation growing within or on the building. The following diagram (Fig 43 ) indicates what species of plant and bee are found within the different areas of the design. Bees can enter and exit the building depending on the direction or location of their destination. All access points however are located above street level. It is hoped by having these access points above street level, the bees entering or exiting the building will not interfere with pedestrian traffic.

As half the building is set aside for bees and half is for humans, there will ultimately be crossover areas where increased interaction between humans and bees occurs. Within the Edward Building beehives are located on three of the five storeys. These beehives are celebrated as points of interaction. The public is invited to view the workings of a beehive and the process of honey being made. Vine tomatoes, passionfruit and capsicums are grown in the apiary and pollinated by bumble bees. These crops hang in planter boxes suspended by a rotating wheel. The constant rotation of these crops ensures each plant is exposed to a sufficient amount of direct sunlight. The following sections illustrates how the building facilitates humans and bees. Although separated, both species share the space and benefit mutually from it. 


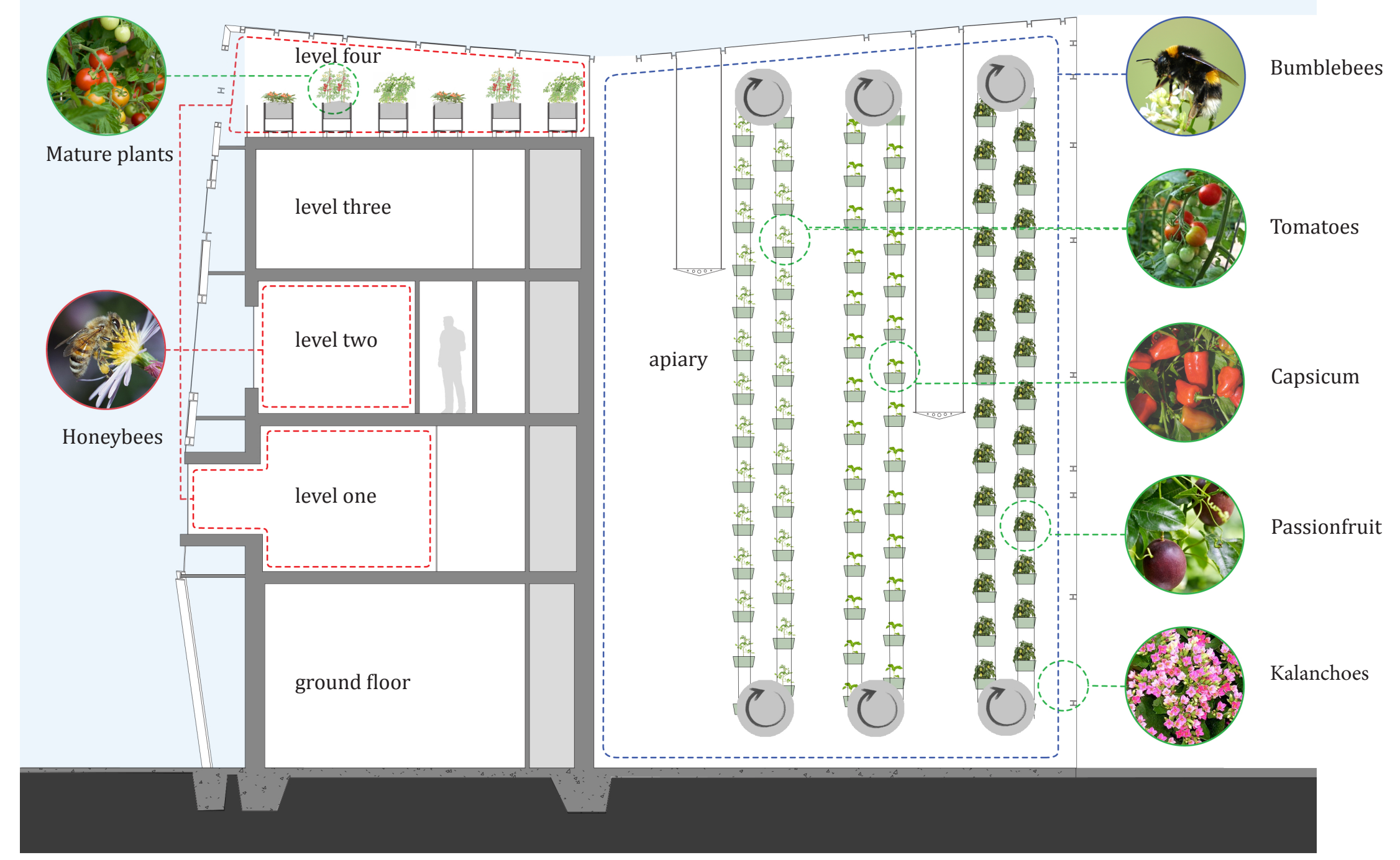

FIGURE 43: The above image illustrates what parts of the design are for different species of bee. This in turn informs the maturity of plants in these spaces. Tomatoes, Capsicum and Passionfruit in their infantry stages of growth, grow within the apiary. Bumblebees pollinate the flowers on these crops. When fruit is bared, these plants are then moved to the top floor where they are ripened by longer sunlight exposure. Image by author, 2012. 


\subsection{Plans}

GROUND FLOOR: On the ground floor there is a mixture of retail and production space. Honey from the above floors flows down a series of small pipes to 'Tank 1'. This collection point supplies the retail space with local honey. Members of the public are invited to fill containers from the tank - the process of which can be seen from the street

FIRST FLOOR: The first floor has spaces that are used for educating people about bees and the reliance humans have on them. Safely located behind glass, observation beehives are placed within the Edward Building; these invite the public to view the inner workings of a beehive. In addition to these observation beehives, an observation platform safely allows people to view the apiary and witness the pollination of crops first hand.

SECOND FLOOR: Meeting rooms on the second floor provide space for National Beekeepers' Association of New Zealand to have gatherings and host meetings. This floor consists of three meeting rooms; two internal and one external. The external meeting room is a novel place for bee enthusiasts to meet. Users of this external meeting room must don apiarist suits for protection. Observation bridges also hang from this level giving visitors additional spaces from which to view the apiary from different perspectives.

THIRD FLOOR: A research laboratory occupies most of this level. Research will be conducted in this space relevant to all aspects of the apian industry, but in particular research seeking to answer the questions surrounding Colony Collapse Disorder.

FOURTH FLOOR: Crops grow amongst beehives on top of the building. The beehives are traditional beehives housing Apis mellifera bees, which are free to enter and exit as they wish. The upper section of the secondary skin surrounding the fourth flow is open to the elements i.e. it has no glass infill. The glass infill has not been included because glass is confusing to honeybees. Bombus terrestris bees live within the confines of the wall on top of the Edward Building. Separated from each other, these bees are used to pollinate the internal crops but are also free to leave the building to pollinate additional crops and flowers. 
N

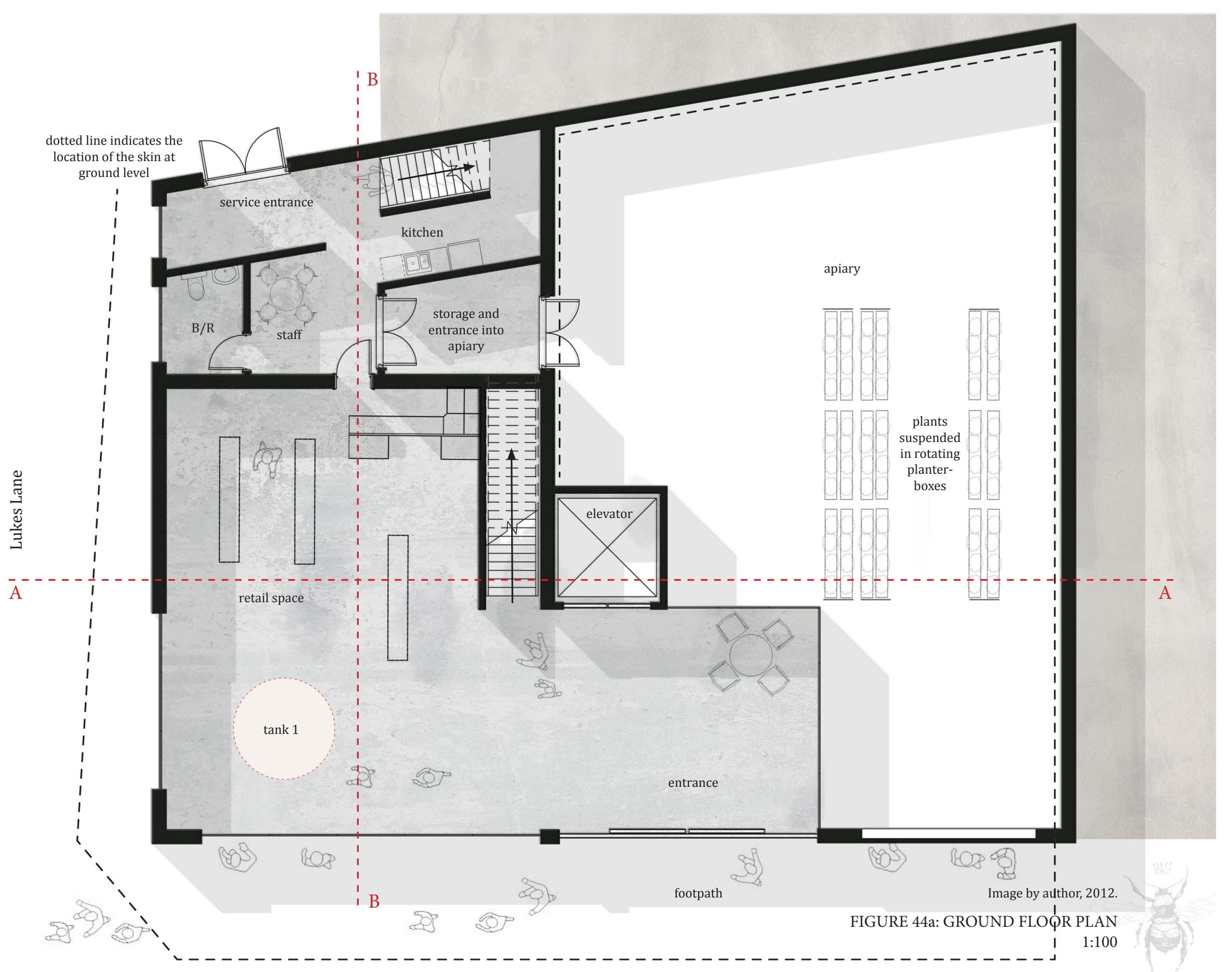


त

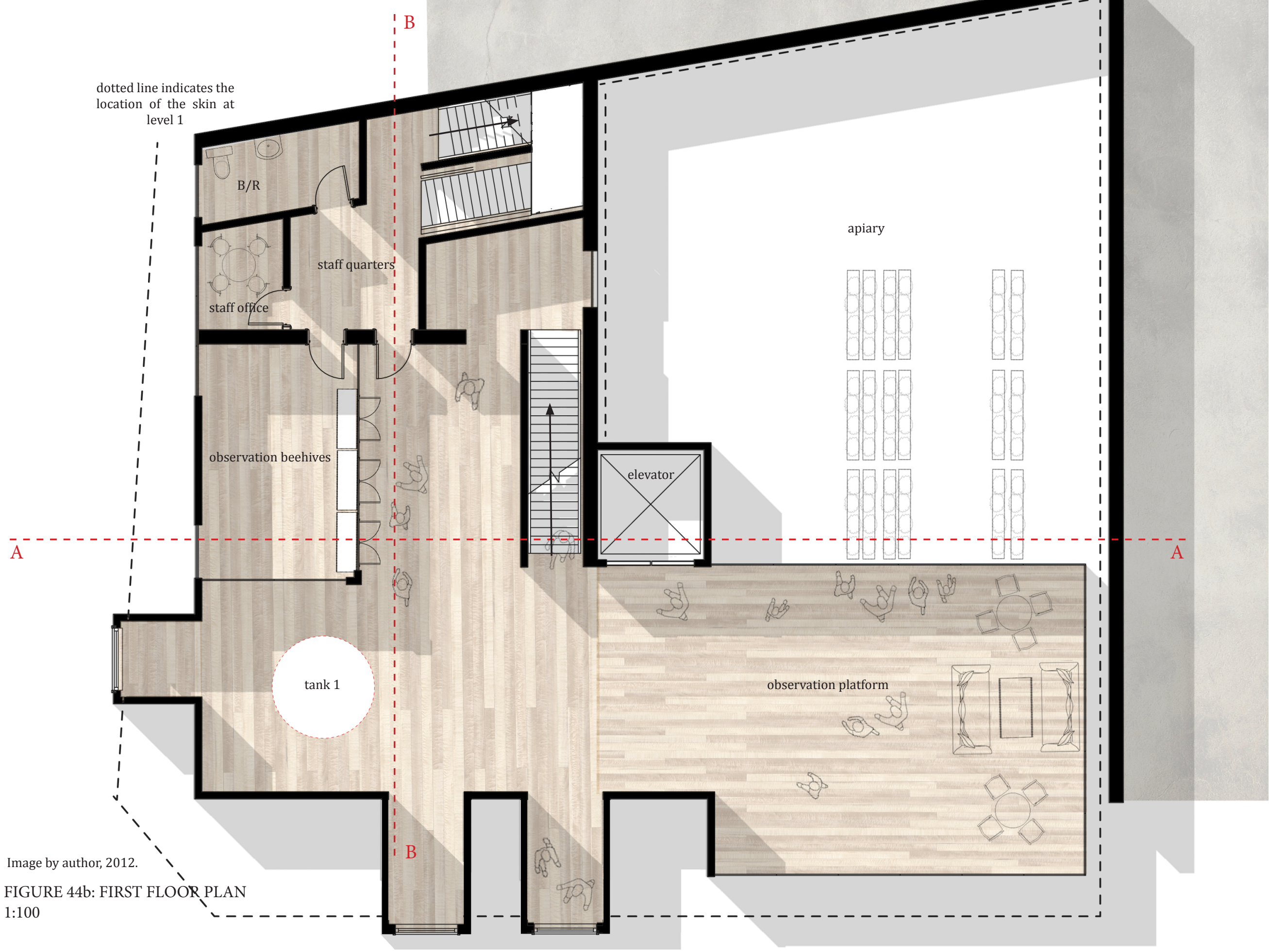


त्र

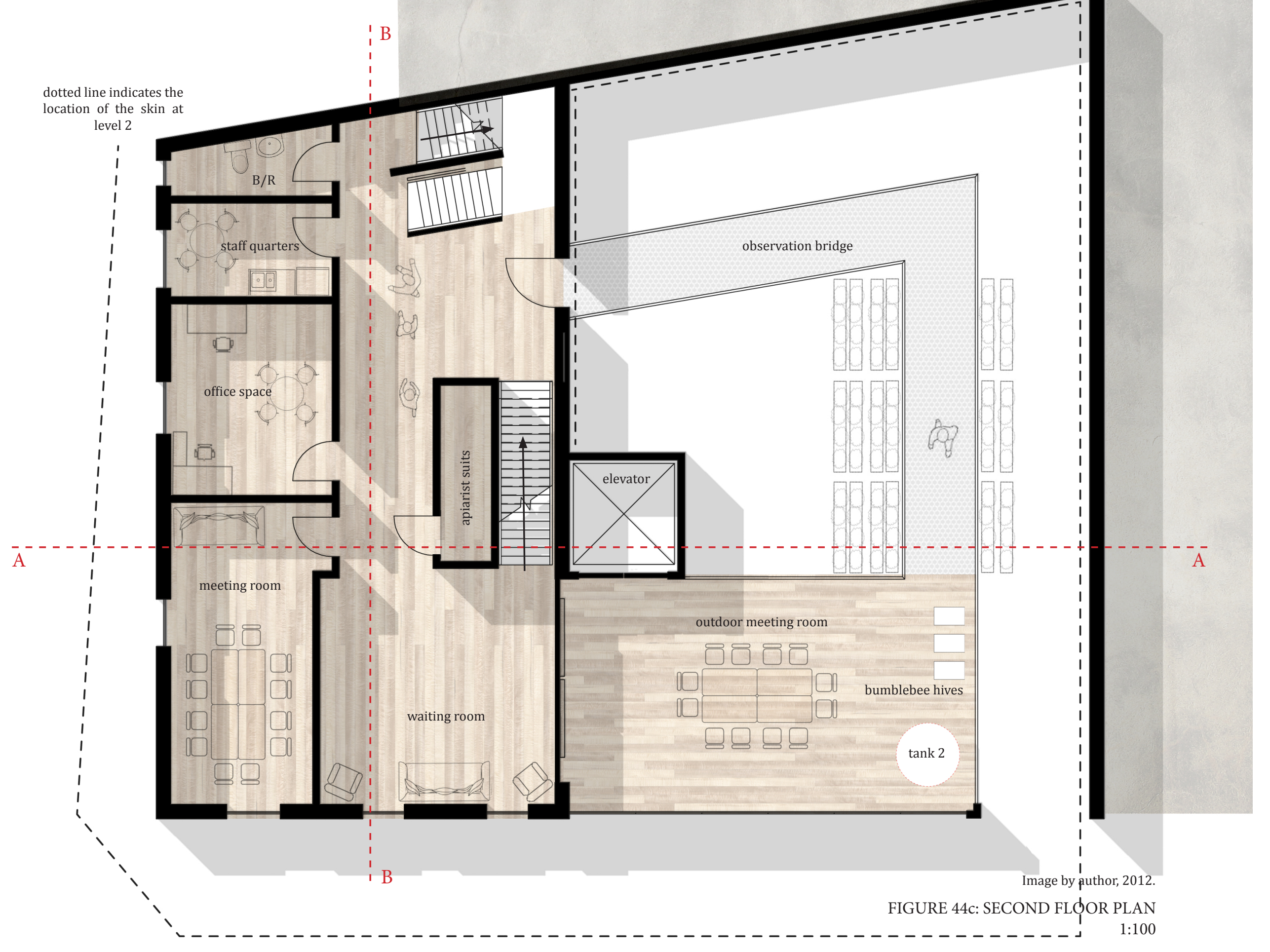


$N_{N}$

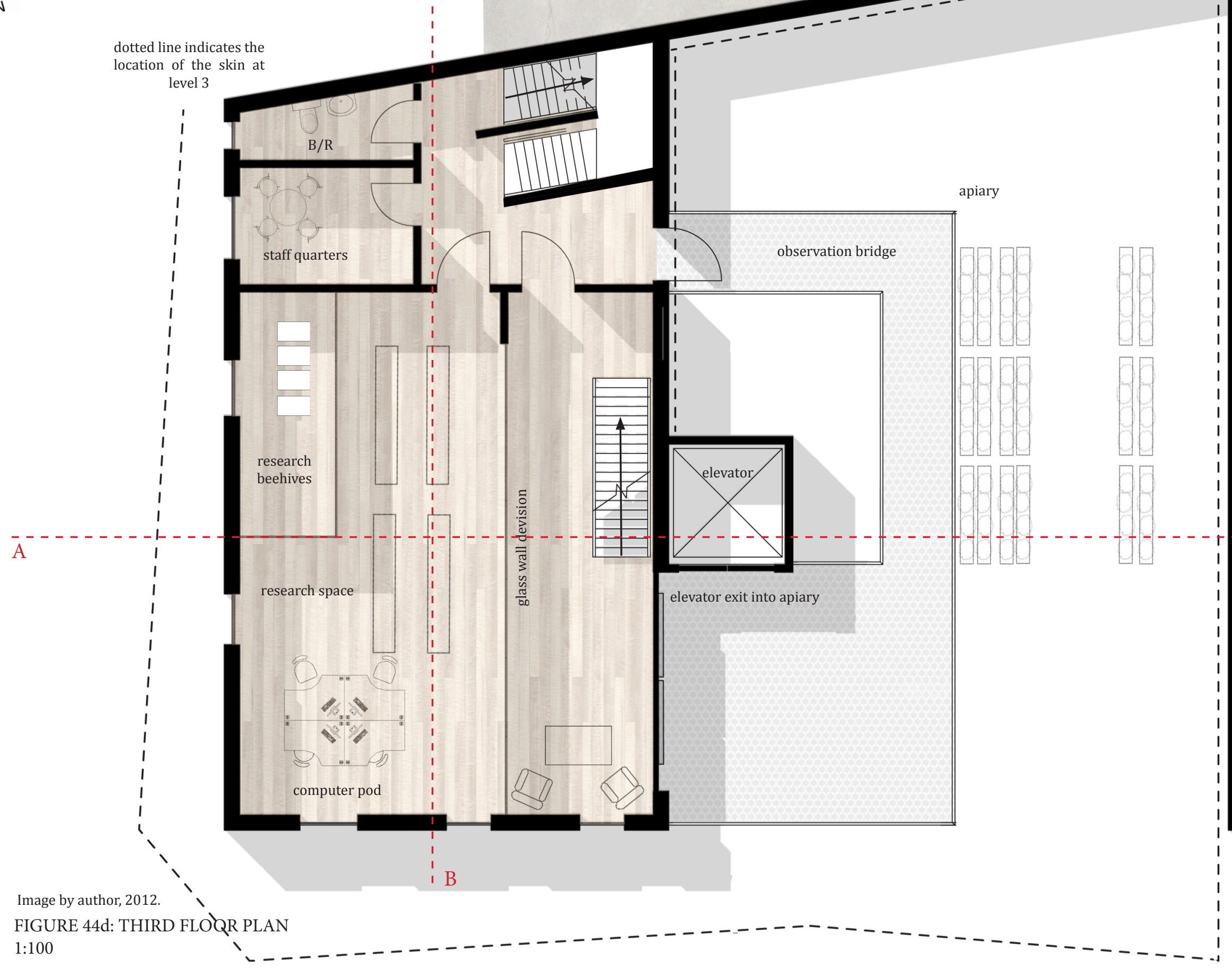


त

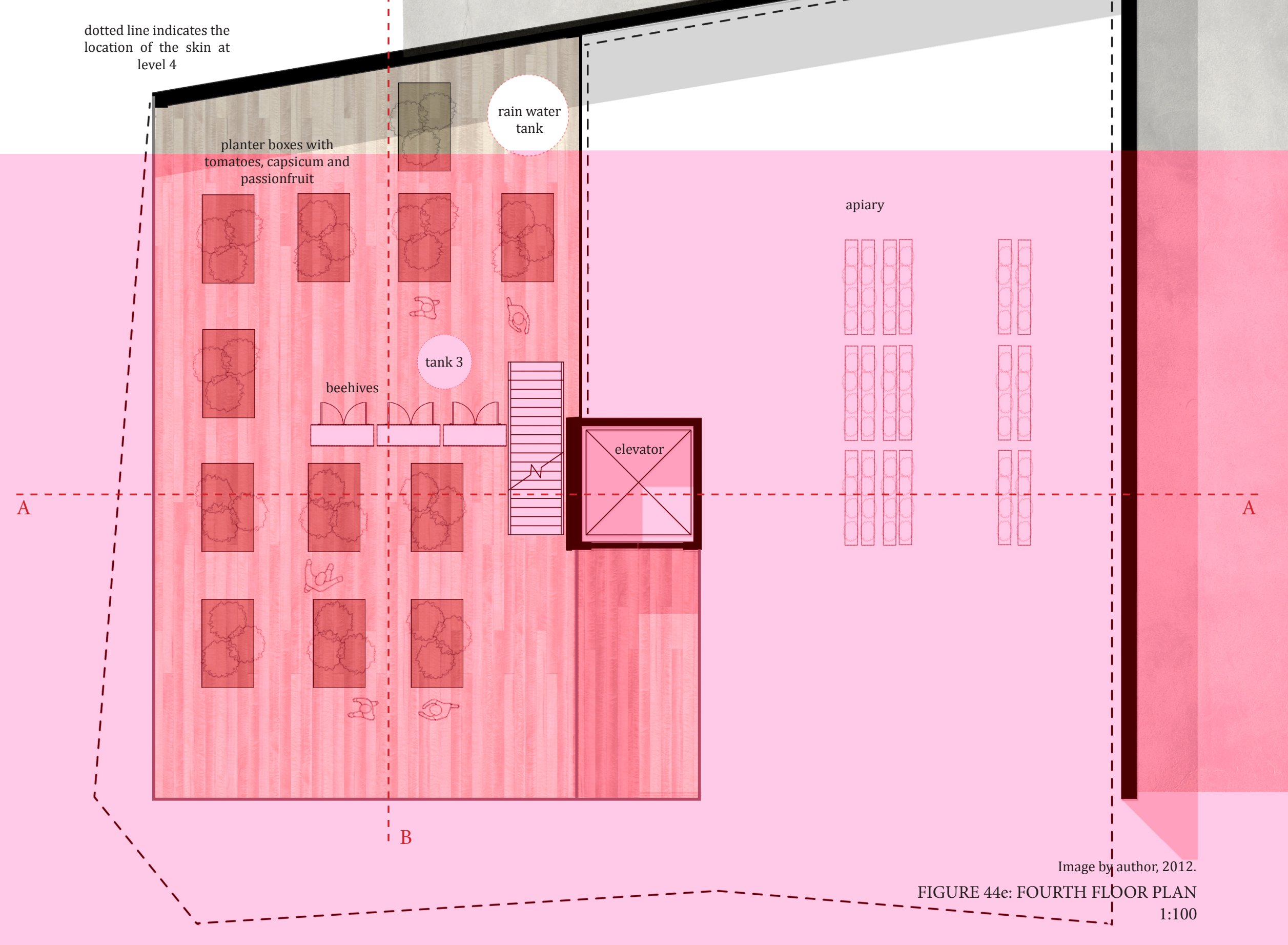


Looking at the organizational layout of a beehive, the spaces occupied by humans in the design follow similar principals to those of a beehive. In a beehive, the young larvae are kept in the lower cells and the honey at the top. In section, the spaces arranged in the design are likened to those of a beehive; the lower floors consist of retail and educational facilities, where the upper floors are primarily office and laboratory space. Finally, the top floor houses bees, small fruits and vegetables. As observation beehives are located throughout the building, honey can be collected from each of these and stored in large tanks. From here, the honey runs down a series of small pipes where it reaches the shop. The public is welcome to fill containers with this honey - the process of which can be seen from the pavement.

The following image (Fig 45) illustrates human interaction with bees. Located on the first floor, the observation facility's primary goal is to bring awareness to bees and to teach people about the role in which bees play in our everyday lives. Visitors can view the inner workings of a beehive by opening cupboard doors. In so doing, this activity engages with the beehive whilst safely being protected behind glass.
Located on the top floor of the design are honey bee hives and crops. These crops are vine tomatoes, passion fruit and capsicum. These plants gain full sunlight hours and are sold in the retail space when ripe. 


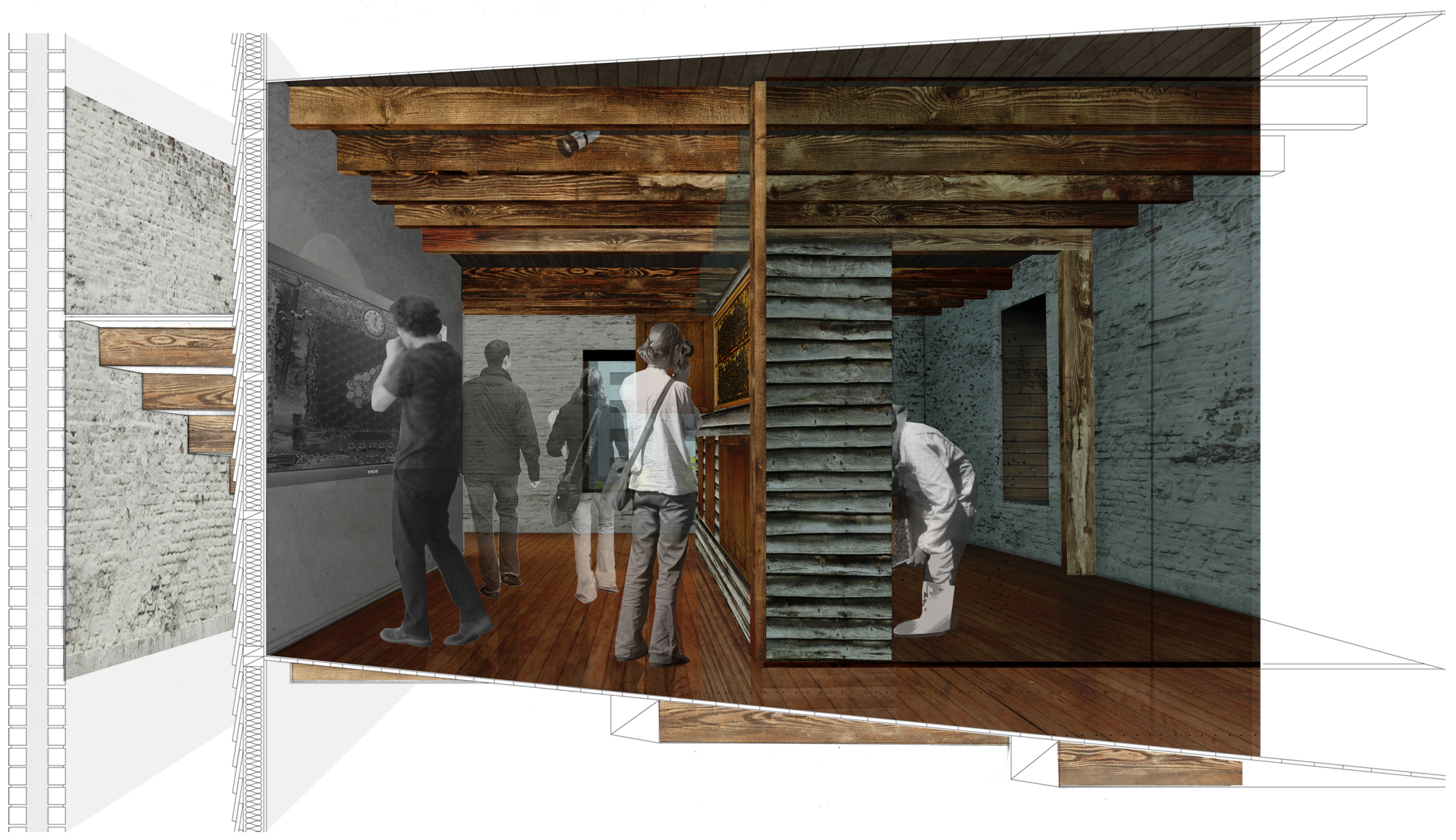

FIGURE 45: Located on level one are observation beehives. These beehives have small cupboard doors that allow visitors to the building to open and gaze into a beehive whilst being protected behind glass. Image by author, 2012 . 


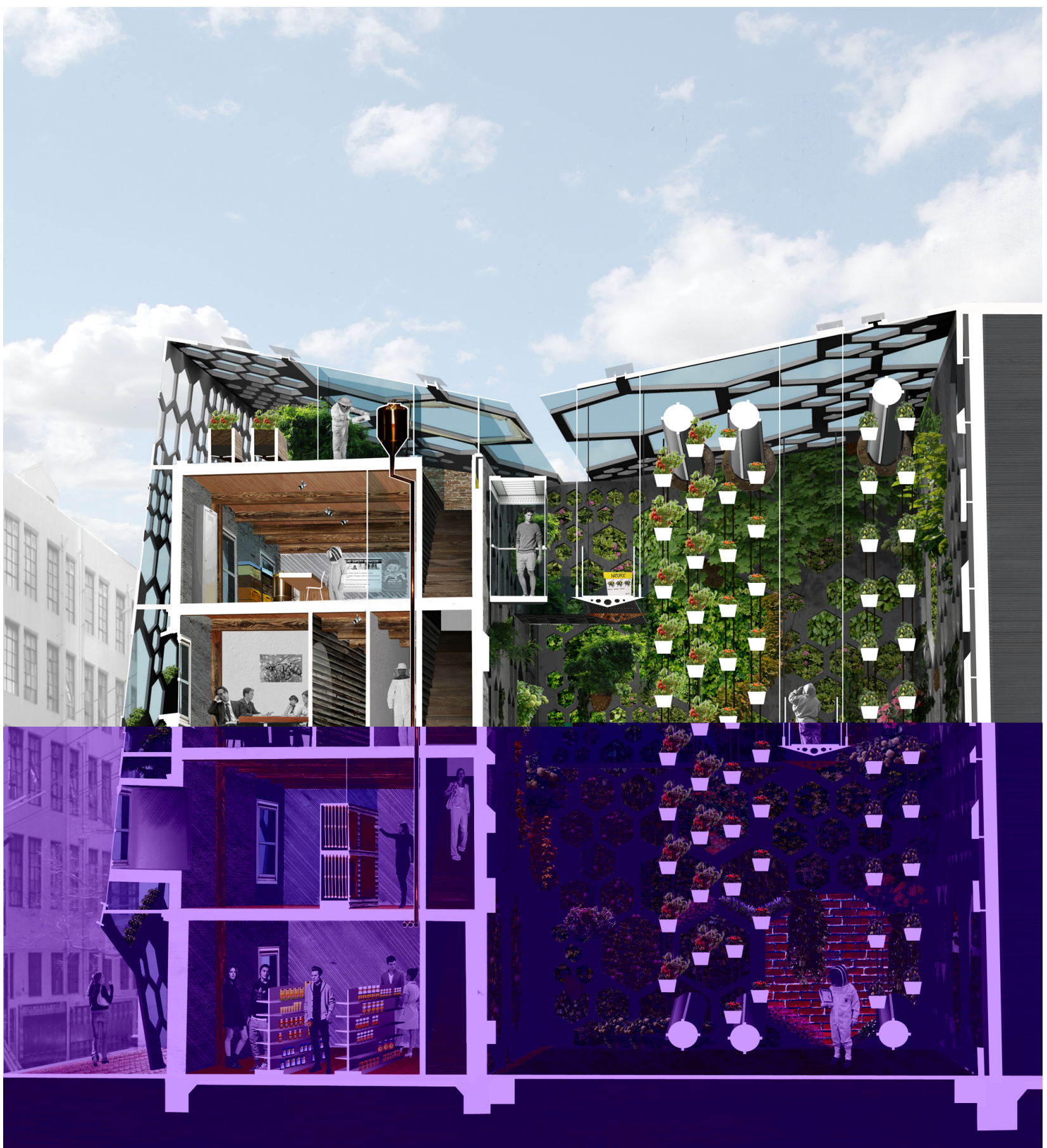

The angled roof means rain water can be collected and stored. This rainwater is then used to irrigate plants growing within the building. Rainwater runs down the webs of connecting I-beams where it is stored in a tank we roof. These solar panels track the sun's movements over the course of the day which in turn, helps generate electricity for
the building. Section A-A and B-B by author, 2011 . 


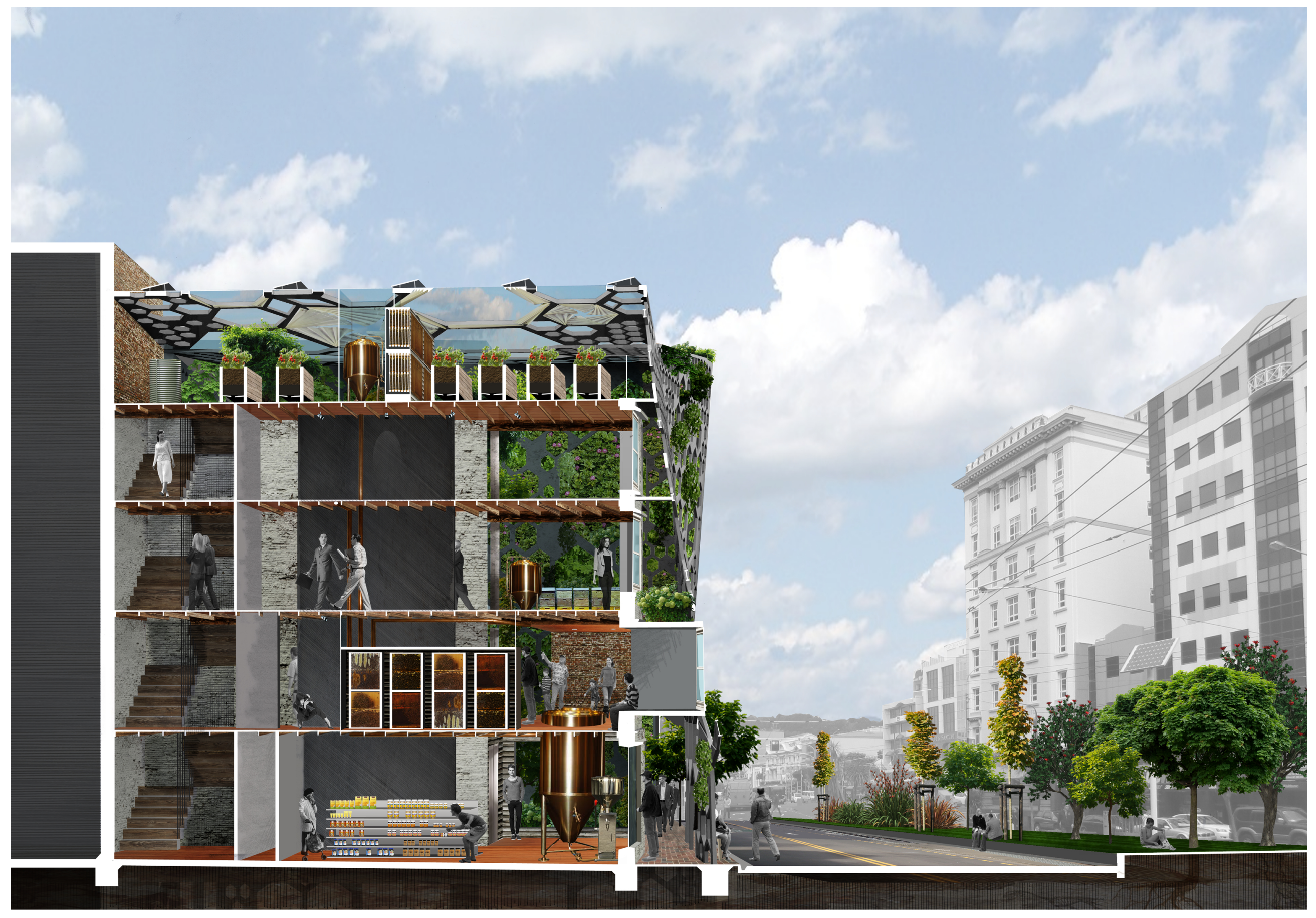




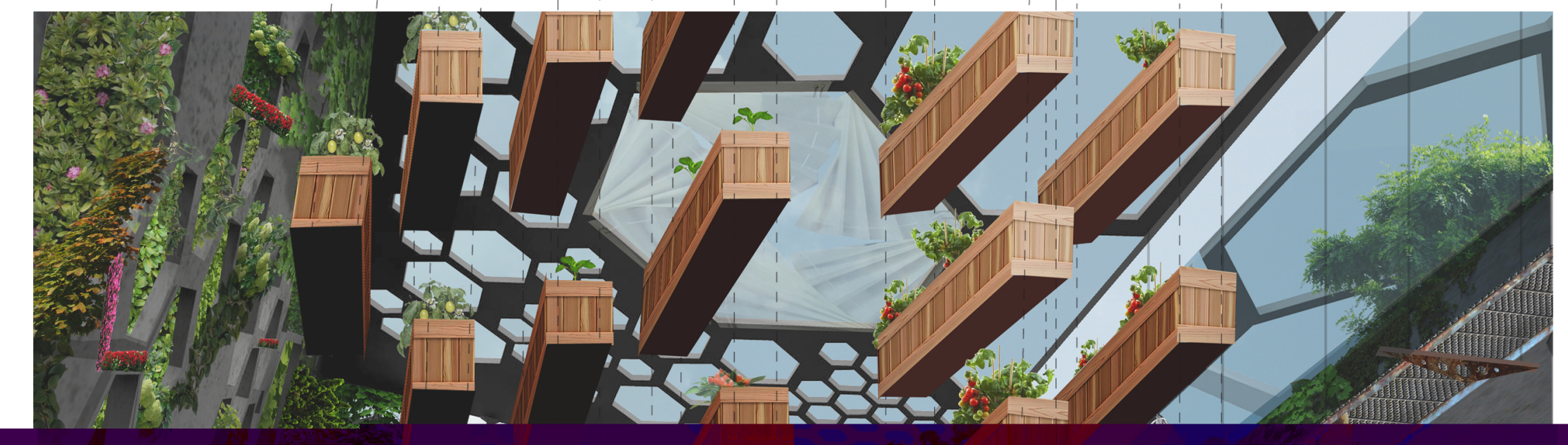

FIGURE 46: These hanging planter boxes rotate to ensure each plant is exposed to long periods of sunlight. When the plants within these suspended planter boxes start to produce fruit, the plants are then transferred to the top floor of the Edward Building. Here this fruit is ripened in full sunlight exposure. Image by author, 2012.

78 


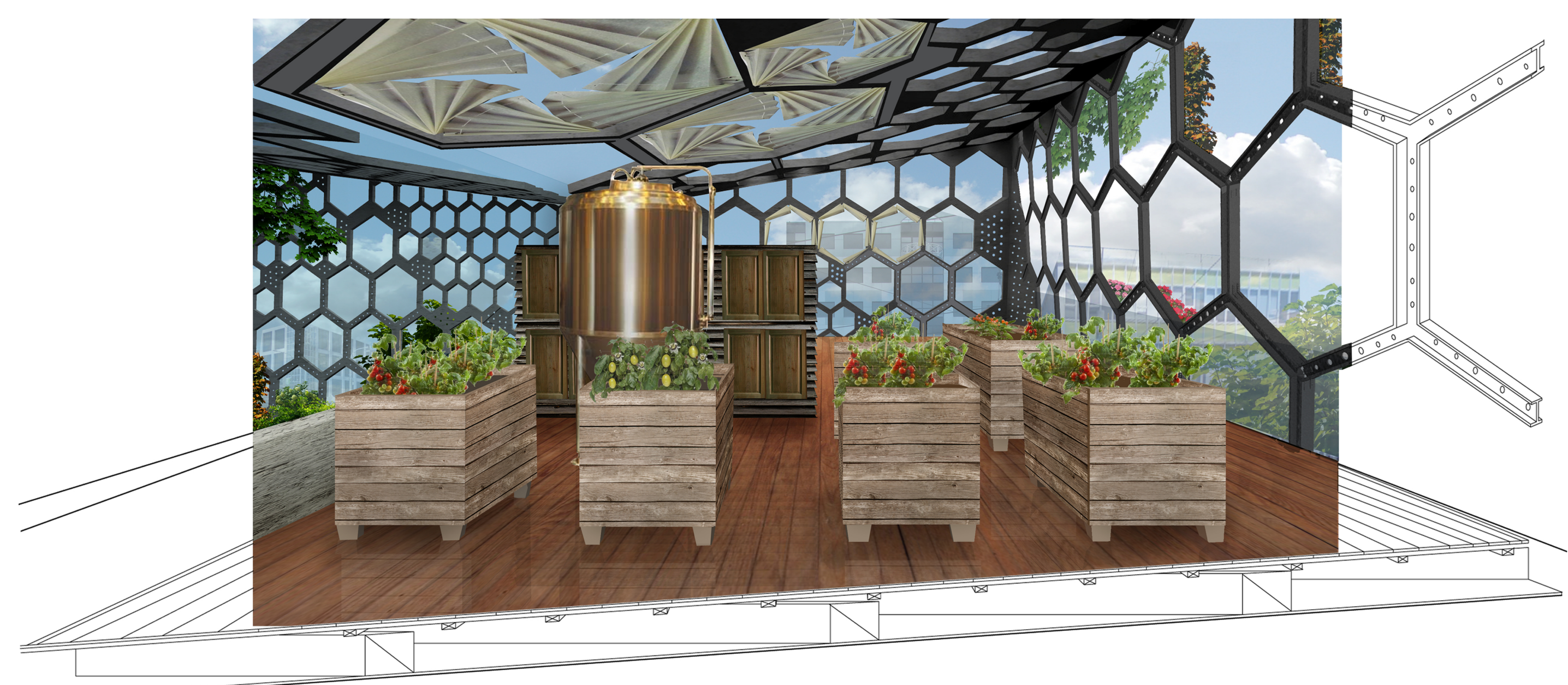

FIGURE 47: The above image illustrates the aforementioned ripening fruit. When this fruit is ripe, it will then be sold in the retail space on the ground floor. Fig. 46 and Fig. 47 are both looking south towards Manners Street. Image by author, 2012. 
Building Details

scale: 1:20

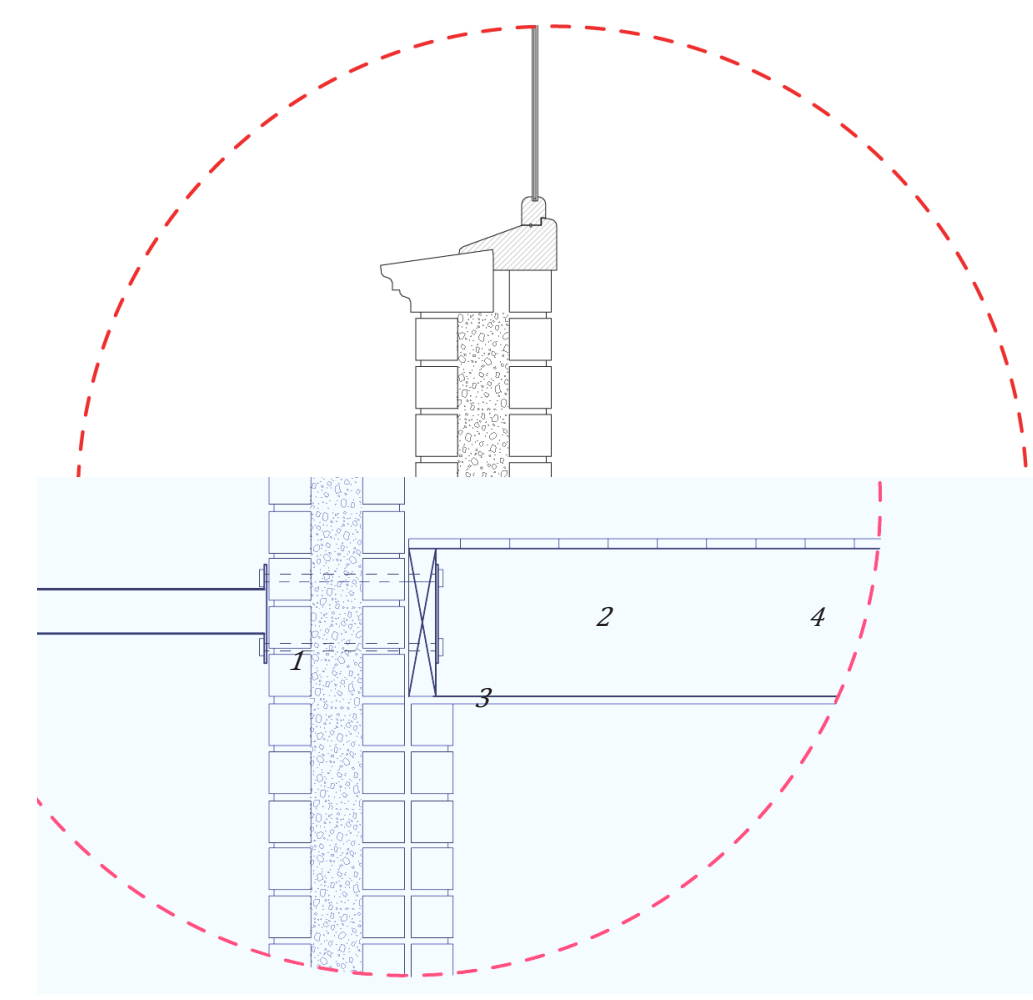

FIGURE 49: Detail B Image by author, 2012

\section{EQ construction:}

$1100 \times 50$ RHS ties

$212 \mathrm{~mm}$ plates, bolted through

3 existing masonry wall with M16

bolts

4 existing timber floor system

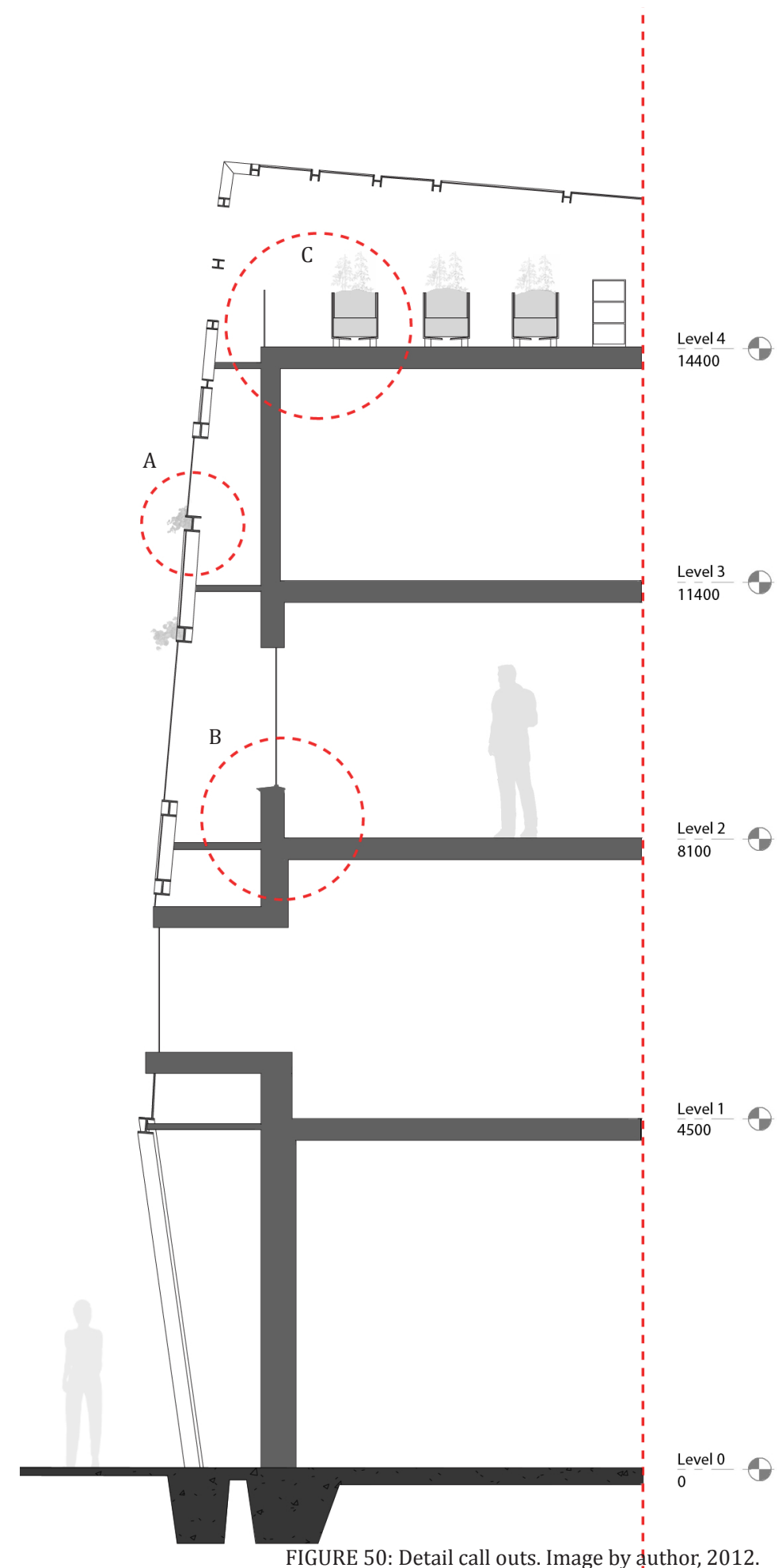


FIGURE 51: Detail C Image by author, 2012.

Roof construction: 1 Refer to Figure 49

Wall construction: Existing brick masonry with infill

Waterproof roof system: $90 \times 19$ Macrocarpa timber decking on packers. Butyl rubber membrane on

$17 \mathrm{~mm}$ C/D screw fixed ply. Laid to 1:40 fall.

Planter box construction: $\mathrm{H} 5$ timber frame at $600 \mathrm{C} / \mathrm{C}$ (dotted) $17 \mathrm{~mm} \mathrm{C/D} \mathrm{screw} \mathrm{fixed} \mathrm{ply.} \mathrm{Butyl} \mathrm{tanking}$ +flo-cell® drainage membrane.

Roof construction: 5

Existing timber rafter system with additional 270 x 50 rafters under planter 
Bees create natural beehives by constructing combs on or within existing structures. This re-use and re-adaptive strategy is something the design has embraced. The fifth design characteristic is reproduction. This is done in by utilizing existing structure and adapting it for a new purpose. Parts of the existing two-storey building on the proposed site will be reused for an outdoor meeting room. The main structure being used in this case will be two moment frames. As previously mentioned in Chapter Three, these moment frames will mean less building material is required during the construction phase of this space.

Another aspect of the design that is being reused is the Edward Building. As previously stated, the Edward Building is in need of earthquake strengthening, a new programme and general repairs. However, most of the original building can be preserved when the proposed programme is complete. The following plans (Fig 52a, 52b, $52 c, 52 d)$ illustrate what parts of the building are new and what parts of the building are existing. The areas highlighted in red show the existing walls of the Edward Building that will be reused. By reusing much of this existing structure and adapting it for a new purpose, it is hoped minimal new building material will be required to accommodate a new programme.

A beehive of bees also reproduces. This activity is something the design welcomes and caters to. When a beehive reaches a certain number, it naturally splits in two and the new colony swarms to look for a new site in which to construct a beehive. Although there are many manmade beehives throughout the building, bees are encouraged to create naturally forming hives within the apiary.

Figure 53 on the ensuing page illustrates the outdoor meeting room and the use of existing structure that supports it. Two moment frames create the boundary to which the meeting room extends. These moment frames have been reused from the original building which once sat upon site 135 Manners Street. This modern interpretation of an urban apiary has large amounts of greenery within it. These plants are a mixture of eatable fruits and vegetables, and flowering climbers. Walkways suspended within this space allow farmers to maintain the produce and harvest it when ripe. 

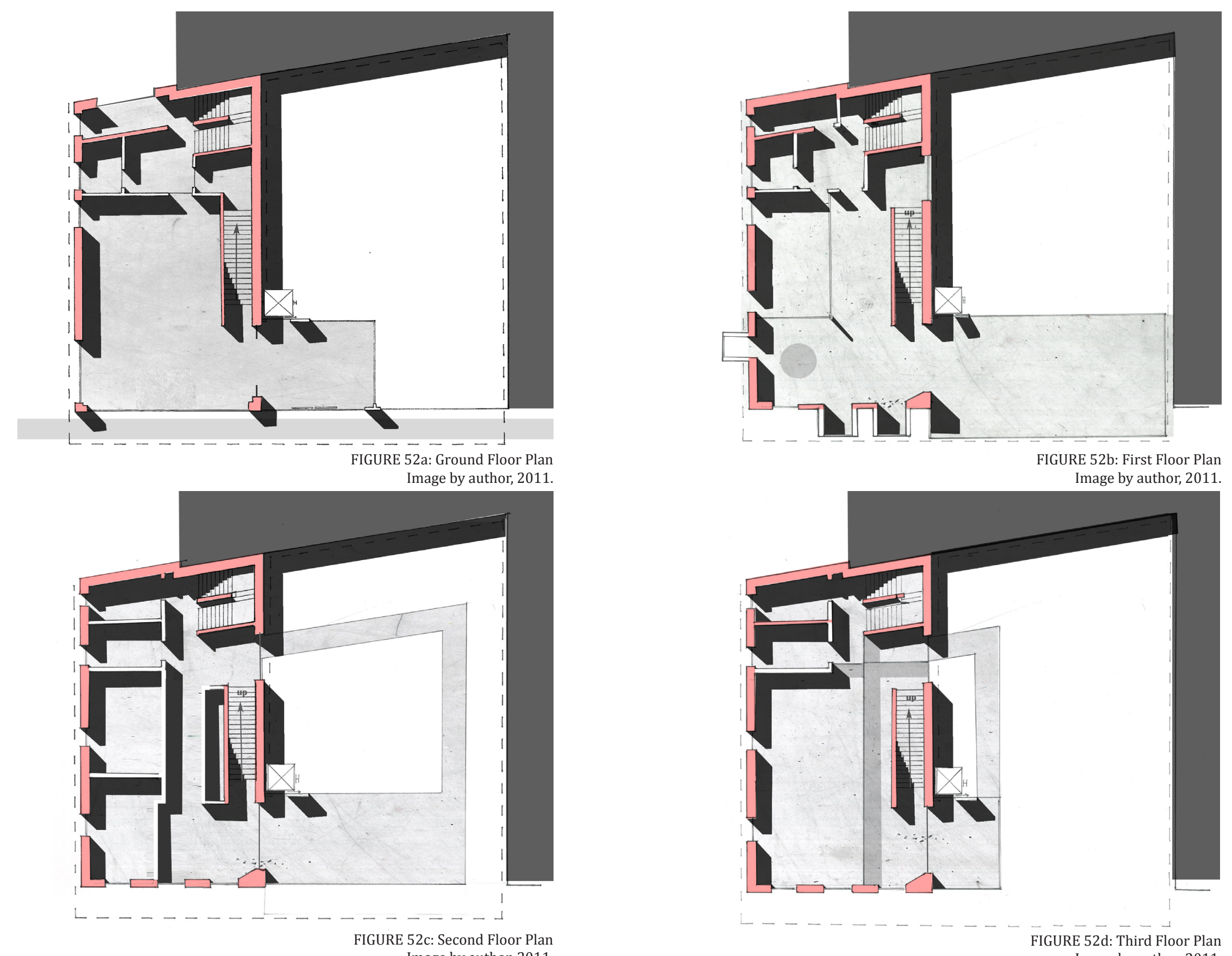


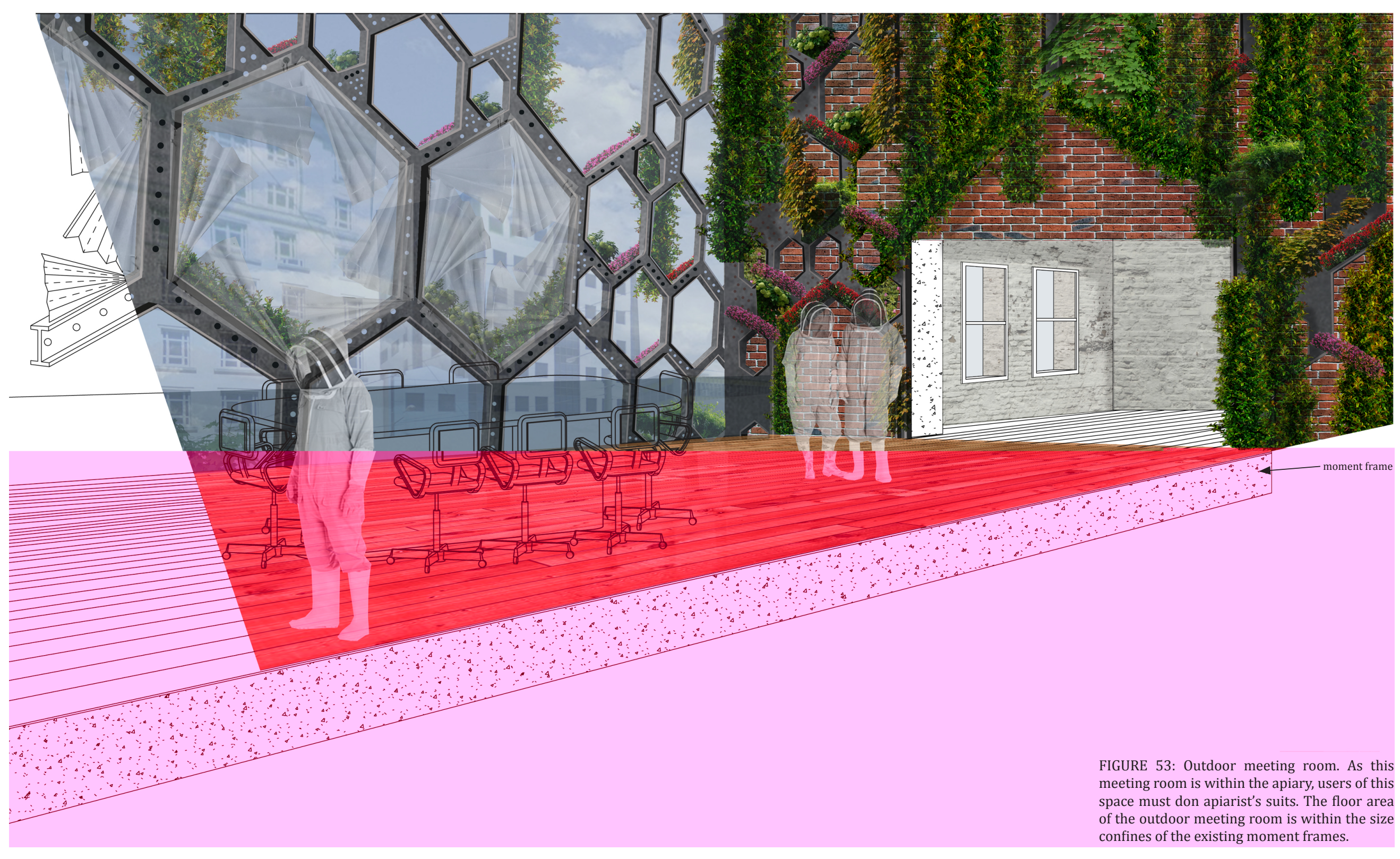


The final two characteristics of nutrition and excretion are also related to one another. This section will discuss how the building consumes (nutrition) and emits (excretion). Although the building aims to minimise the consumption needs by relying on efficient and sustainable systems within, there will inevitably be some consumption needs outside this area that rely on more traditional forms of energy. Although the design has not been built, by looking at the Lloyd Crossing Project as a case study, an estimation of how the building consumes and emits can be determined based upon the similar technologies used. In order glean an estimation of this, this section looks at three ways the design aims to minimise resource consumption based upon similar methods used in the Lloyd Crossing Project. This project was chosen as best for comparison because of its recent publication, emphasis on environmentally sustainability and incorporation of similar alternative technologies. The results have been calculated based upon data expected over a 40-year timeline.

The sun plays a large part in how the building saves energy. Sunlight also plays an important part in a bee's life. It provides the fuel for the plants which produce the bee's food (nectar) and it serves as a navigational tool that guides them during flight. Solar panels cover a large area of the roof. These solar panels track the sun's movements over the course of the day to maximise the energy harvested from the sun. Energy efficiency, including natural lighting and solar technology, is predicted to achieve an energy savings of 23 percent based on the findings from the Lloyd Crossing Project in which uses similar solar design methods (Mithun, 2004).

The heating and cooling systems of the building are the biggest energy saving techniques. By using heat trapped within the apiary and circulating it throughout the building, electrical heating costs are minimised. This not only works similar to the techniques that bees employ, but also adapts certain parts of the beehive metaphor to a human context. In so doing, based upon the results from the Lloyd Crossing Project, it is predicted that the "energy consumptions for heating will reduce by 60 percent” (Mithun, 2004, p. 107).

Finally, to reduce and reuse water consumption within the Lloyd Crossing Project, rainwater is collected, stored and used for irrigation for gardens and landscaping in place of city water 


\section{Design Reflection}

(Mithun, 2004). This is similar to how this design collects rainwater runoff and uses it to irrigate plants on the skin and crops growing within the apiary. This is predicted to achieve "60 percent overall water conservation aided by the use of highly efficient fixtures" (Mithun, 2004, p. 107). Although both projects differ somewhat in terms of location and aesthetics, they share similar ideas to help reduce the consumption of local nonrenewable resources. Linkages have been made to a beehive through the use of sun and heating technologies. These systems help create linkages and in so doing, create a habitat for humans, bees and plants.
In this chapter, the seven characteristics of life - respiration, movement, senses, growth, reproduction, nutrition and excretion - have been addressed. It has been illustrated how they have been realised in a design based upon an ecological relationship with bees. The use of these seven characteristics aims to create a living structure that mimics aspects of bees and beehives, and this approach has been applied to a Wellington-based design. In so doing, linkages are created between bees and their structures with the benefits they offer helping to reduce reliance on nonrenewable resources. Based on the findings from the Lloyd Crossing Project, it can be predicted that by utilising solar energy sources, collecting rainwater, adapting to changing weather conditions and creating a habitat for bees and plants large energy savings can be achieved in this design. If this research was to continue any further, the next step could be to implement this hypothesis presented in this thesis and do practical testing of this in order to calculate actual energy savings. 
Chapter Five Conclusion

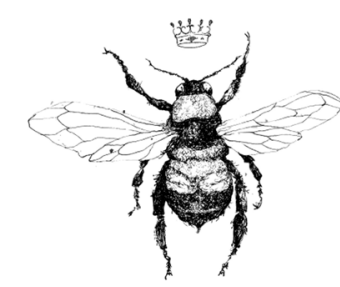




\section{CONCLUSION}

With the amount of vegetation in Wellington City expected to increase, consideration as to how these additional plants will be pollinated is often overlooked. Bees excel at pollination. The introduction of bees and beehives within central Wellington City offers a model for sustainable living to future generations. Throughout the research, biomimicry of bees has been explored in the form of ecomimicry. By studying the bee, bee societies and beehives, the research revealed that it was possible to create linkages to an apian ecosystem in order to reduce human reliance on non-renewable resources. What is significant about this research is that it revealed the potential for humans and bees to co-inhabit a building which in turn provides a model for an essential aspect of a sustainable city i.e. a city that supports plant pollination.

The design was able to cater for the pollination and nectar needs of bees through the planting of flowering crops within and on the building. By bringing bees into central Wellington City the design is also able to meet the additional pollination needs of planting that is expected to increase around Wellington City over the coming years (WCC, 2011). It is expected that these plants would benefit from bees being present in the city as the plants would be more likely to reach their full flowering potential. With many threats facing the apian industry (for example, the oft-reported Varroa mite and Colony Collapse Disorder), the impact bees - and especially any lack thereof have on the pollination of food providing crops and the role in which bees play in society is arguably more critical now than ever before.

A review of the literature on ecomimicry revealed that it may be possible to conceptualise a building as a living structure by having the building replicate the seven characteristics of life, namely - respiration, movement, senses, growth, reproduction, nutrition and excretion. By studying how these seven characteristics are achieved in an apian environment, the design was able to incorporate similar approaches in the building. The design was able to take on a sustainable focus maximising renewable resource use through heat displacement, ventilation, planting of eatable crops, solar gains, water conservation and an external skin respondent to different environmental conditions.

In Chapter Two, a review of how notable 20th Century architects (such as Antoni Gaudi, Frank Lloyd Wright, Hans Söder and Mies van der Rohe) 
used the hexagon revealed the tendency to use it: as an aesthetic gesture to a society in harmony with its surroundings; as a modular model to order space; and as a structural element used for its strength properties. Although bees and their produce have been a source of design inspiration for many architects, the push to include bees in this design and consider them paramount in a new building for Wellington City, was motivated by the potential of a more sustainable city. This is achieved several ways. First, by creating a habitat for bees within central Wellington City, the distance bees must travel in order to collect nectar and pollinate flowers is significantly reduced. This has the benefit of providing pollination to the additional vegetation proposed for Wellington City. Secondly, the inclusion of similar systems to those that bees utilise in their beehives. This has the inherent benefit of the sustainability of design solutions sourced from nature.

Chapter Three focused on the planting of vegetation around Wellington City and used this discussion as the basis for the site selection. The questions this chapter answered included:

- Why is greening a city important?

- Where can greening be done?

- How can pollination within a city be done? And;
- What kind of bee would do best in a Wellington context?

A site adjacent to Te Aro Park was chosen as the best candidate of site to test the concept of a design based on ecomimicry of apian ecosystems in Wellington City.

\subsection{The Design}

The research showed that the use of bee structures as a design generator historically has been primarily aesthetic. This thesis engages with the formal treatment of things apian but allies them with a wider ecomimetic consideration. The design of a bee facility centred on cohabitation is synonymous with the research's aim of establishing a livingstructure and creating a model for ecomimetic and sustainable architecture, with broader implications for a sustainable city.

This thesis has developed a position on ecomimicry that utilises pre-existing sustainable techniques and applied them to an ecomimetic building centred on cohabitation between bees and humans. However, one could argue that these pre-existing methods could be applied to any number of biomimetic inspired designs. 
Although these methods could potentially be applied to other buildings, the importance of bees to human survival and sustainable futures may not necessarily transpire.

The inclusion of bees within this design gives the bee paramount importance to the concept, both in terms of design inspiration and design motivation. The apiary provides a habitat for bees and plants, and also helps collect and store solar energy from the sun, which is used to reduce heating costs for the building. The secondary skin around the Edward Building provides many different functions which include earthquake strengthening, providing a habitat for humans, bees and plants, trapping solar energy and communicating an aesthetic dialogue with a beehive. Physical and systematic structures of beehives have been considered in the design. Other possible avenues for future development of this research include structures such as the social structure within a beehive.

\section{Limitations}

One of the main limitations in this thesis was the case-study which enabled an understanding of how successful a concept such as this might actually work in real world terms. Chosen for its similar use of alternative technologies, the Lloyd Crossing Project provided some predicted figures of how much a building incorporating these kinds of systems, would save on non-renewable resources. These predictions are based on an un-built project over a 40 year timeframe. For these reasons it is expected there will be some discrepancies between these figures and the actual figures were this project to come to fruition.

Another limitation that initial research revealed was the strict regulations and size constraints domestic beehives must conform to. Throughout the history of domesticated beehives, many people have tried to redesign the beehive, with very few modern alterations ever being successful. Hence, the domestic beehive has remained relatively unchanged. This is largely due to the size, functional nature and tendency for bees to cover surfaces in wax. This was proved challenging throughout the preliminary design phase as early concepts saw beehives being used as structural components as well as observation beehives inside the Edward Building.

The research presented in this thesis has led to an architectural model of mutual inhabitation for 
bees and humans. In particular, it is a model that draws inspiration from apian ecosystems aesthetically and functionally. In return, it is also a model that promotes the well-being of those ecosystems. It is has been demonstrated that this can have on-flow benefits for other aspects of urban design (e.g. the pollination of urban green space). This is therefore an architectural model of design that is especially suited to sustainable cities. With social and cultural shifts towards more sustainable options, particularly in the building industry, bees and their structures offer an alternative approach to design that has a sustainable focus. 


\section{BIBLIOGRAPHY}

Aguirre, A. A. (2012). New Directions in Conservation Medicine. Applied Cases of Ecological Health, 292.

Bunge, E. (2001). Bee Modern. Cabinet, Animals, Issue 4.

Construction, S. (Sep. 2008). Steel construction : design and research. Steel construction.

Corbet, S. A. (1987). Bumblebees. Caimbridge University Press.

Ian Abley, J. S. (2006). Manmade modular megastructures. Manmade modular megastructures, Volume 76, Issue 1.

Institut für Internationale Architektur-Dokumentation. (2005). Review of architecture and construction details. Detail.

Koh, S. (2010). Datuk Ken Yeang, the master of green skyscrapers. Malaysia, Star Publications Malaysia: Star Publications .

McGraw-Hill. (1973). An International Reference Work. University of Michigan.

Mertens, D. (Spring 1922). The presence of Mies. Fruhlicht, no 3.

Mithun. (2004). Lloyd Crossing Urban Design Plan. Seattle, USA.

Mithun. (2004). Lloyd Crossing Urban Design Plan. Retrieved September 2, 2012, from Mithun:

http://mithun.com/knowledge/article/sustainable_urban_catalyst/

Nihon Daigaku, K. G. (2009). Honeycomb Tube Architecture Technology. Japan: Nobu yuki Yoshida. 
Pawlyn, M. (2011). Biomimicry in Architecure. Riba Publishing.

Proctor, M. (1996). The Natural History of Pollination . Rotherwick: Brittish Wildlife Publishing.

Ramirez, J. A. (2000). The Beehive Metaphor: From Gaudi to Le Corbusier. London: Reaktion Books Ltd.

Soar, J Scott Turner and Rupert C. (2008). Beyond biomimicry: What termites can tell us about. First International Conference on Industrialized, Intelligent Construction. Leicester, UK: Loughborough University.

Steel Construction New Zealand Inc. (issue 10. Apr. 2009). Steel futures: Steel Construction New Zealand. SCNZ magazine.

Wellington City Council. (2011, ). Green Infrastructure. Retrieved November 01, 2011, from WGTN 2040: http://www.wellington2040.co.nz

Winston, M. (1987). The Biology of the Honey Bee. Cambridge, Massachusetts: Harvard University Press.

Zari, M. P. (2007). Biomimetic Approaches to Architectural Design for Increased Sustainability. Sustainable Building Conference. Auckland: School of Architecture, Victoria University. 


\section{LIST OF FIGURES}

Bee image used throughout

Weschensky, D. (2009). Queen Bee Fine Art Print [Drawing]. Retrieved from http://fineartamerica. com/featured/queen-bee-deborah-wetschensky.html accessed 10/12/2012

Inside cover images

Cortes Ferreira, J. (2011) Flowers [Photography] Retrieved from http://footage.shutterstock. com/clip-2327990-stock-footage-honey-bee-on-knapweed-flower-close-up-macro.html accessed $10 / 11 / 2011$

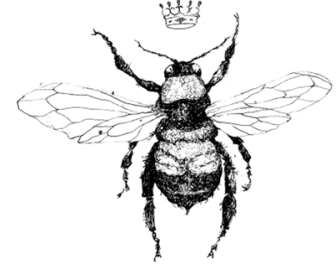

Bee image used throughout

FIGURE 1: A completed virgin comb. Photographed by Alvard Bishop, 1946

From: Bishop, A. (1946). The Hive and the Honeybee (p154). [Photograph] A completed virgin comb.

USA: R. R. Donnelley \& Son (accessed 6/6/2011)

FIGURE 2: Cooperativa Obrera Mataronese. Photographed by J Perramon.

From: Güell, P and Perramon, J. (2012). Cooperativa Obrera Mataronese [Photograph]. Retrieved

1/12/11 from http://www.parkguell.es/en/hist_1.php

FIGURE 3: The construction process of a virgin comb. Image authors own.

FIGURE 4: A domestic beehive: Image authors own.

FIGURE 5: Hans Söder; Ground plan and elevation of the skyscraper project, Berlin. 1921.

From: Ramires, J. A. (2000). The Beehive Metaphor. London, UK: Reaktion Books Ltd.

(retrieved 10/12/2012, page 97)

FIGURE 6: Mies van der Rohe; Ground plan and elevation of the glass skyscraper project, Berlin. 1021.

From: Ramires, J. A. (2000). The Beehive Metaphor. London, UK: Reaktion Books Ltd.

(retrieved 10/12/2012, page 94)

FIGURE 7: Frank Lloyd Wright; Ground floor plan of the Hanna House using the hexagon to arrange space.

FIGURES 8a, 8b, 8c: Slovenia's Honeycomb Housing Complex. Photographed by M Chino, (2011).

From: Yoneda, Y. (2010). Beehive Tower [Renders]. Retrieved 1/12/11 from http://inhabitat.com/

beehive-tower-is-a-honeycomb-inspired-vertical-farm-for-london/ 
FIGURE 9: Beehive Tower Yoneda, Y. (2010).

From: Yoneda, Y. (2010). Beehive Tower [Renders]. Retrieved 1/12/11 from http://inhabitat.com/ beehive-tower-is-a-honeycomb-inspired-vertical-farm-for-london/

FIGURE 10: Vertical Farm Meinhold, B. (2011).

From: Bonner, T. (2006). Beehive [Photographs]. Retrieved 1/12/11 from http://www.floornature. com/projects-commerce/project-the-beehive-conference-center-culver-city-california-eric-owenmoss-2001-4772/

FIGURE 11: Te Aro Park redevelopment. Source: Figure from Wellington City Council (2011)

From: Te Aro Park redevelopment. (2011). Retrieved 1/12/11 from http://www.wellington.govt.nz/ projects/index.html

FIGURE 12: Triangular Spaces. Image authors own.

FIGURE 13: Laneways. Image authors own.

FIGURE 14: Boulevard Design. Image authors own.

FIGURE 15: Green Infrastructure. Image authors own.

FIGURE 16: Pollination radius bees will travel within Wellington City. Image authors own.

FIGURE 17: Te Aro Park and proposed site. Image authors own.

FIGURE 18: Redevelopment of Te Aro Park extending from Cuba Street to Courtenay Place. Image authors Own

FIGURE 19: Sites 131 and 135 Manners Street. Image authors own.

FIGURE 20a, 20b: Plan of shadows at midday in summer and winter. Image authors own.

FIGURE 21a, 21b: Section of shadows at midday in summer and winter. Image authors own.

FIGURE 22: Figure-ground diagram illustrating the position on the selected site within central Wellington City. Image authors own. 
FIGURE 23: Boundary footprints. Image authors own.

FIGURE 24: Building heights within central Wellington City. Authors own image.

FIGURE 25: Contour map of central Wellington City. These contours are spaces at one metre intervals. Authors own image.

FIGURE 26: Wind zone. The site sits within a high wind zone (code three). Authors own image. FIGURE 27: Pedestrian transportation

FIGURE 28: Vehicular transportation

FIGURES 29a, 29b: Site photos. Authors own images.

FIGURE 30: Original plans of the Edward Building.

From: The Wellington City Archives (1902). Accessed from the Wellington City Archives on 1/6/11.

FIGURE 31: Moment frames that will be reused. Image authors own.

FIGURE 32: Ground Floor Plan of 135 Manners Street. Source: Figure from the Wellington City Archives (1962. Accessed from the Wellington City Archives on 1/6/11.

FIGURE 33: Early conceptual sketch using the hexagonal grid for structural and aesthetic purposes. Image authors own.

FIGURE 34: Development of the skin. Image authors own.

FIGURE 35: Street perspective of design the concept. Image authors own.

FIGURE 36: Structural makeup of the skin. Image authors own

FIGURE 36.2: Detail: Structural makeup of the skin. Image authors own.

FIGURE 36.3: Detail: Structural makeup of the skin with window joinery. Image authors own. 
FIGURE 37: Construction members of the skin. Image authors own.

FIGURE 38: Member assembly. Image authors own.

FIGURE 39: Heating diagram. Image authors own.

FIGURE 40: Cooling diagram. Image authors own.

FIGURE 41: Working model of window shutter design. Image authors own.

FIGURE 42: Shutter design. Image authors own.

FIGURE 43: Bee and plant species diagram. Image authors own.

FIGURE 44a: Ground floor plan. Image authors own.

FIGURE 44b: First floor plan. Image authors own.

FIGURE 44c: Second floor plan. Image authors own.

FIGURE 44d: Third floor plan. Image authors own.

FIGURE 44e: Fourth floor plan. Image authors own.

FIGURE 45: Interior view of observation hives. Image authors own.

SECTION A-A: Image authors own.

SECTION B-B: Image authors own.

FIGURE 46: Interior view of the apiary. Image authors own.

FIGURE 47: Rooftop perspective. Image authors own. 
FIGURE 48: External planting detail. Image authors own.

FIGURE 49: EQ construction detail. Image authors own.

FIGURE 50: Detail call-outs. Image authors own.

FIGURE 51: Roof construction detail. Image authors own.

FIGURES 52a, 52b, 52c and 52d: Existing structural members to be reused in a new design concept. Image authors own.

FIGURE 53: Outdoor meeting room. Image authors own. 


\section{APPENDIX}

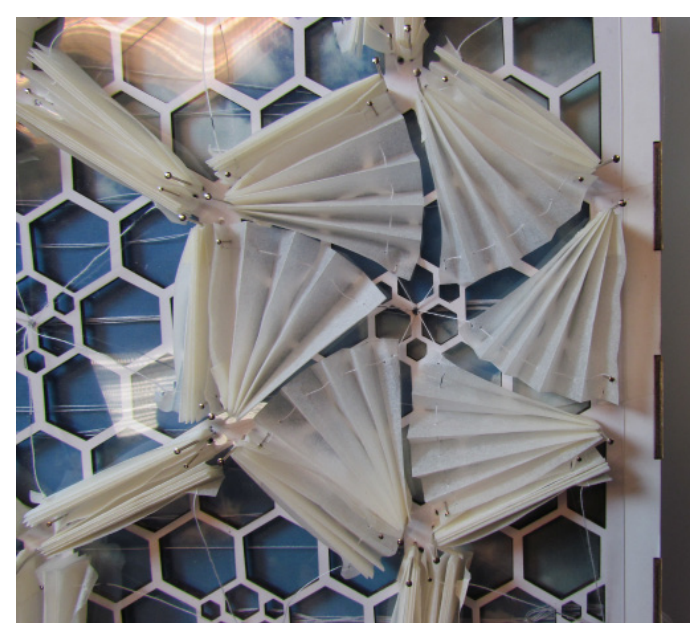

Window shutter design
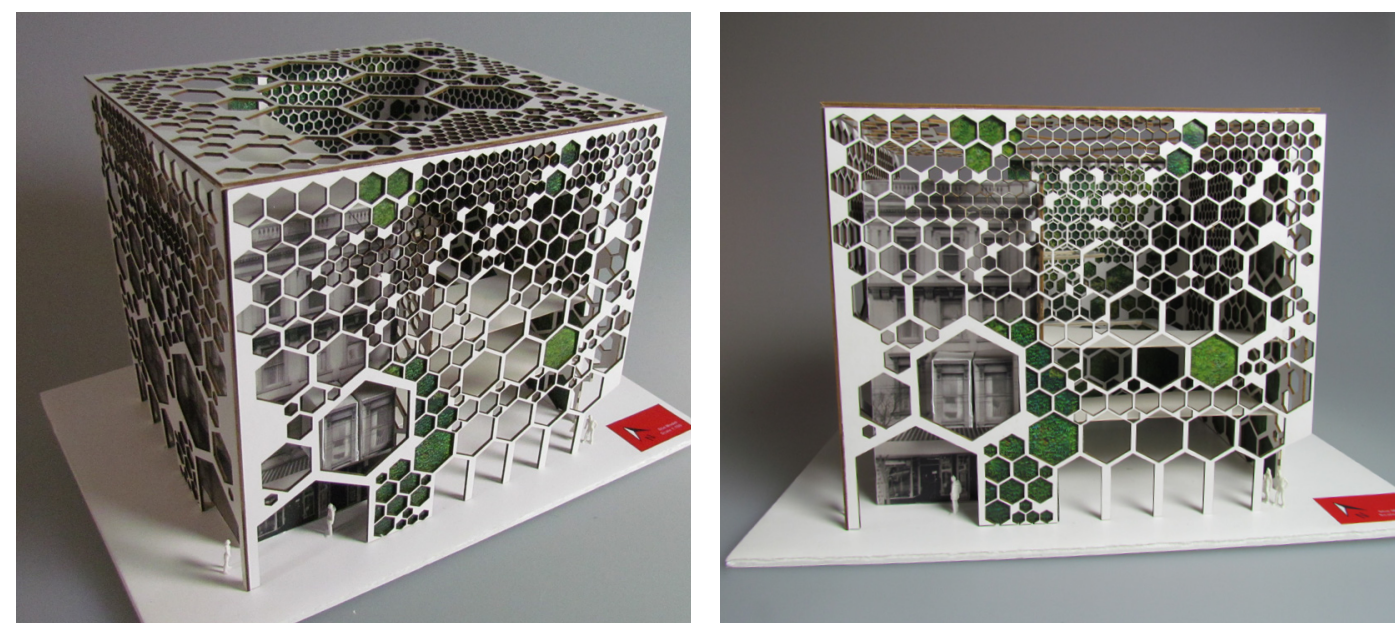

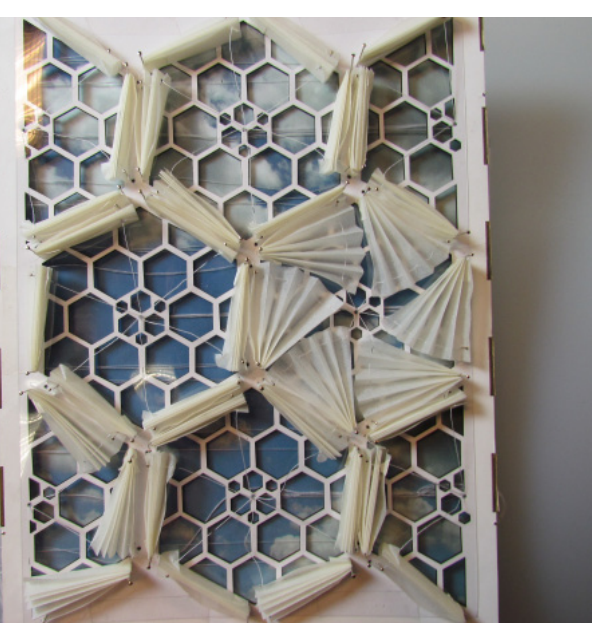

吸

3D section model

These models were used to test the idea of an ecomimetic design based on apian systems. Modifications were made to the design after the first review addressing feedback from reviewers. These changes include faceting the skin that wraps around the building and promoting the idea of humans living alongside bees. Images by author, 2011. 
